Portland State University

PDXScholar

Summer 1-1-2012

\title{
Groundwater Surface Trends in the North Florence Dunal Aquifer, Oregon Coast, USA
}

Sarah Rebecca Doliber

Portland State University

Follow this and additional works at: https://pdxscholar.library.pdx.edu/open_access_etds

Part of the Fresh Water Studies Commons, Natural Resources Management and Policy Commons, and the Water Resource Management Commons

Let us know how access to this document benefits you.

\section{Recommended Citation}

Doliber, Sarah Rebecca, "Groundwater Surface Trends in the North Florence Dunal Aquifer, Oregon Coast, USA" (2012). Dissertations and Theses. Paper 530.

https://doi.org/10.15760/etd.530

This Thesis is brought to you for free and open access. It has been accepted for inclusion in Dissertations and Theses by an authorized administrator of PDXScholar. Please contact us if we can make this document more accessible: pdxscholar@pdx.edu. 
Groundwater Surface Trends in the North Florence Dunal Aquifer, Oregon Coast, USA

by

Sarah Rebecca Doliber

A thesis submitted in partial fulfillment of the

requirements for the degree of

Master of Science

in

Geology

Thesis Committee:

Curt Peterson, Chair

Robert B. Perkins

Dennis Nelson

Portland State University

2012 


\begin{abstract}
The Florence Dunal Aquifer is the only feasible source for drinking water for the coastal city of Florence, Oregon and Florence's Urban Growth Boundary. High infiltration rates and a shallow groundwater table leave the aquifer highly susceptible to contamination from septic tank effluent, storm runoff, chemical fertilizers and recreational ATV use throughout the dunes. Public interest in the quality and quantity of the aquifer water has been sparked since the City of Florence received a grant from the Environmental Protection Agency for a watershed protection and restoration project.

Delineation of the shallow groundwater surface and its relationship to the surface water bodies within the dunes is crucial in protecting this drinking water source from contamination. This thesis project created a GIS representation of the shallow groundwater elevation and associated prediction error map. Surface water bodies were confirmed as window lakes into the dunal aquifer and no signs of perched aquifer conditions were observed between Holocene and Pleistocene dunes. Ground Penetrating Radar, well data provided by the city of Florence and LiDAR were the primary sources for data collection.
\end{abstract}




\section{Dedication}

For Dad- because if it was easy, everyone would do it. 


\section{Acknowledgements}

Special thanks to Dr. Curt Peterson for allowing me to partake in his coastal research. Curt helped me grow as a scientist as well as an individual and I am forever grateful for the hours of advice and multiple cups of Dutch Brothers Coffee. Thank you to Dr. Ben Perkins for teaching me hydrologic processes in Groundwater Geology, Winter 2011. Thank you to Dr. Dennis Nelson for being enthusiastic from the very beginning and for providing me with my first contracting experience. I would like to express gratitude to my committee members for being flexible with me while I try to balance sanity and schoolwork. Thank you to Hollie Heesacker for help on the first GPR excursion, the extra pair of hands were invaluable! Thank you to the City of Florence municipal workers, in particular Matt B. and Dan Graber for help navigating the dunes. 


\section{Table of Contents}

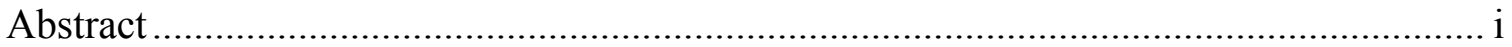

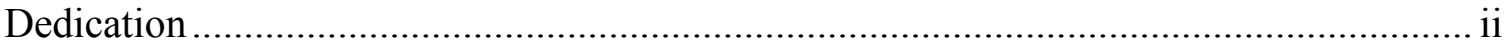

Acknowledgements .............................................................................................

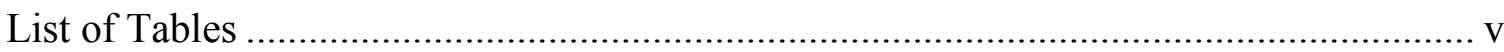

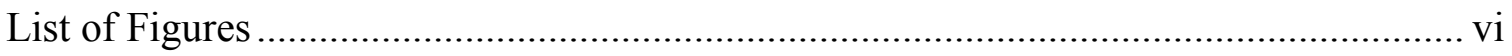

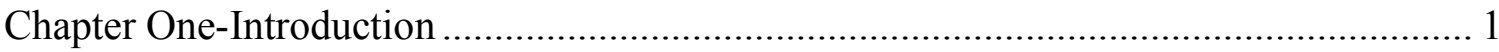

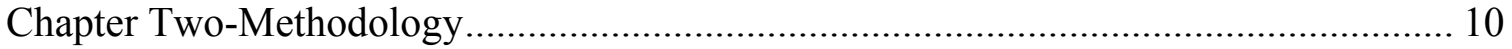

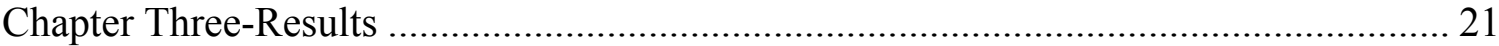

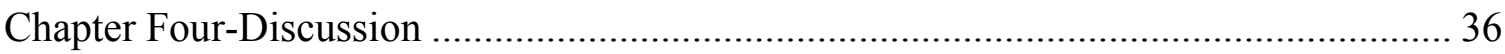

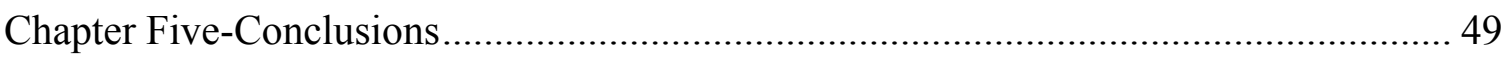

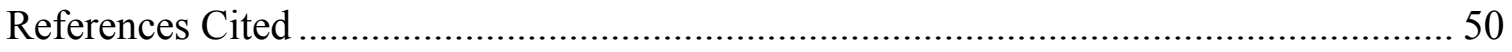

Appendix A- North Florence Dunal Aquifer Groundwater Elevation Database .............. 53

Appendix B- Groundwater Groundtruthing Locations and Elevations ......................... 75

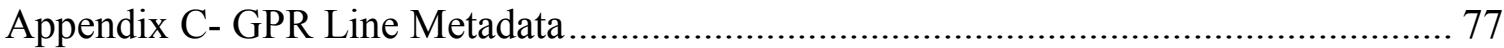

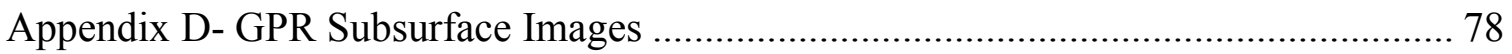




\section{List of Tables}

Table 1: Monitoring well water elevations from September 2011 are compared to nearby points (on GPR tracts) whose groundwater elevation was identified from Ground Penetrating Radar in Spring and Summer 2011. These monitoring wells represent vertical head components of the aquifer................................27

Table 2: Table of prediction error for groundwater elevation data. $\ldots \ldots \ldots \ldots \ldots \ldots \ldots . . .28$

Table 3: Table of groundwater elevations taken from GPR reflections and elevation of surface waterbodies. Measurements taken near the Siuslaw River represent the lowest elevations in the study and measurements near Mussel lake c represent the highest elevations. Surface water elevations were taken from LiDAR...........39

Table 4: 55 points from 6 different GPR tracts compared the groundwater elevation and ground elevation. In areas throughout the city the groundwater elevation was observed to mimic the local topography, especially in Holocene dune fields 


\section{List of Figures}

Figure 1- Areal photograph mosaic of the city of Florence and its major water bodies. The City of Florence is outlined in black, Urban Growth Boundaries in yellow and the approximate boundaries of the North Florence Dunal Aquifer are outlined in blue. The current well field of the City of Florence as well as the location of a proposed well field are outlined in red. The bounding coordinates for this area are (from SW corner clockwise): 414369 E $486971 \mathrm{~N}, 409760 \mathrm{E} 4882791 \mathrm{~N}, 413935 \mathrm{E}$ $4882791 \mathrm{~N}$ and $414369 \mathrm{E} 4869713 \mathrm{~N}$. Map coordinates are in longitude and latitude.

Figure 2- Map of coastal dunes in Oregon and Washington (from Peterson at al., 2007b). The Florence dune sheet is centrally identified at FLOR, while CLAT represents the Clatsop Plains and LONG represents Long Beach Peninsula where previous ground penetrating radar groundwater studies have been successfully conducted........................................................................4

Figure 3- Ground penetrating radar profile in the southern Clatsop Plains showing a groundwater surface reflection as the semi-continuous, thick black line at maximum depth of $15 \mathrm{~m}$ (Peterson et al., 2007a).

Figure 4- The Sensors and Software Inc. PulseEKKO PRO GPR unit was towed behind a vehicle on a carbon trailer in order to avoid any interference from metal hardware on the trailer. The receiver was placed next to the tow vehicle to reduce interference with shallow ground water reflectors.

Figure 5-Ground penetrating radar coverage shown as points in $100 \mathrm{~m}$ intervals. A LiDAR hillshade basemap shows the topography of the study area. Map coordinates in longitude and latitude. Lidar data is from (http://seamless.usgs.gov) (2011). Representative profiles (numbers) are from 1:Sutton Lake (purple), 2: Clear Lake (yellow), 3: City Center Profile E-W (green), 4: City Center Profile N$\mathrm{S}$ (orange). The GPR tracts for these lines can be found in Figure 9, Figure 10, Figure 12 and Figure 15 respectively.

Figure 6- Raw (A) and topographically corrected (B) subsurface images for the same survey line (profile number 2 in Figure 5). At about $1500 \mathrm{~m}$ position distance Clear Lake was approached (red line), from west to east, and an interpreted 
groundwater surface reflection is seen near the surface in both the raw and topography processed profiles, within the lake bounding dune ridge (see Results section for further interpretations of the Clear Lake GPR profile). Raw data (A) has a horizontal surface because the GPR antennas are at a constant height from the ground. Once elevation data is added (B) the reflection is adjusted to display actual elevation. The location of the Clear Lake GPR profile is shown in Figure 5. Figure 6 (C) shows the location of this line, with each 100-m interval represented as a blue point. Distances labeled on this map correspond to the Position of the GPR from $6 \mathrm{~A}$ and $6 \mathrm{~B}$........

Figure 7-Surface water is not present in this seasonally ephemeral pond, but the presence of Carex sp. and willow shrubs, as well as the darker, more saturated soil indicate a shallow groundwater surface depth (less than $2 \mathrm{~m}$ depth). Earlier in the spring, a small surface water pond was observed at this site, at the south end of the City of Florence well field. The location of the City of Florence well field is shown in Figure 1

Figure 8- Basic statistics for the groundwater elevation data show a bell-shaped histogram using 10 quartiles. The same quartiles are plotted against the standard normal values for the data and show most of the data lies on or near a Gaussian (normal) trend line. Both of these diagrams suggest that simple kriging is a viable technique for interpolation of the groundwater surface elevation point data in the Florence dunal aquifer. .20

Figure 9-Subsurface image of the Sutton Lake GPR line where the survey began in bedrock (profile 1 in Figure 5). From position $0 \mathrm{~m}$ to about $1100 \mathrm{~m}$ (blue arrow) there is very little signal and no identifiable groundwater reflection. The strong and somewhat continuous shallow reflection in the thicker dune sand is the identified and groundtruthed groundwater reflection (arrows). Deeper GPR reflections could be bedrock contacts or dunal paleosols in the deeper subsurface. See Figure 5 for location of Sutton Lake GPR profile...

Figure 10- Plot of Clear Lake GPR profile, with interpretations of ground water surface reflections (same profile previously shown uninterpreted in Figure 6). From line position $50 \mathrm{~m}$ to about $800 \mathrm{~m}$ carax and ponded bog water was observed on either side of the road. The GPR reflections over that area shows one stronger reflection near the surface and multiples of that top reflection to a depth of about $4 \mathrm{~m}$ below the surface (red arrows). With continued GPR surveying into higher elevations in dune ridges (1100 m-1450 m line positions) a single groundwater surface reflection is shown to be more distinct (blue arrows). The location of Clear Lake 
is marked with a purple line. A much deeper reflection (10-15 m depth subsurface) in this area may be a Pleistocene dune surface or paleosol. The shallower groundwater surface trends are not correlated to the deeper GPR reflection trends. There is no evidence of groundwater elevation being affected by the deeper reflection feature(s). See Figure 5 for location of Clear Lake GPR profile.

Figure 11- Subsurface image from the Clear Lake GPR profile showing the groundwater surface reflection staying relatively horizontal beneath a large sand dune ridge (100 m-550 m line position) adjacent to Clear Lake. GWS variation beneath dune ridge (distances $100 \mathrm{~m}-1000 \mathrm{~m}$ ) are attributed to changing dune morphology since LiDAR data was collected. At $550 \mathrm{~m}$ line position Clear Lake(red line) was approached and the groundwater surface reflection is observed at the elevation of the lake surface (about $40 \mathrm{~m}$ NAVD88). A reversal of profile direction (550-900 $\mathrm{m}$ line position) helps to confirm the connection between lake surface and the equivalent elevation of the subsurface groundwater surface reflection in the dune field aquifer. It is clear from in this figure that in higher elevations (open dunes $100 \mathrm{~m}-1000 \mathrm{~m}$ ) the GWS is imaged as one continuous reflection, but in lower elevation wetlands and bogs the continuous line splits into multiple reflections

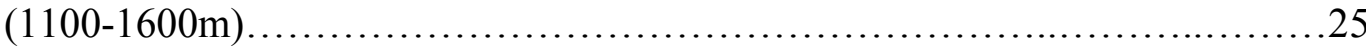

Figure 12- Locations of the City of Florence Monitoring wells used to help groundtruth GPR groundwater reflections .26

Figure 13- The deeper reflection (lower red arrows) is believed to be a Pleistocene/Holocene dune deposit contact or Pleistocene dune paleosol, based on the dune isopach map from Couch et al. (1980). This GPR line was taken in the center of the city (Profile 3 in Figure 5) where the groundwater surface is close to the surface (blue upper arrows). The morphology of the Pleistocene dune contact does not show any control over the nearly horizontal groundwater surface reflection.

Figure 14- The semivariogram (blue line) created for groundwater elevations with a Gaussian model shows greater variability in groundwater elevation points when there is a larger distance between the measured points. This suggests that the groundwater elevations are somewhat spatially correlated. The y axis is variance and the $\mathrm{x}$ axis is distance between points. This dataset has been divided into 12 lags each with a lag size of .00062618 . Each blue cross on this graph shows the averaged lag values. 
Figure 15- Map of predicted groundwater based on window surface water bodies and on subsurface groundwater surface reflections in GPR profiles (Appendix A and 2).

Figure 16- Prediction error map created during kriging process. In areas where measured GPR or lake elevation data is abundant, the error associated with the predicted groundwater surface is low (white areas). In locations where there was few or no measurements taken, more error is associated with the prediction of groundwater elevation (bright

red)

Figure 17- Map of Significant Wetlands in the Florence area. The map shows significant wetland in yellow, non-significant wetlands in green and wetlands that are significant only for public use or recognition (from City of Florence, Planning Department, 2011). The locations of two profiles taken near these wetlands (A and $\mathrm{B}$ ) represent the GPR lines 49 and 51 (Figures 10 and 11)

Figure 18- Hydraulic Head map (in feet) modeled using MODFLOW GWVistas created by GSI Water Solutions based on water levels in city monitoring wells (red squares) (GSI Water Solutions Inc, 2012, unpublished data). Residual mean error (difference between measured and modeled water levels) is \pm 4.3 feet

Figure 19- Kriging results for the same area (in feet), based on a three month average of water levels in city monitoring wells (blue triangles). Black arrows indicate predicted groundwater flow based on hydraulic gradient. Both methods show higher groundwater elevation directly west of Clear and Collard Lakes with a downward gradient to the south and east. Modeling done by GSI Water Solutions Inc. does not extend far enough north to the groundwater trough (Figure 15) .35

Figure20- Ground Penetrating Radar image part of Line 14 running south to north along Highway 101 (profile 4 in Figure 5). Most of this tract lacks a strong, continuous reflection, in part, due to the surrounding electromagnetic interference along the highway. However, discontinuous groundwater reflections are apparent at $500 \mathrm{~m}$, $1,500 \mathrm{~m}, 3,500 \mathrm{~m}, 4,500 \mathrm{~m}, 5,500 \mathrm{~m}$ and 7,000 $\mathrm{m}$ line positions, showing rising groundwater surface from south to north in the North Florence Dune Aquifer...........................................................................37

Figure 21- Groundwater elevations from GPR plotted against surface water elevations from LiDAR show a strong linear relationship. The highest and lowest elevations 
are shown by the points at $(0,0)$ and

$(49,55)$......

Figure 22- Plot of ground elevations ( $\mathrm{X}$ axis) and groundwater elevations ( $\mathrm{Y}$ axis) for 55 points throughout the city of Florence. A correlation coefficient of .72 indicating a linear relationship between the two

variables.

Figure 23- Plot of ground elevations (meters) and groundwater elevations (meters) for 55 points throughout the city of Florence. A correlation coefficient of .72 indicates a linear relationship between the two

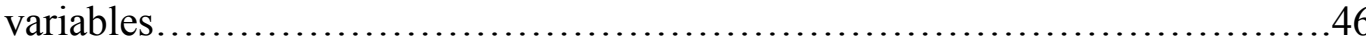




\section{Chapter One-Introduction}

\section{Background}

The North Florence Dunal Aquifer (Hampton, 1963; Couch et al, 1980) underlies the coastal city of Florence, Oregon and supplies municipal water to the city of Florence, and adjacent communities (Figure 1). In 1987 the aquifer was named a Sole Source Aquifer by the EPA, alerting local and state officials and citizens to the critical importance of preventing contamination of groundwater. Designation of an aquifer as a sole source aquifer is a tool used by the EPA to protect fresh water sources from contamination. A Sole Source Aquifer must supply at least $50 \%$ of the drinking water and if contaminated would leave no other dependable source for clean drinking water (EPA, 1987). The rapid infiltration rates of the North Florence Dunal Aquifer combined with a shallow water table leave the it extremely vulnerable to contamination from the surface (EPA, 1987).

In addition to directly supplying the North Florence area's drinking water, the aquifer is believed to be partly responsible for recharging Clear Lake (Figure 1) (EPA, 1987). The relationships between the surface water bodies in and surrounding the aquifer and the groundwater surface (water table) in the aquifer have not been established. It is suspected but not known whether the small lakes, ponds, and wetland bogs in the Florence dune fields are window lakes to the underlying dunal aquifer. Window lakes are bodies of groundwater that are exposed at ground surface, or areas where the ground is at a lower elevation than the groundwater. Window lakes grant direct access to the aquifer making these lakes possible entryways for surface contaminants. As the city of 
Florence continues to expand, developments made in or near the aquifer recharge zones might result in aquifer contamination. Additionally, local well water draw down of the groundwater surface could impact sensitive creeks, ponds, and wetlands by lowering water levels or drying up the wetland or riparian habitats. Surveys are needed in the North Florence Dunal Aquifer to establish any potential links between the surface water bodies and the underlying groundwater surface and investigate groundwater flow direction. The city well field (Figure 1) pumps directly from the dunes and any contamination in the aquifer would surely manifest in the drinking water supply. Recent studies have been successful in identifying groundwater surfaces and their relationships to surface water bodies in coastal dunes of Oregon and Washington using a combination of piezometer well data, surface water data, and ground penetrating radar (GPR) surveys (Figure 2) (Brown, 2008; Peterson et al., 2007a; Nielsen, 2005; Thomas, B.E., 1995). This study of the North Florence Dunal Aquifer 1) delineates the elevation of the shallow groundwater surface using Ground Penetrating Radar as a subsurface imaging tool, 2) establishes the relationship between surface waterbodies, including lakes, wetlands and bogs, and the dunal aquifer, and 3) creates a groundwater database and surface elevation map that shows groundwater surface trends for the North Florence Dunal Aquifer. 


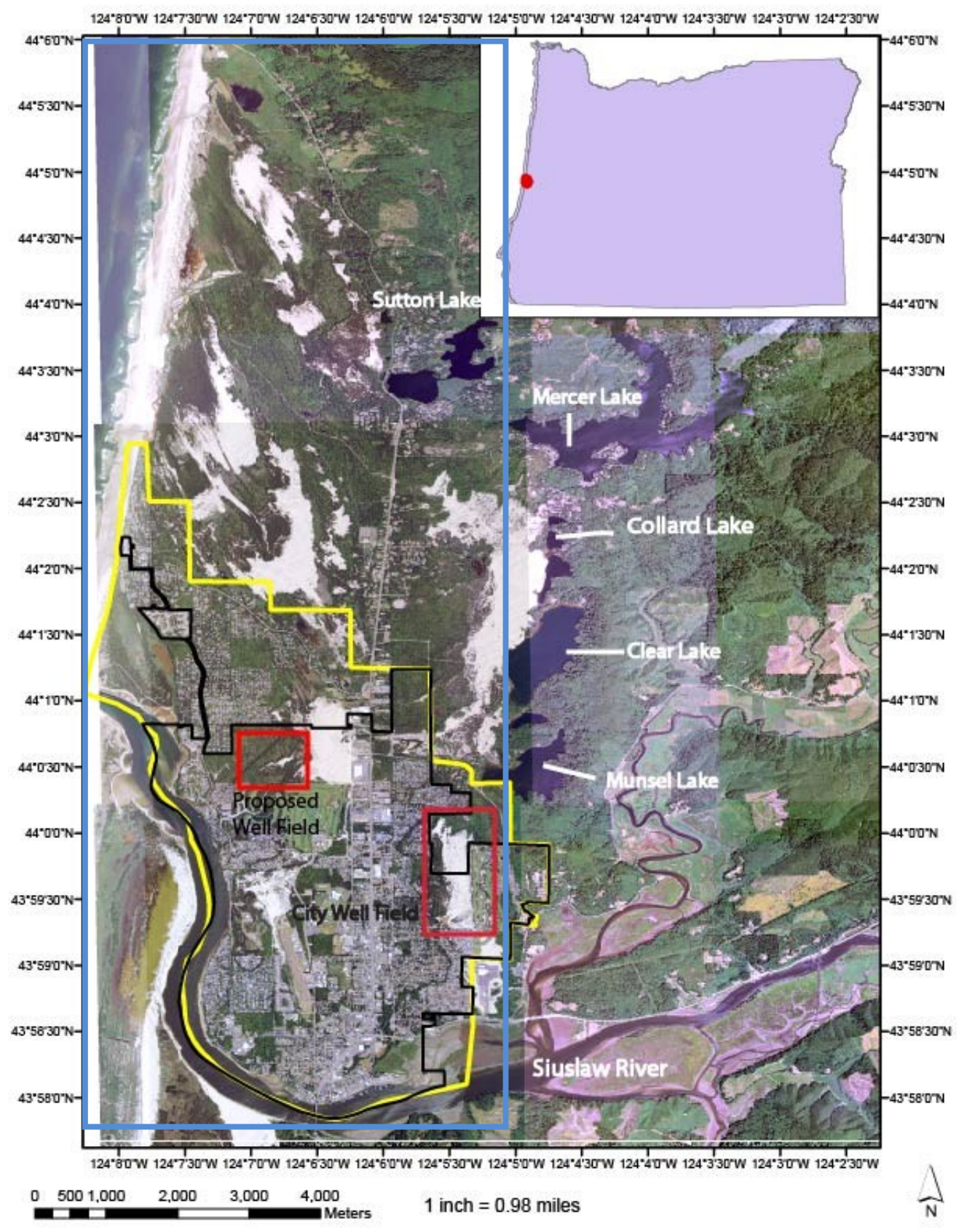

Figure 1: Areal photograph mosaic of the city of Florence and its major water bodies. The City of Florence is outlined in black, Urban Growth Boundaries in yellow and the approximate boundaries of the North Florence Dunal Aquifer are outlined in blue. The current well field of the City of Florence as well as the location of a proposed well field are outlined in red. The bounding coordinates for this area are (from SW corner clockwise): 414369 E 486971N, 409760E 4882791 N, 413935 E $4882791 \mathrm{~N}$ and 414369 E 4869713 N. Map coordinates are in longitude and latitude. 


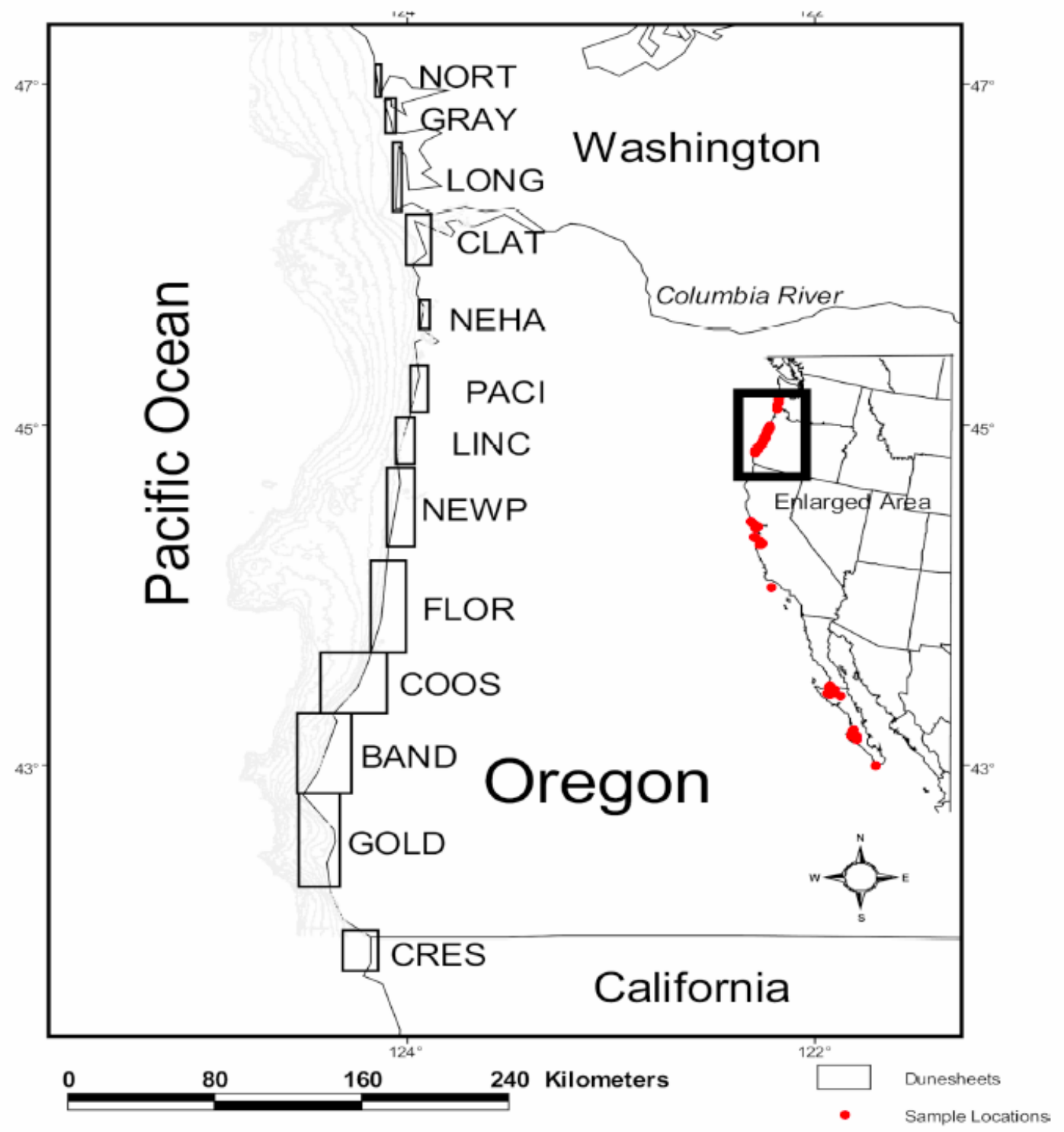

Figure 2: Map of coastal dunes in Oregon and Washington (from Peterson at al., 2007b). The Florence dune sheet is centrally identified at FLOR, while CLAT represents the Clatsop Plains and LONG represents Long Beach Peninsula where previous ground penetrating radar groundwater studies have been successfully conducted 


\section{Previous Work}

The dimensional parameters of the Florence Dunal Aquifer were first studied in 1979 by the Florence Dunal Aquifer Geophysics group at Oregon State University (Couch et al., 1980). This involved using seismic refraction and reflection to measure the thickness of Quaternary sand layers above the bedrock formations, located north of the Siuslaw River and south of Sutton Creek as well as the thickness of the sand layers beneath the Siuslaw River (Couch et al., 1980). Although the 'water table' was very roughly delineated by seismic refraction, the seismic study concentrated on the depth of the sand aquifer down to the bedrock, locally identified as the Eocene consolidated marine sandstone/siltsone Flournoy Formation (Newton, 1980). Late Pleistocene bay and marine terrace deposits are thought to locally overlie the bedrock and underlie the Pleistocene-Holocene dune sands (C. Peterson, Personal Communication, 2012). The groundwater surface depths, slope directions, and slope gradients in the overlying Pleistocene and Holocene dunal aquifer were not well resolved by the seismic refraction methods.

This thesis study area overlaps that of Couch et al (1980), which is located north of the Siuslaw River. Large dunes, barrage lakes, popular ATV riding areas, and deflation plain bogs are located south of the Siuslaw River in the South Florence Dune sheet (Cooper, 1958; Reckedorf, 1975). Barrage lakes differ from window lakes in that they are created when a dune migrates and dams natural spring water which collects and forms a lake. 
Groundwater surface (GWS) trends in beach plain aquifers in Long Beach Peninsula, southwest Washington (LONG in Figure 2), were studied with GWS elevation data from 150 shallow wells and 20 surface water locations, including streams and lakes (Thomas, 1995). A groundwater elevation model and surface flow trend model of the Long Beach Peninsula aquifer were created showing maximum water table elevation and ranges, and depth from land surface to water table. For the remainder of this thesis the surface of the groundwater aquifer is referred to as the ground water surface rather than as the groundwater table. The groundwater surface is defined by different characteristics depending on season, hosting deposits, and survey methods, as discussed further below.

A study of groundwater geochemistry was conducted in the prograded Clatsop beach plains, in northernmost Oregon, to test whether the numerous ponds and bogs in valleys between the abandoned foredune ridges were window lakes in the shallow groundwater aquifer (Nielson, 2005). Ground penetrating radar was then used in the Clatsop beach plains to identify the groundwater surface trends between abandoned foredune ridges and the environmentally sensitive lakes in the intervening valleys (Peterson et al., 2007a; Brown, 2010). A semi-continuous groundwater surface was identified at depths of 1.0-15.0m in prograded Clatsop beach deposits using GPR with a 1000v transmitter and $100 \mathrm{MHz}$ antennae (Figure 3) (Peterson et al., 2007a).

The studies identified above are examples of successful groundwater surface surveys in low elevation coastal dune aquifers, which utilized piezometers, surface water bodies, and/or ground penetrating radar to establish the depth and slope of groundwater surfaces. Those studies focused on the shallow groundwater surface in low elevation 
barrier beach plains and not in upland dune sheets, such as the North Florence Dunal Aquifer.

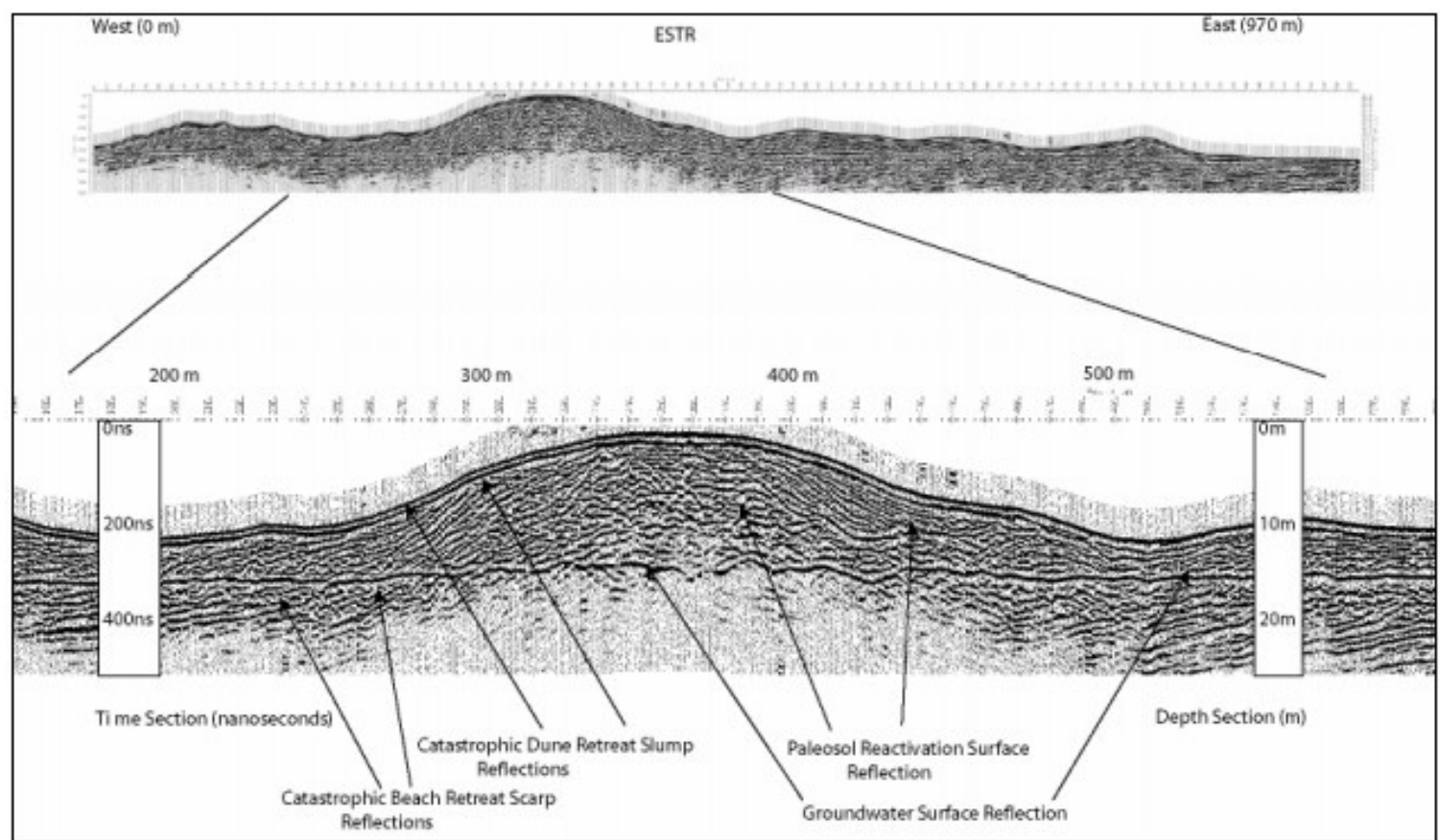

Figure 3: Ground penetrating radar profile in the southern Clatsop Plains showing a groundwater surface reflection as the semi-continuous, thick black line at maximum depth of $15 \mathrm{~m}$ (Peterson et al., 2007a).

There is a general public interest in investigating the relationship between the groundwater surface and the dunal surface water bodies, in terms of water quality issues (Dennis Nelson GSI Water Solutions, personal contact 3/23/2011). In the Fall of 2009 the City of Florence was awarded a grant from the Environmental Protection Agency in order to assist local governments in managing land uses to protect watersheds. As one result of this grant support the Siuslaw Estuary Partnership was established to further local efforts in watershed restoration. The Siuslaw Estuary Partnership project includes water quality and water quantity monitoring, wetland and riparian protection, and planning for ecologically-sustainable growth in the Florence area. The City of Florence 
is working with consultants from GSI Water Solutions to monitor groundwater and surface water at several locations throughout the City of Florence and the city's Urban Growth Boundary, in support of the EPA study objectives (Dennis Nelson GSI Water Solutions, personal contact 3/23/2011).

\section{Study Area}

The North Florence Dunal Aquifer encompasses the "entire continuous body of sand located north of the Siuslaw River and east of the Pacific Ocean" (EPA, 1987). Initial geologic mapping in this area identified the sand dunes as Pleistocene-Recent with no differentiation made between ages of dune forming events (Hampton, 1963; Lund, 1971, Reckendorf, 1980). These studies identified some major bodies of water including Clear Lake, Sutton Lake, Mercer Lake and Munsel Lake, as sitting on the contact between the dunes and the underlying sandstones and siltstones of the Flournoy formation (Hampton, 1963; Lund, 1971). However, it was not determined whether the lakes occur from perched aquifers above internal dune aquitards, or what relations the larger barrage lakes and smaller deflation trough ponds have with regional ground water surface trends.

Radiocarbon and thermoluminescence dates from the upland dune deposits in the Florence and Coos Bay areas confirm that there are two dominant periods of dune deposition. Holocene and Pleistocene dune sheets correspond to periods of marine high and low stand, respectively (Peterson et al., 2007b). The Florence Pleistocene dune sheet deposits yield average dates of $40 \mathrm{Ka}$ and $49 \mathrm{Ka}$ from radiocarbon and thermoluminescence, respectively. The Pleistocene dunes are associated with loess 
interbeds, weak interstratal cementation, and variably developed paleosols (Peterson et al., 2006).

The Florence Holocene dune sheet deposits yield average dates of 3Ka and 5Ka, based on radiocarbon and thermoluminescence techniques, respectively (Peterson et al., 2007b). The Holocene dunes are uncemented, contain no loess interbeds, and are lacking any well developed paleosols. The oldest Holocene dunes dated in the North Florence Dune Aquifer were deposited at 7,822 RCYBP (Radio Carbon Years Before Present) (Peterson et al., 2007b). GIS coverages of the surficial extent of the Holocene and Pleistocene dune sheets are available for the Florence dune sheets (Peterson et al., 2006) although some additional mapping was required for this thesis to confirm the boundaries of the two dune sheet types (see Methods below). 


\section{Chapter Two-Methodology}

\section{Data Collection}

A Sensors and Software Inc. PulseEKKO PRO GPR system was towed behind a vehicle at speeds of $5-8 \mathrm{~km} / \mathrm{hr}$, while the data acquisition unit was in the car. The set up is shown in Figure 4. Ground Penetrating Radar data was collected in 54 lines or tracts throughout the city of Florence (Figure 5). The data was collected in three survey trips over the summer of 2011, which followed an unusually late and wet spring season. Two different sized antennae, 50 and $100 \mathrm{MHz}$, were used with a $1000 \mathrm{~V}$ transmitter. In both cases, the antennae were secured 1.0 meter apart in broadside orientation on a carbon trailer. A ground penetrating radar (GPR) profile is created when the transmitter generates and sends a high frequency electromagnetic pulse into the subsurface (Jol and Bistrow, 2003). A change in electrical impedance across deposit strata, such as produced by changes in water content or lithology, will cause part of the energy to be reflected back to the surface (Jol and Bistrow, 2003). The system was programmed to transmit a pulse every meter, as measured by the odometer. A signal velocity of $(0.1 \mathrm{~m} / \mathrm{ns})$ was established for the dry to moist sand deposits above the groundwater surface from known groundwater reflectors at measured depths (see Results Section below). The reflected pulses are recorded as two-way nanosecond delay time, and are converted to depth from the surface using the established signal velocity. The depth to groundwater is later converted to elevation, based on the NAVD88 datum using surface elevations from LiDAR (see further details below). Sediments such as sand, gravel, peat and limestone or 
fresh water saturated sediments have produced high quality data and are highly suitable for ground penetrating radar studies (Doolittle, 2002; Jol and Bistrow, 2003). Both the 50 $\mathrm{mHz}$ and $100 \mathrm{mHz}$ antennae penetrated the dry sand and recognized changes in electrical conductivity throughout the dunes. The spatial resolutions of the $2 \mathrm{~m}$ long $50 \mathrm{mHz}$ antennae and the $1 \mathrm{~m}$ long $100 \mathrm{mHz}$ antennae are $.5 \mathrm{~m}$ and $.25 \mathrm{~m}$ using a velocity of 0.1 $\mathrm{m} / \mathrm{ns}$ (Jol and Bristow, 2003). Spatial resolution can be approximated as $1 / 4$ to $1 / 2$ of the wavelength, where wavelength $=$ velocity/frequency $(\mathrm{Jol}$ and Bristow, 2003). Higher antenna frequencies have smaller wavelengths and increase spatial resolution but decrease the depth of penetration. In this study the primary focus was on regional depth of the ground water surface reflection(s) so the intermediate frequency antennae, 50 and $100 \mathrm{MHz}$, were used. 


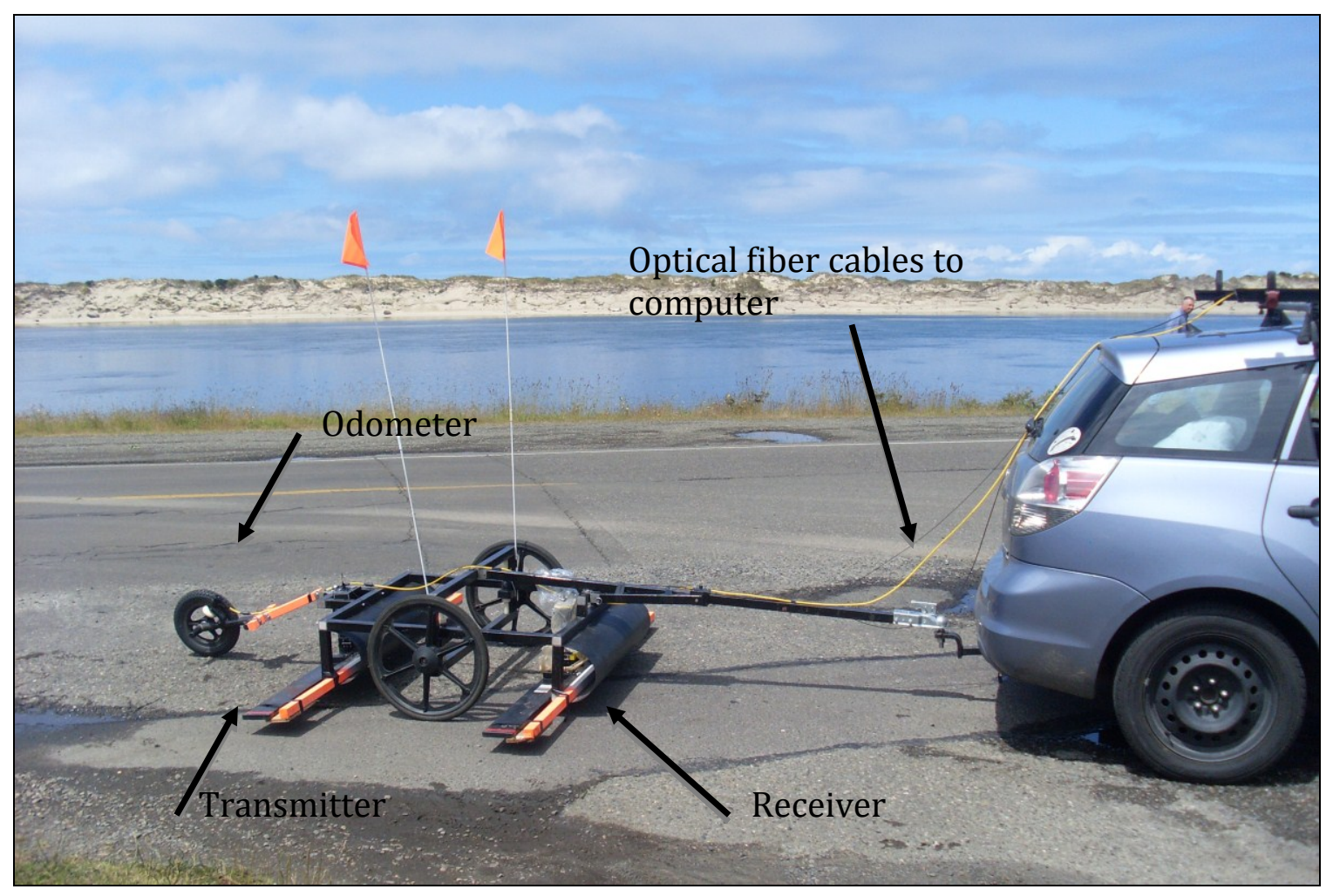

Figure 4: The Sensors and Software Inc. PulseEKKO PRO GPR unit was towed behind a vehicle on a carbon trailer in order to avoid any interference from metal hardware on the trailer. The receiver was placed next to the tow vehicle to reduce interference with shallow ground water reflectors. 


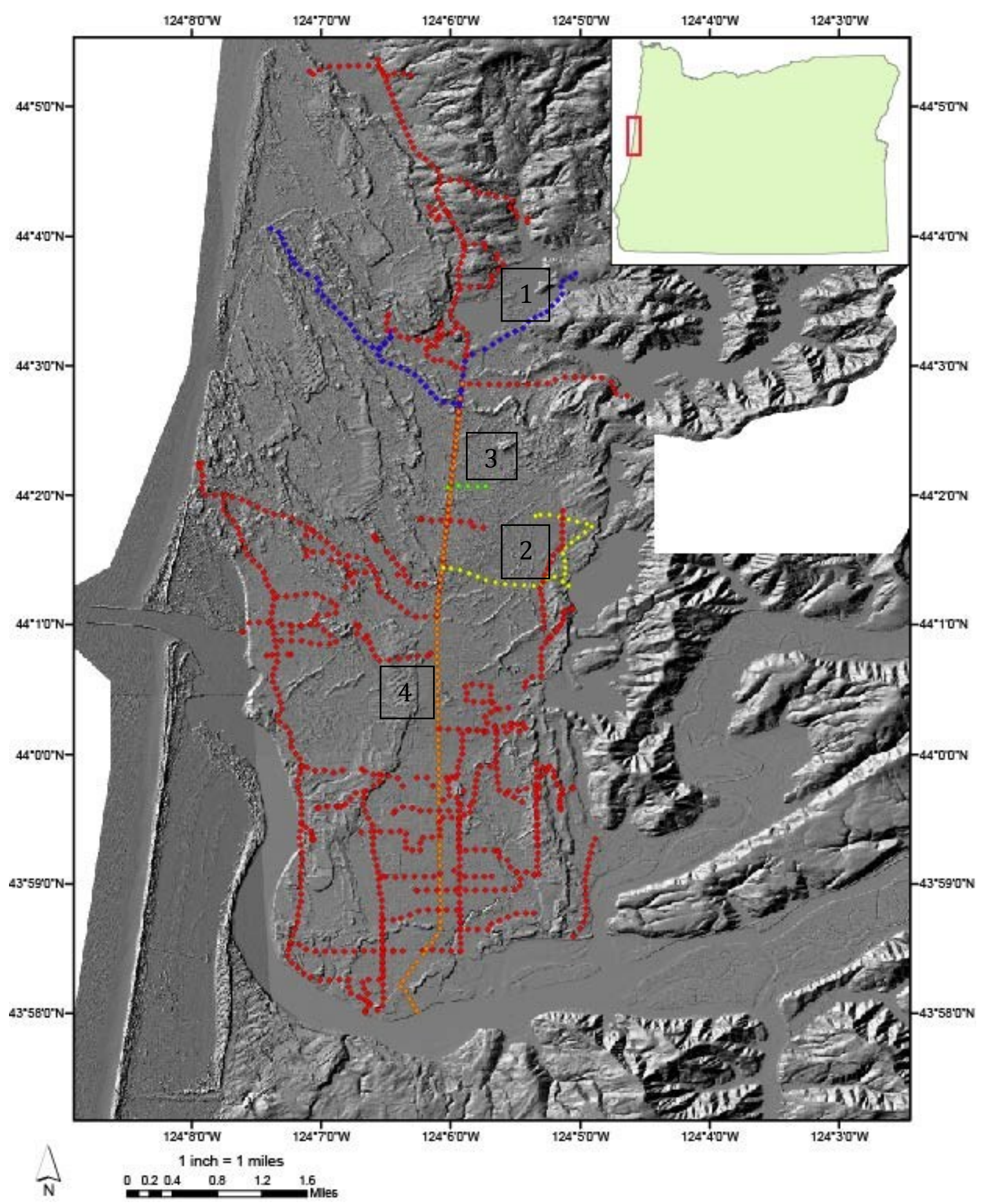

Figure 5: Ground penetrating radar coverage shown as points in $100 \mathrm{~m}$ intervals. A LiDAR hillshade basemap shows the topography of the study area. Map coordinates in longitude and latitude. Lidar data is from (http://seamless.usgs.gov) (2011). Representative profiles (numbers) are from 1:Sutton Lake (purple), 2: Clear Lake (yellow), 3: City Center Profile E-W (green), 4: City Center Profile N-S (orange). The GPR tracts for these lines can be found in Figure 9, Figure 10, Figure 12 and Figure 15 respectively. 


\section{Data Processing}

The GPR data acquisition unit stored each GPR profile or line as a data file (.dt1) with an associated header file (.hd). The GPR profile data were processed using Sensors and Software's ProEKKO View and ProEKKO View Deluxe programs. Topographic correction was achieved in several steps, beginning with LiDAR elevation data preprocessing in ESRI's ArcMap 10.0. The first step in the elevation preprocessing was recording coordinates in $100 \mathrm{~m}$ intervals along each profile. Global positioning system (GPS) coordinates taken in the field intermittently throughout data collection were used as a guide to for recording the tracts in ArcMap and from GIS geo-referenced maps were used for surface water body elevations. Each line of GPR data was converted to points in 100 meter intervals in ArcMap using the simple measuring tool to measure the interval. Using the 'Add XY coordinates' tool, coordinates were assigned to each point and the elevations were extracted. Elevations were extracted from the USGS NED 1/9 arcsecond dataset (the main source of this database is LiDAR) using the 'Extract Multivalues to Point' tool (http://ned.usgs.gov/Ned/index.asp). This dataset has 3 meter resolution vertical accuracy, expressed as a Root Mean Square Error of 2.44 meters (http://ned.usgs.gov/Ned/index.asp). This raster file was projected in North American Vertical Datum of 1988 (NAVD88), which uses a value of about $1 \mathrm{~m}$ below local mean tide or sea level as zero meters (http://ned.usgs.gov/Ned/index.asp, Gesch et al., 2007). All elevations used in this thesis study are relative to the NAVD88 datum. An ASCII format topography file (.top) was created for each GPR line consisting of two columns: meters traveled $(0,100,200)$ and elevation at that location. When applied to raw data, 
the topography file translated the calibrated signal velocity $\left(0.1 \mathrm{~m} \mathrm{~ns}^{-1}\right)$ to the elevation given at that distance allowing for interpretation of water surface elevation, relative to the NAVD88 datum (Figure 6).

In some tracts reflections at depth were not well resolved and gain was applied during processing to amplify weaker reflections. Sensors and Software offers several types of gain to help increase the visibility of reflections at depth, which are sometimes muted as the signal is weaker at depth. In this study SEC (spreading and exponential compensation) gain was used as a primary gain. SEC sets starting and ending gain values, generally between 0 and 20 . Less gain is needed near the surface but as depth increases, the signal becomes weaker and more gain is needed to amplify features. This gain application is typical for geologic and sedimentilogical GPR investigations. 

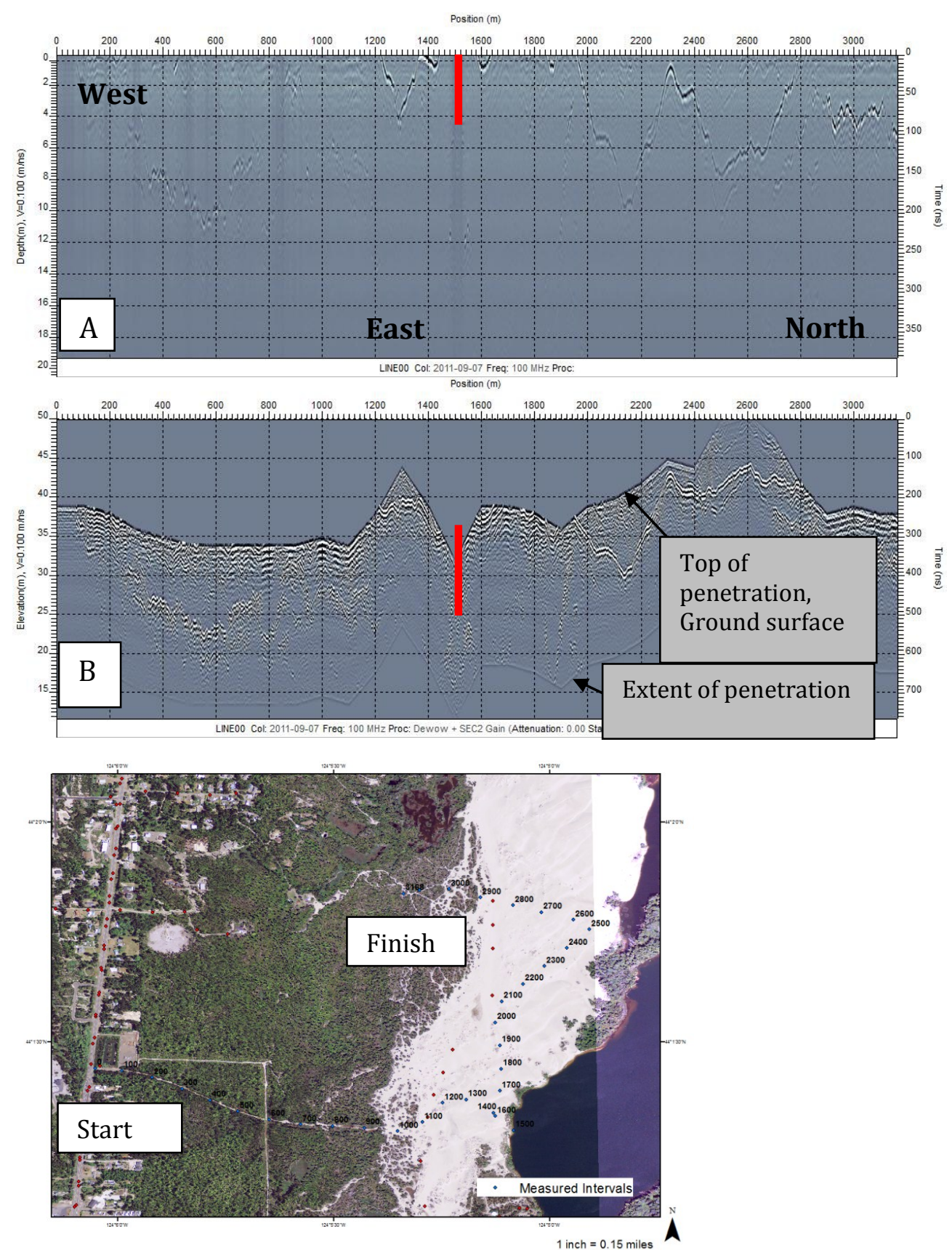

Figure 6: Raw (A) and topographically corrected (B) subsurface images for the same survey line (profile number 2 in Figure 5). At about $1500 \mathrm{~m}$ position distance Clear Lake was approached (red line), from west to east, and an interpreted groundwater surface reflection is seen near the surface in both the raw and topography processed profiles, within the lake bounding dune ridge (see Results section for further interpretations of the Clear Lake GPR profile). Raw data (A) has a horizontal surface because the GPR antennas are at a constant height from the ground. Once elevation data is added (B) the reflection is adjusted to display actual elevation. The location of the Clear Lake GPR profile is shown in Figure 5. Figure 6 (C) shows the location of this line, with each 100 -m interval represented as a blue point. Distances labeled on this map correspond to the Position of the GPR from $6 \mathrm{~A}$ and $6 \mathrm{~B}$. 
The identification of the groundwater surface was obtained using a combination of locating a strong and somewhat continuous GPR reflection in the processed GPR profile and groundtruthing the origin of the target reflection to an observed groundwater surface in 1) standing water in a lake, pond, or wetland bog, and 2) groundwater monitoring wells (well data provided by the City of Florence). Water elevations in creek bottoms were also recorded relative to road or bridge surfaces where GPR lines crossed the creeks. Field notes taken during the GPR profiling provide GPS positions of 1) surface water bodies, 2) hydrophytic or wetland plants in bogs that are indicators of the local depth of a shallow groundwater surface, and 3) creek bottom water elevations, (Figure 7). Once a GPR groundwater surface reflection was traced to an observed surface water body the GPR reflection was followed along the profile until it discontinued, became intermittent or branched into multiple reflections. Multiple reflections were observed in some wetlands or bogs and are interpreted to represent multiple horizons of variably saturated soil, all zones becoming fully saturated in winter months when wetlands receive more water from precipitation. Only continuous, single, groundtruthed reflections were used to pick subsurface groundwater surface depths from the GPR profiles. Multiple groundtruthing sites along the individual GPR profiles and multiple crossings of groundwater surface reflections in crossing GPR profiles reinforced the interpretations of subsurface ground water surface depths.

Once the groundwater surface reflection was confirmed by groundtruthing, a groundwater surface depth and associated elevation relative to the NAVD88 datum was 
recorded for each $100 \mathrm{~m}$ interval or point where the groundwater surface reflection was traced along the GPR line. The groundwater surface elevation information is stored in a database file (.dbf) containing position coordinates, ground elevation and groundwater elevation for each $100 \mathrm{~m}$ interval point. These data are used to compile a groundwater surface map or model for the North Florence Dune Aquifer, as detailed below.

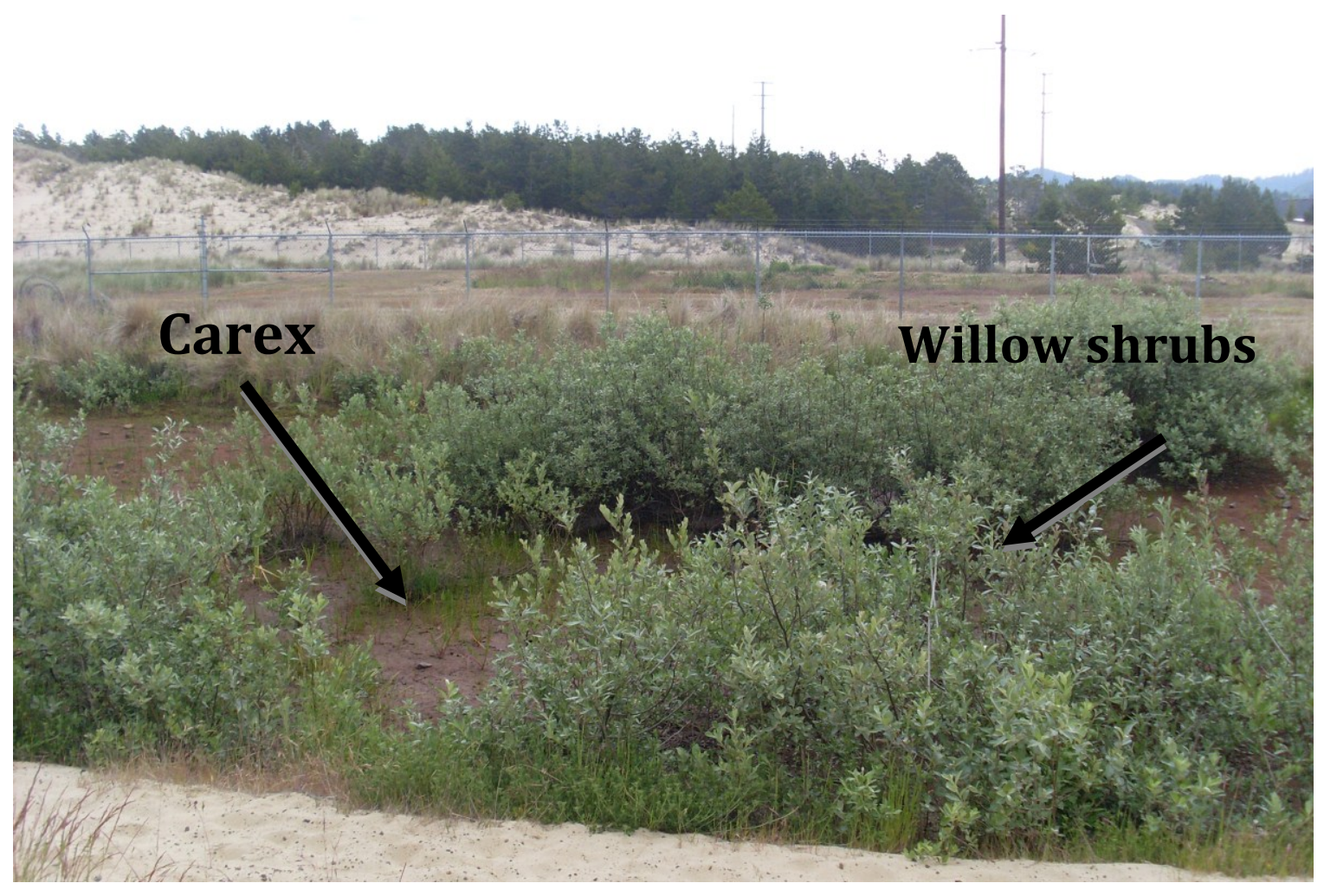

Figure 7: Surface water is not present in this seasonally ephemeral pond, but the presence of Carex $s p$. and willow shrubs, as well as the darker, more saturated soil indicate a shallow groundwater surface depth (less than $2 \mathrm{~m}$ depth). Earlier in the spring, a small surface water pond was observed at this site, at the south end of the City of Florence well field. The location of the City of Florence well field is shown in Figure 1. 


\section{Creating a GIS Representation of the Groundwater Surface}

The input database (.dbf) file, North Florence Dunal Database, stores 943 points containing groundwater elevations at about $100 \mathrm{~m}$ intervals along GPR profiles (Appendix A). In order to construct groundwater elevation map with continuous data, these points were interpolated using the simple kriging method. This method is a geostatistical method that relies on autocorrelation within a variable (groundwater elevation). Another way of saying this is the elevations of points close to each other are more similar than points farther away. One advantage to using a geostatistical method is the ability to predict and conduct error analysis, discussed in results below (Davis, 2002). The Kriging method used in ArcGIS has a two-step procedure: 1) uncover dependency rules by creating a semivariogram and 2) make predictions. A histogram and a Normal Quartile-Quartile plot were created to confirm that the groundwater elevation data was normally distributed, which is assumed with simple kriging (Figure 8). Semivariograms show the variance between all point pairs:

2

$* h=$ the value of the semivariance for lag (distance) $h$; $N(h)$ is the number of $i+h$ (Isaaks, 1989). In the case of the groundwater surface elevations in the study area the data is normally distributed (see Results section below) so a simple kriging method was employed to build the groundwater surface elevation map or model. 
Histogram

Transformation: None

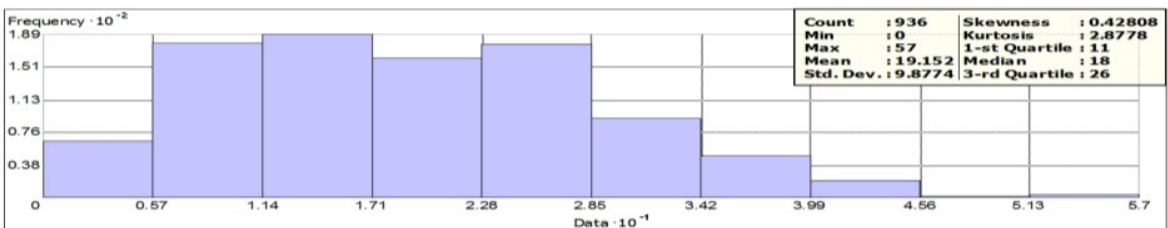

Data Source: Measured Points Attribute: gwater

Normal QQPlot Transformation: None

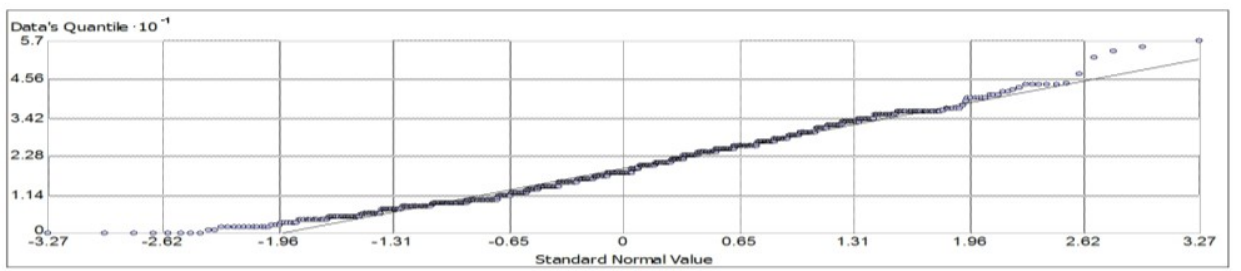

Data Source: Measured Points Attribute: gwater

Figure 8: Basic statistics for the groundwater elevation data show a bell-shaped histogram using 10 quartiles. The same quartiles are plotted against the standard normal values for the data and show most of the data lies on or near a Gaussian (normal) trend line. Both of these diagrams suggest that simple kriging is a viable technique for interpolation of the groundwater surface elevation point data in the Florence dunal aquifer 


\section{Chapter Three-Results}

\section{Ground Penetrating Radar Survey Results}

Ground Penetrating Radar successfully recorded the groundwater surface in 43 survey lines covering a total of 95 kilometers. In the homogenous North Florence Dunal Aquifer both $50 \mathrm{Mhz}$ and $100 \mathrm{Mhz}$ antennae were successful with average penetration depths of 17 and 20 meters respectively. Factors that affected the quality of the radar imagery include proximity to high power transmission lines (and other electromagnetic devices) and surveying over shallow bedrock (see Discussion)(Figure 9).

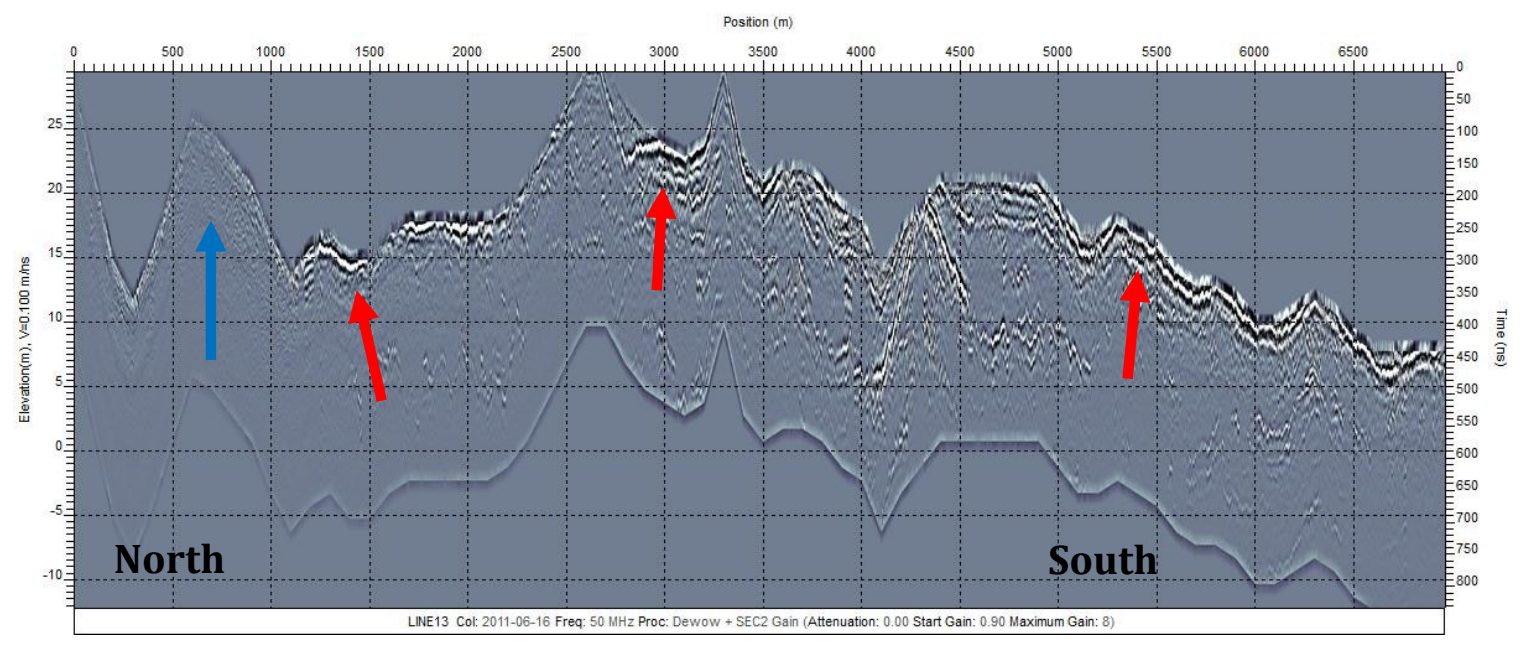

Figure 9: Subsurface image of the Sutton Lake GPR line where the survey began in bedrock (profile 1 in Figure 5). From position $0 \mathrm{~m}$ to about $1100 \mathrm{~m}$ (blue arrow) there is very little signal and no identifiable groundwater reflection. The strong and somewhat continuous shallow reflection in the thicker dune sand is the identified and groundtruthed groundwater reflection (arrows). Deeper GPR reflections could be bedrock contacts or dunal paleosols in the deeper subsurface. See Figure 5 for location of Sutton Lake GPR profile.

The majority of the surveying done throughout the North Florence Dunal Aquifer was done either on residential roads with little through traffic or on open dunes thus reducing interference with city traffic on the major roads and highways. GPR lines or 
profiles were selected on the basis of 1) approximate equal spacing between profiles, 2) crossing of creeks and surface water bodies to groundtruth the groundwater reflection interpretations, and 3) orthogonal crossing of multiple GPR lines to confirm groundwater surface reflection interpretations.

\section{Confirming Surface Water Bodies as Window Lakes}

Groundwater reflection elevations identified from GPR were compared with the elevation of surface water bodies, including ponds, lakes and wetlands, in order to confirm interpreted GPR reflections as a groundwater surface, as well as, to establish surface water bodies as window lakes into the aquifer. Some small creeks were also measured for water elevation to test whether the creeks were recharging from or discharging into the dunal aquifer. Confirmation of the groundwater reflection interpretations differed slightly between dunal wetlands and lakes or ponds. Wetland areas exhibited multiple shallow reflections in dune deposits that were located immediately adjacent or over the top of the wetlands or bogs (Figure 10). With greater distance and increasing elevation away from the wetlands the multiple groundwater surface reflections generally transitioned into a single reflection. The very-shallow multiple groundwater reflections in some bogs or seasonal wetlands could represent capillary fringes above shallow saturated groundwater surfaces during summer months. Confirmation of window lakes (eg. Clear Lake) was achieved by running GPR profiles in perpendicular traverses from bounding dune shorelines down to the edge of the lake (Figure 11). 
Water levels in monitoring wells provided by the City of Florence also served as groundtruthed data to compare the groundwater elevations interpreted from GPR profiles to measured phreatic surfaces in constructed wells (Table 1, Figure 12). For the most part the groundwater surface elevations identified from GPR profiles are within 3 meters of the monitoring well levels, though the GPR and well data were not collected synchronously in 2011 In several GPR profiles a deeper reflection was recorded in the dunal aquifer. Based on isopach maps from Couch et al. (1980) the deeper reflections are thought to represent the Pleistocene dune surface or loess paleosols within the Pleistocene dune strata (Figure 13). The trends of the shallow groundwater surface reflections are not apparently correlated to the terminations or slope trends of the deeper Pleistocene dune or paleosol reflections (see Discussion section below). 


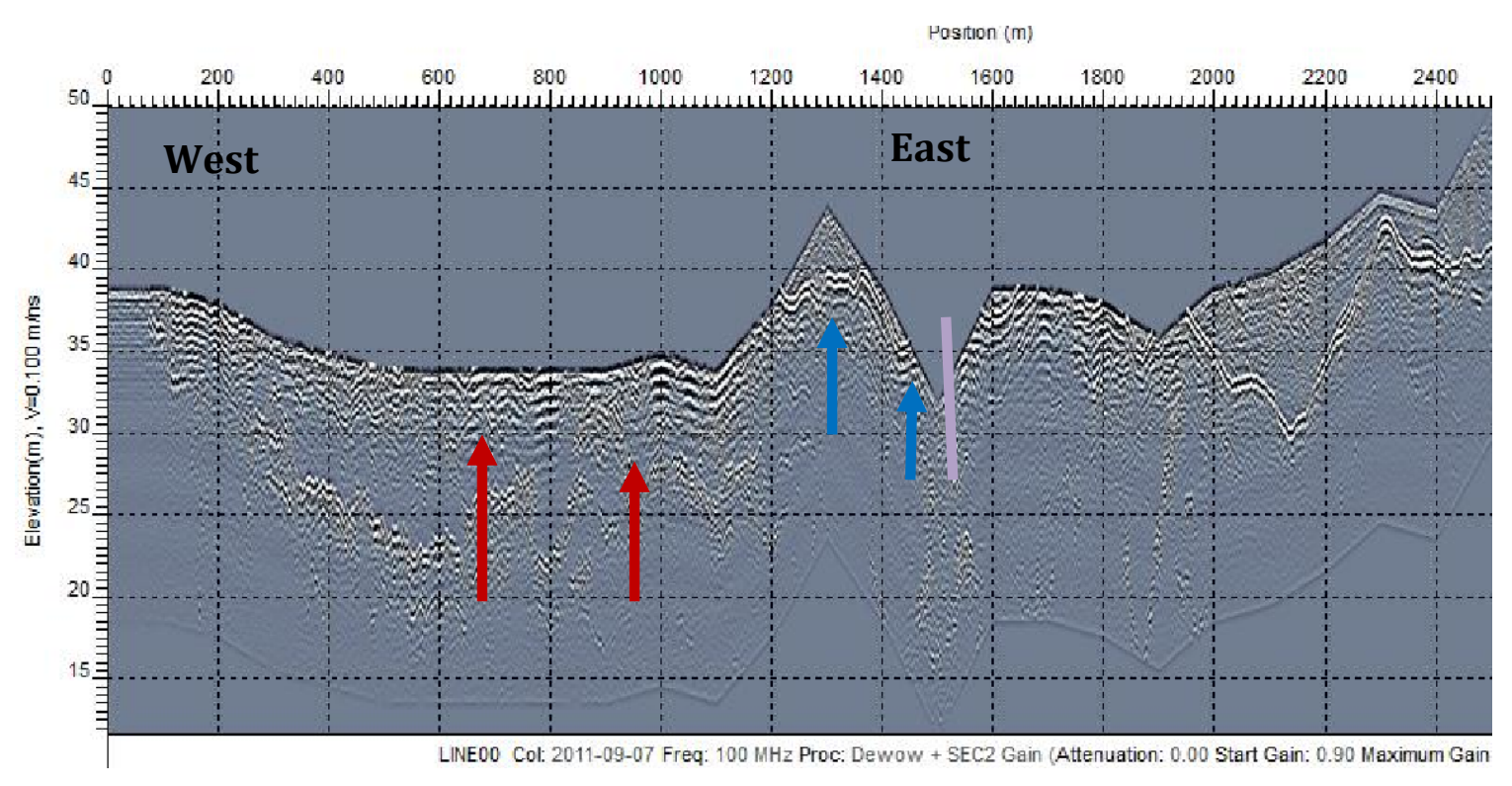

Figure 10: Plot of Clear Lake GPR profile, with interpretations of ground water surface reflections (same profile previously shown uninterpreted in Figure 6). From line position $50 \mathrm{~m}$ to about $800 \mathrm{~m}$ carax and ponded bog water was observed on either side of the road. The GPR reflections over that area shows one stronger reflection near the surface and multiples of that top reflection to a depth of about $4 \mathrm{~m}$ below the surface (red arrows). With continued GPR surveying into higher elevations in dune ridges (1100 m-1450 m line positions) a single groundwater surface reflection is shown to be more distinct (blue arrows). The location of Clear Lake is marked with a purple line. A much deeper reflection (10-15 m depth subsurface) in this area may be a Pleistocene dune surface or paleosol. The shallower groundwater surface trends are not correlated to the deeper GPR reflection trends. There is no evidence of groundwater elevation being affected by the deeper reflection feature(s). See Figure 5 for location of Clear Lake GPR profile. 


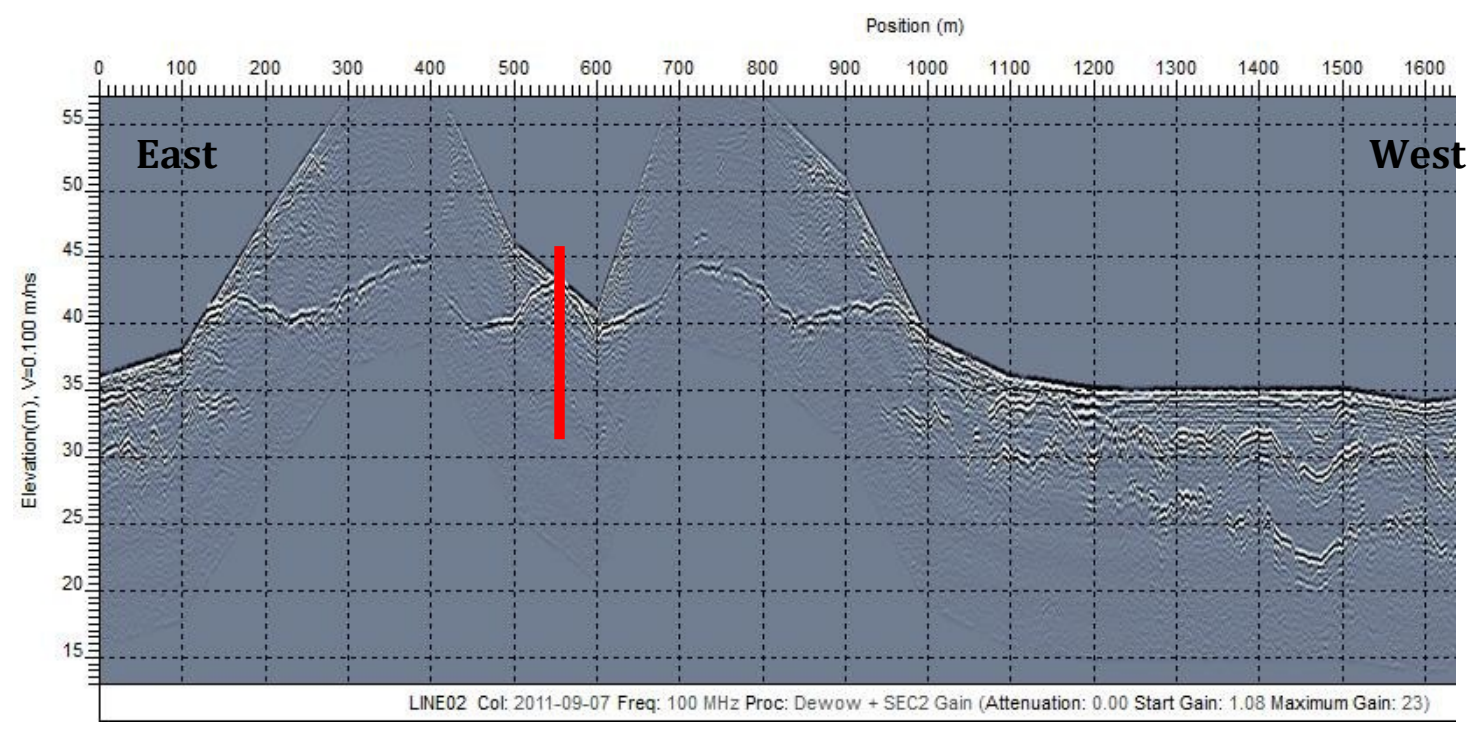

Figure 11: Subsurface image from the Clear Lake GPR profile showing the groundwater surface reflection staying relatively horizontal beneath a large sand dune ridge $(100 \mathrm{~m}-550 \mathrm{~m}$ line position) adjacent to Clear Lake. GWS variation beneath dune ridge (distances $100 \mathrm{~m}-1000 \mathrm{~m}$ ) are attributed to changing dune morphology since LiDAR data was collected. At $550 \mathrm{~m}$ line position Clear Lake(red line) was approached and the groundwater surface reflection is observed at the elevation of the lake surface (about 40 m NAVD88). A reversal of profile direction (550-900 m line position) helps to confirm the connection between lake surface and the equivalent elevation of the subsurface groundwater surface reflection in the dune field aquifer. It is clear from in this figure that in higher elevations (open dunes $100 \mathrm{~m}-1000 \mathrm{~m}$ ) the GWS is imaged as one continuous reflection, but in lower elevation wetlands and bogs the continuous line splits into multiple reflections $(1100-1600 \mathrm{~m})$ 


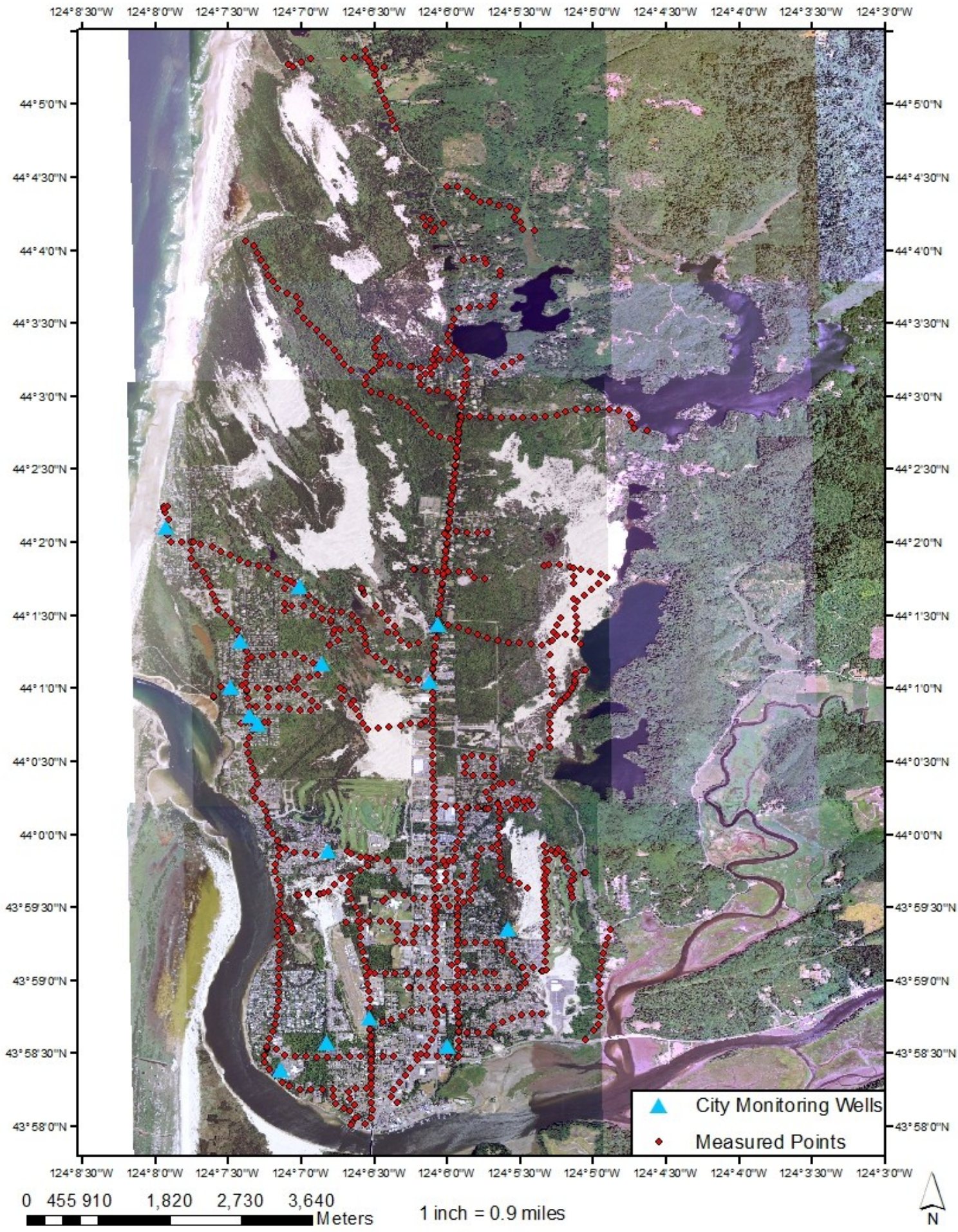

Figure 12: Locations of the City of Florence Monitoring wells used to help groundtruth GPR groundwater reflections. 


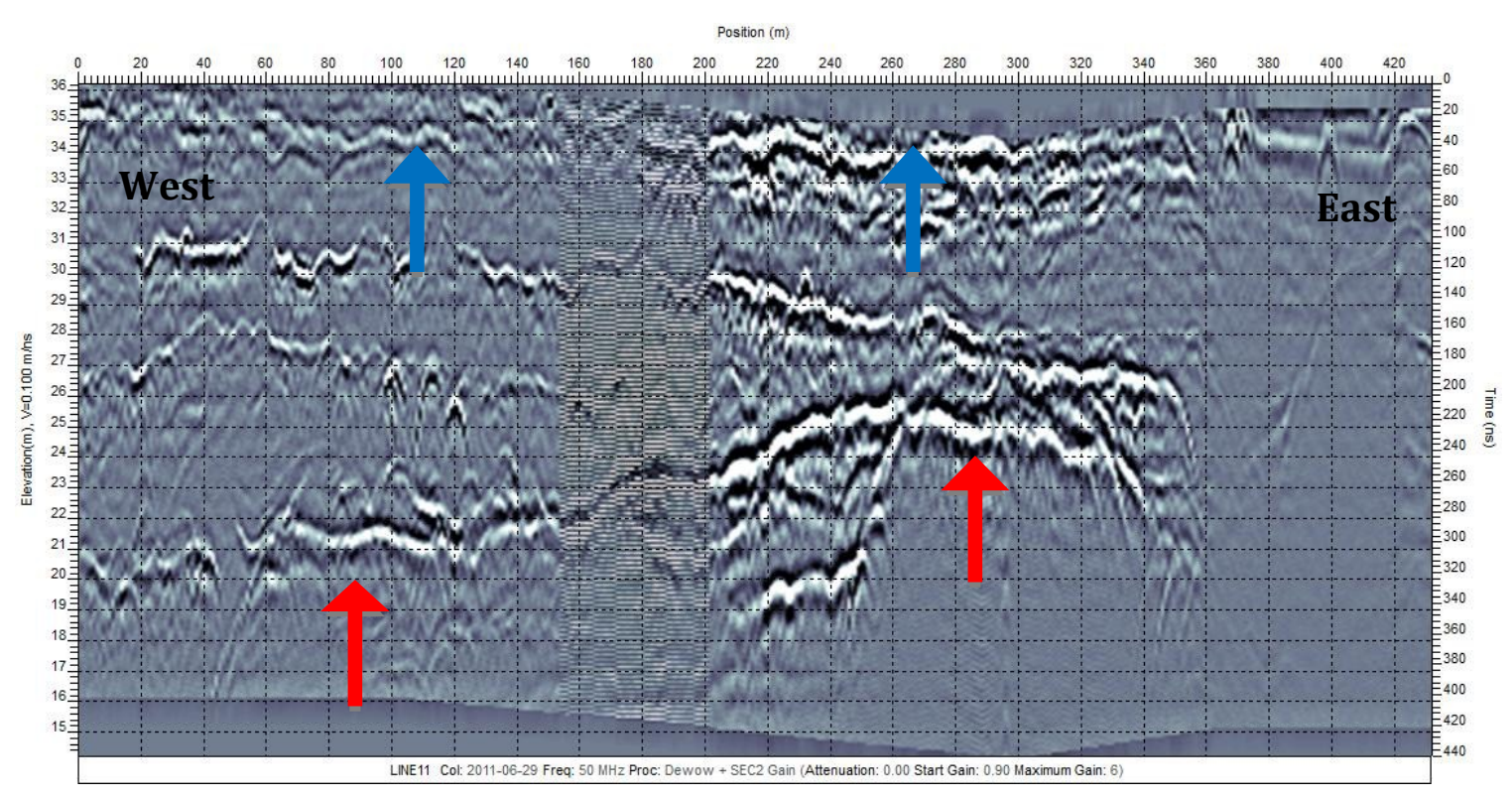

Figure 13: The deeper reflection (lower red arrows) is believed to be a Pleistocene/Holocene dune deposit contact or Pleistocene dune paleosol, based on the dune isopach map from Couch et al. (1980). This GPR line was taken in the center of the city (Profile 3 in Figure 4) where the groundwater surface is close to the surface (blue upper arrows). The morphology of the Pleistocene dune contact does not show any control over the nearly horizontal groundwater surface reflection.

Table 1: Monitoring well water elevations from September 2011 are compared to nearby points (on GPR tracts) whose groundwater elevation was identified from Ground Penetrating Radar in Spring and Summer 2011. These monitoring wells represent vertical head components of the aquifer.

\begin{tabular}{llllllll}
\hline $\begin{array}{l}\text { Well } \\
\#\end{array}$ & $\begin{array}{l}\text { Water } \\
\text { elevation in } \\
\text { well } \\
\text { (m) }\end{array}$ & $\begin{array}{l}\text { GPR } \\
\text { Point ID }\end{array}$ & $\begin{array}{l}\text { GWS } \\
\text { from } \\
\text { GPR (m) }\end{array}$ & $\begin{array}{l}\text { GPR } \\
\text { Point } \\
\text { ID }\end{array}$ & $\begin{array}{l}\text { GWS from } \\
\text { GPR (m) }\end{array}$ & $\begin{array}{l}\text { GPR } \\
\text { Point ID }\end{array}$ & $\begin{array}{l}\text { GWS } \\
\text { from } \\
\text { GPR (m) }\end{array}$ \\
\hline B-1 & 8 & 483 & 10 & 484 & 10 & 485 & 9 \\
\hline B-2 & 15 & 671 & 19 & 128 & 21 & 129 & 21 \\
\hline B-3 & 16 & 137 & 21 & 138 & 21 & & \\
\hline B-6 & 18 & 602 & 19 & 601 & 19 & & \\
\hline B-8 & 10 & 570 & 11 & 72 & 12 & 73 & 12 \\
\hline B-9 & 8 & 11 & 8 & 12 & 8 & 13 & 8 \\
\hline B-10 & 4 & 750 & 5 & 749 & 8 & 750 & 8 \\
\hline B-11 & 3 & 0 & 5 & 1 & 5 & 20 & 5.5 \\
\hline B-16 & 17 & 126 & 21 & 127 & 21 & 669 & 22 \\
\hline B-15 & 12 & 666 & 15 & 664 & 20 & & \\
\hline B-14 & 31 & 653 & 27 & 654 & 26 & 655 & 26 \\
\hline B-13 & 29 & 162 & 26 & 163 & 25 & 164 & 24 \\
\hline B-12 & 29 & 181 & 29 & 182 & 29 & 183 & 30 \\
\hline
\end{tabular}

Well \#- City of Florence monitoring well number.

Water elevation in well-Elevation of vertical head in monitoring well (m).

GPR point ID- Each 100 - $\mathrm{m}$ interval point is assigned an individual ID

GWS from GPR- The groundwater surface elevation as identified from GPR for that point. 


\section{Creating Predicted Groundwater Surface Maps}

The Geostatistical Analyst extension in ArcGIS 10.0 was used to perform ordinary kriging methods for the groundwater surface elevations. This extension toolpack is more advantageous than the Spatial Analyst kriging method, which does not provide error analysis or statistics. Summary statistics on measured groundwater elevations show a mean elevation of $19.2 \mathrm{~m}$ and a standard deviation of $9.8 \mathrm{~m}$. A semivariogram was created using values calculated from Equation 1 and a Gaussian model to fit the normally distributed data (Figure 14). Table 2 shows mean Prediction Error values for the dataset.

A contoured surface map of the predicted values of groundwater elevation was created as well as a map of the prediction standard error (Figure 15, Figure 16). The predicted groundwater elevation contours range from 0-57 meters and the standard error contours has a range of 0.57-5.48 meters. Analyses of mapped groundwater surface trends in the North Florence Dunal Aquifer are provided in the thesis Discussion section below.

Table 2: Table of summary statistics for the prediction error for groundwater elevation data.

\begin{tabular}{ll}
\hline \multicolumn{2}{c}{ Prediction Errors } \\
\hline Mean (m) & .020 \\
\hline $\begin{array}{l}\text { Mean } \\
\text { Standardized (m) }\end{array}$ & .008 \\
\hline $\begin{array}{l}\text { Root Mean } \\
\text { Square (m) }\end{array}$ & 1.86 \\
\hline $\begin{array}{l}\text { Root Mean } \\
\text { Square } \\
\text { Standardized (m) }\end{array}$ & .946 \\
\hline $\begin{array}{l}\text { Average Standard } \\
\text { Error (m) }\end{array}$ & 1.94 \\
\hline
\end{tabular}




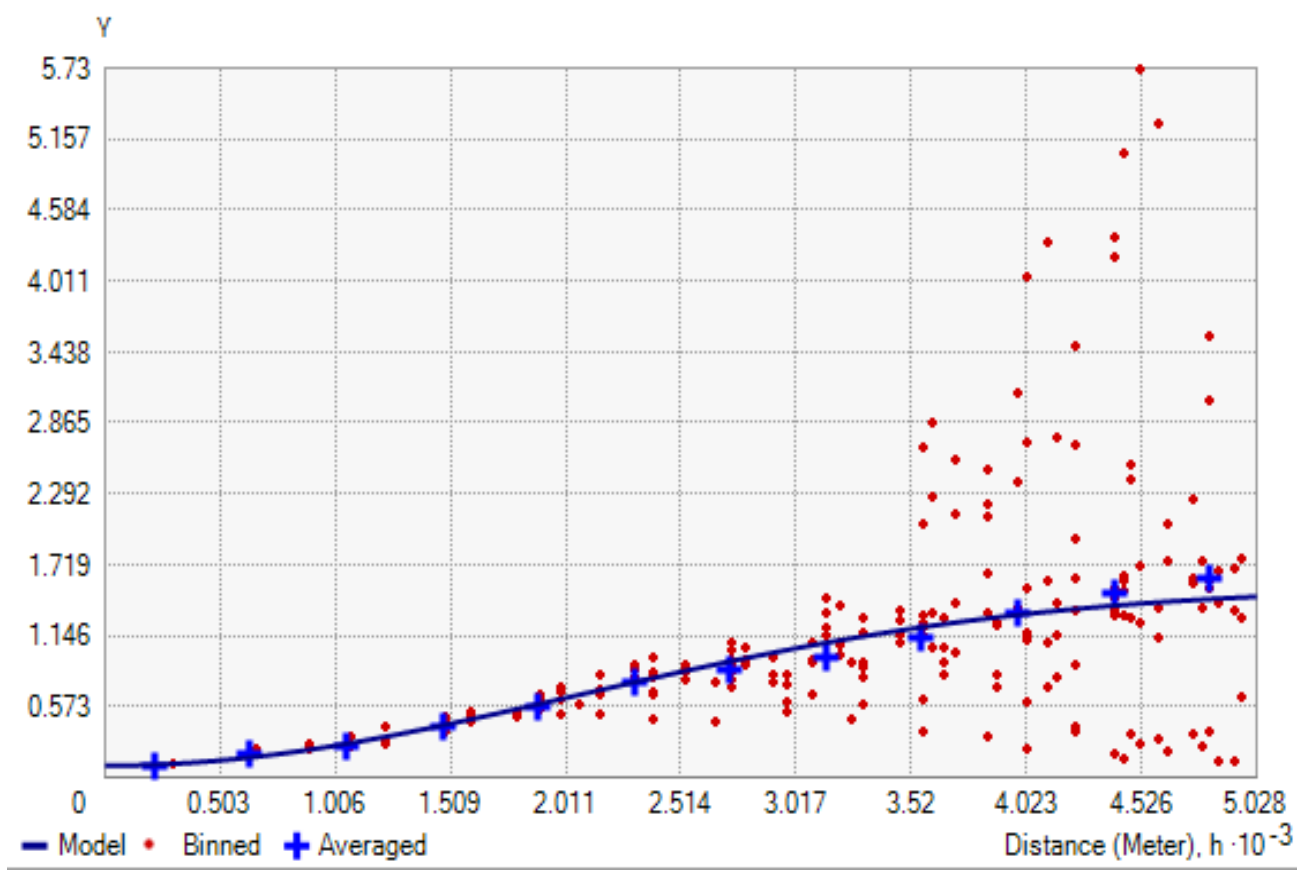

Figure 14: The semivariogram created for groundwater elevations with a Gaussian model (blue line) shows greater variability in groundwater elevation points when there is a larger distance between the measured points. This suggests that the groundwater elevations are somewhat spatially correlated. The y axis is variance and the $\mathrm{x}$ axis is distance between points. This dataset has been divided into 12 lags each with a lag size of .00062618 . Each blue cross on this graph shows the averaged lag values. 


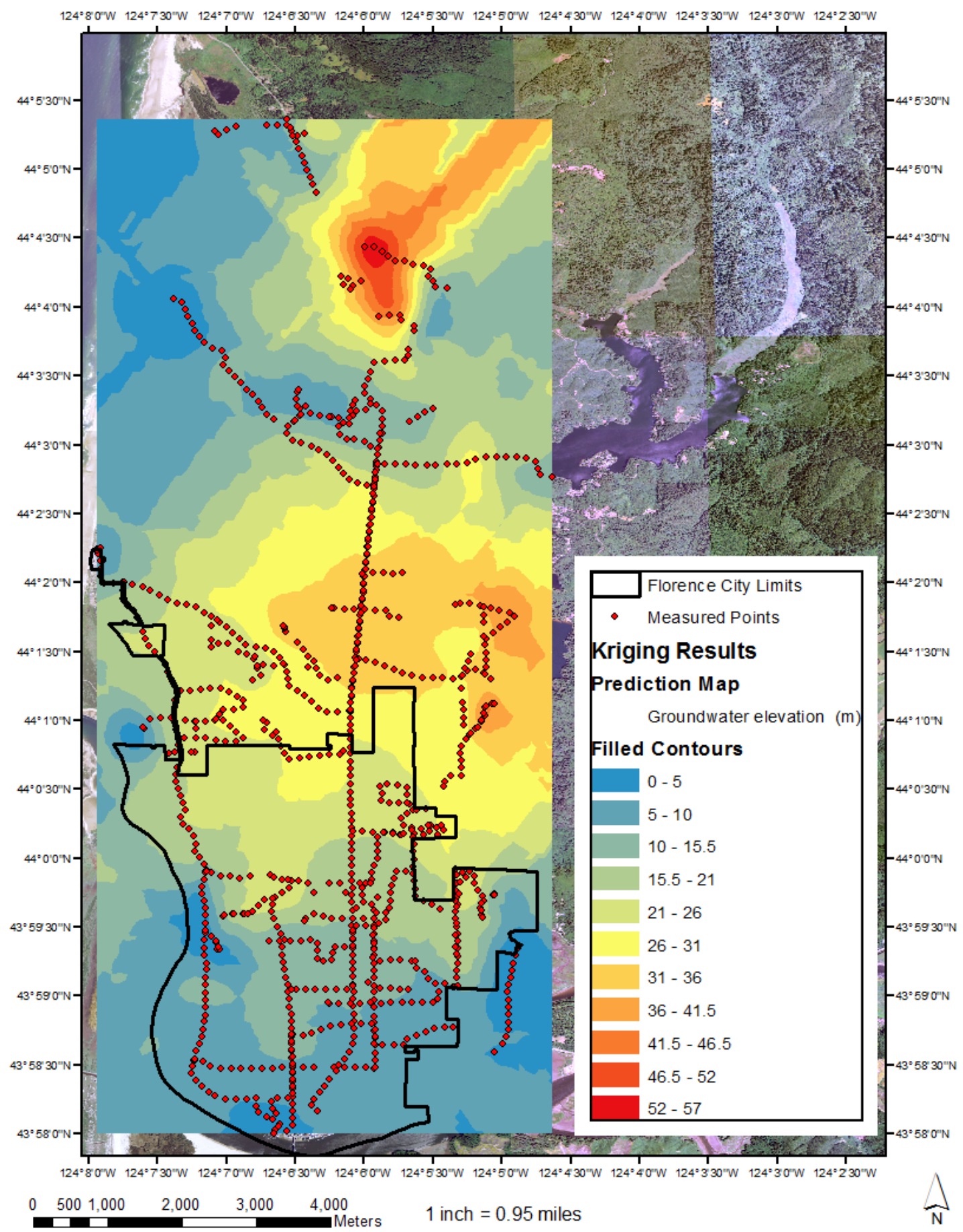

Figure 15: Maps of predicted groundwater based on window surface water bodies and on subsurface groundwater surface reflections in GPR profiles (Appendix A and 2). 


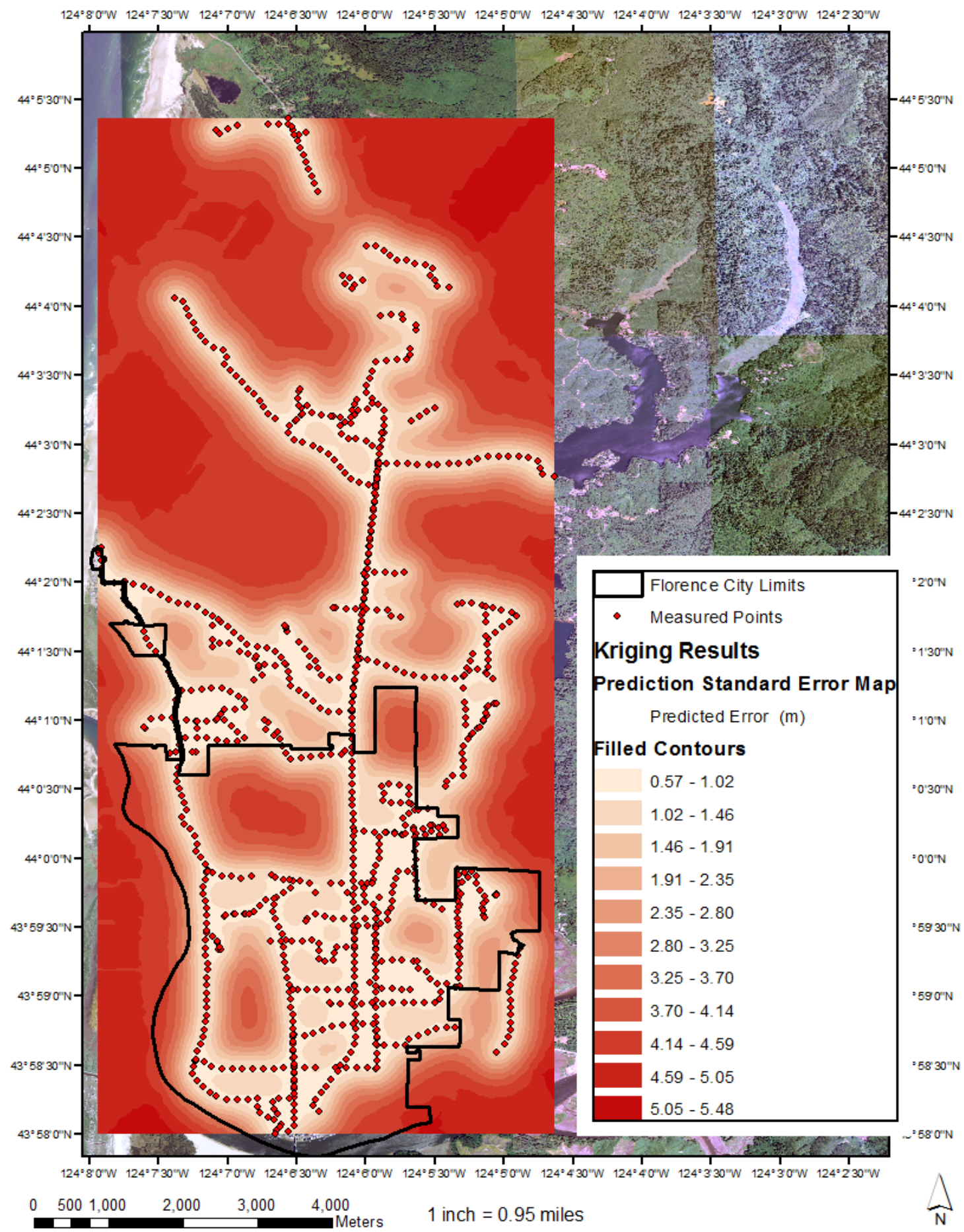

Figure 16: Prediction error map created during kriging process. In areas where measured GPR or lake elevation data is abundant, the error associated with the predicted groundwater surface is low (white areas). In locations where there was few or no measurements taken, more error is associated with the prediction of groundwater elevation (bright red). 


\section{Testing Environmentally Significant Wetlands}

Particular wetland areas have been identified by the city as environmentally significant, based mainly on plant species and population, and efforts are being made to protect and maintain these areas (verbal communication Dennis Nelson September 2011, Figure 17). Significant wetlands are important for the city to preserve because of their suspected connection with the groundwater table (verbal communication Dennis Nelson 9/6/2011). A lowering of the groundwater elevation of the North Florence Dunal Aquifer could be fatal to many wetland plant species. Figures 10 and 11 show two lines surveyed in or near significant wetland boundaries. Both lines show a distinct groundwater surface in higher elevation dunes and multiple reflections subsurface in areas recognized as wetlands.

Previous groundwater modeling in this area has relied mainly on water levels in creeks, lakes, and monitoring wells. A modeled head map produced by GSI Water Solutions Inc. (Figure 18) was not based on any ground penetrating radar or LiDAR data and shows higher groundwater levels in the center of the city following the hydraulic gradient and flowing south to the Siuslaw and west to the Pacific (City of Florence, unpublished data, 2011). The model created by GSI Water Solutions Inc. used hydraulic conductivity values ranging from 5-55 ft/day. This was calculated as a function of the thickness of the sand, which varied from 20-200 ft. Average hydraulic conductivity used in the modeling was $40 \mathrm{ft} /$ day. This map is compared to kriging results of the same area using only well data provided by the city (Figure 19). Predicted groundwater flow paths based on shallow groundwater gradient are shown with black arrows. 


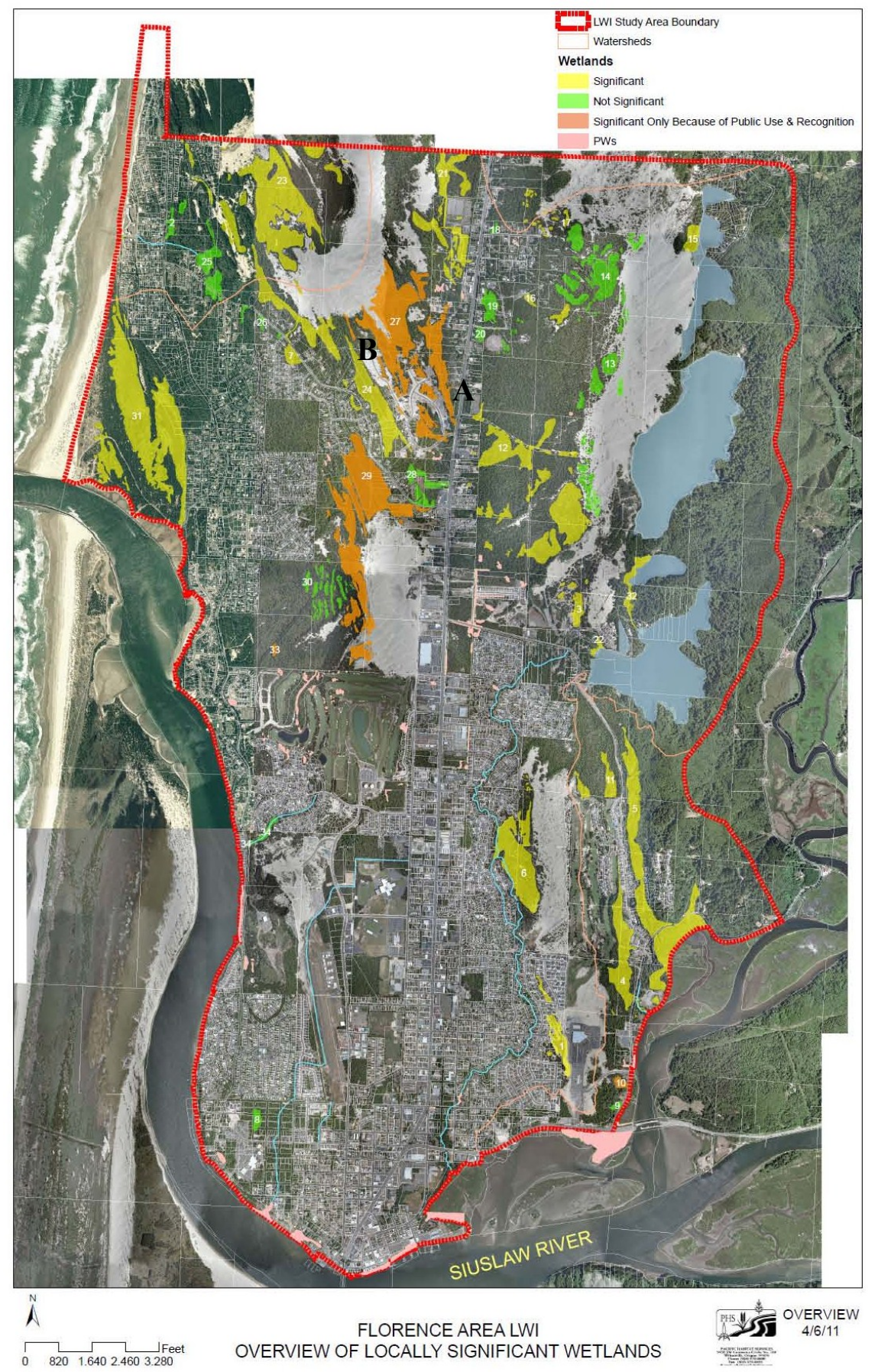

Figure 17: Map of Significant Wetlands in the Florence area. The map shows significant wetland in yellow, non-significant wetlands in green and wetlands that are significant only for public use or recognition (from City of Florence, Planning Department, 2011). The locations of two profiles taken near these wetlands (A and B) represent the GPR lines 49 and 51 (Figures 10 and 11). 


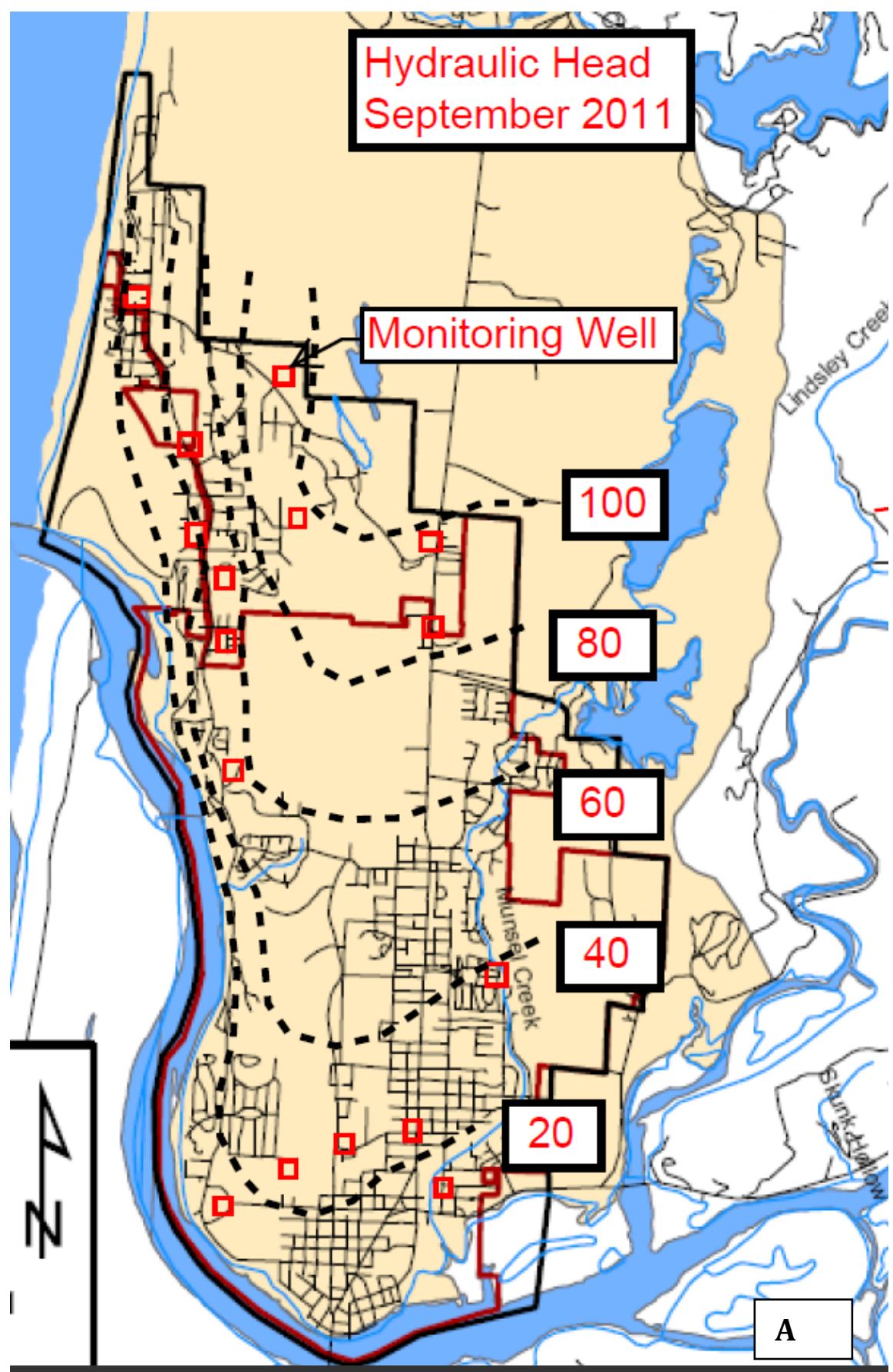

Figure 18: Hydraulic Head map (in feet) modeled using MODFLOW GWVistas created by GSI Water Solutions based on water levels in city monitoring wells (red squares) (GSI Water Solutions Inc, 2012, unpublished data). Residual mean error (difference between measured and modeled water levels) is \pm 4.3 feet. 


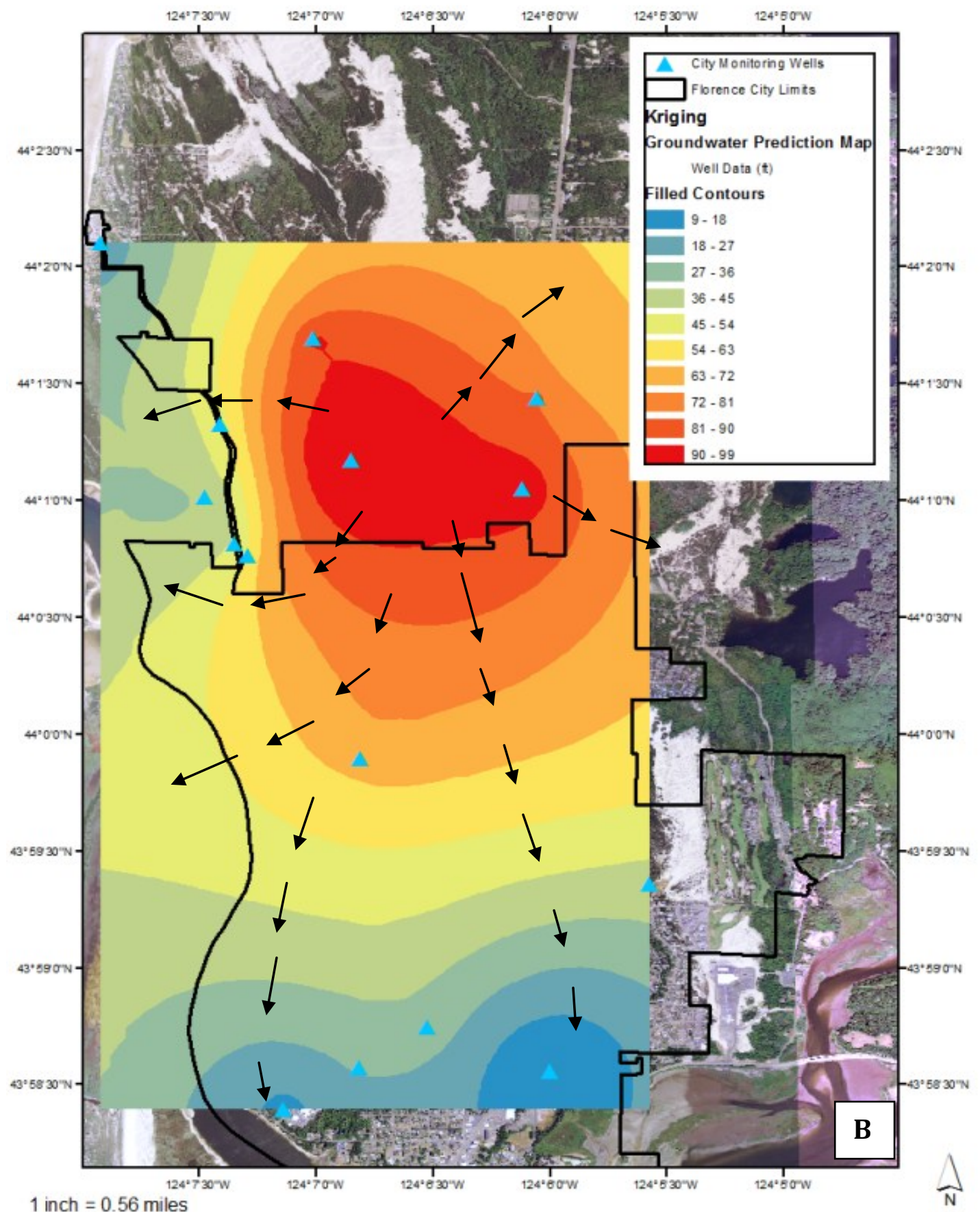

Figure 19: Kriging results for the same area (in feet), based on a three month average of water levels in city monitoring wells (blue triangles). Black arrows indicate predicted groundwater flow based on hydraulic gradient. Both methods show higher groundwater elevation directly west of Clear and Collard Lakes with a downward gradient to the south and east. Modeling done by GSI Water Solutions Inc. does not extend far enough north to the groundwater trough (Figure 15). 


\section{Chapter Four-Discussion}

\section{Ground Penetrating Radar as a Subsurface Surveying Technique}

Ground penetrating radar was successfully used as a method to record and identify the shallow groundwater surface in the North Florence Dunal Aquifer. There was little GPR penetration in the arkosic sandstone and siltstone bedrock, relative to the dune deposits in the north Florence dune sheets (Cooper, 1958). The bedrock in this area has weathering products of vermiculite, kaolinite and gibbsite making this clay rich material poorly suited for Ground Penetrating Radar (Hampton, 1963; Beckstrand, 2001). The lack of GPR signal penetration was helpful in identifying the contact between Tertiary bedrock and Quaternary dune deposits.

Using the ground penetrating radar close to high power electrical lines or in areas of under ground utility pipes, cables, and drains caused signal interference and made the groundwater surface less distinguishable. These EM field anomalies, evident as profile parallel reflections or crossing profile parabolas (Jol and Bristrow, 2003), were particularly evident along Highway 101. This north-south highway divides the city (west from east) (Figure 2) and is a major traffic corridor with overhead transmission lines and underground utilities running parallel to the roadway. The HW 101 GPR profiles tended to have weaker or less continuous groundwater surface reflections relative to GPR lines in residential roads or in the undeveloped dune settings (Figure 20). 


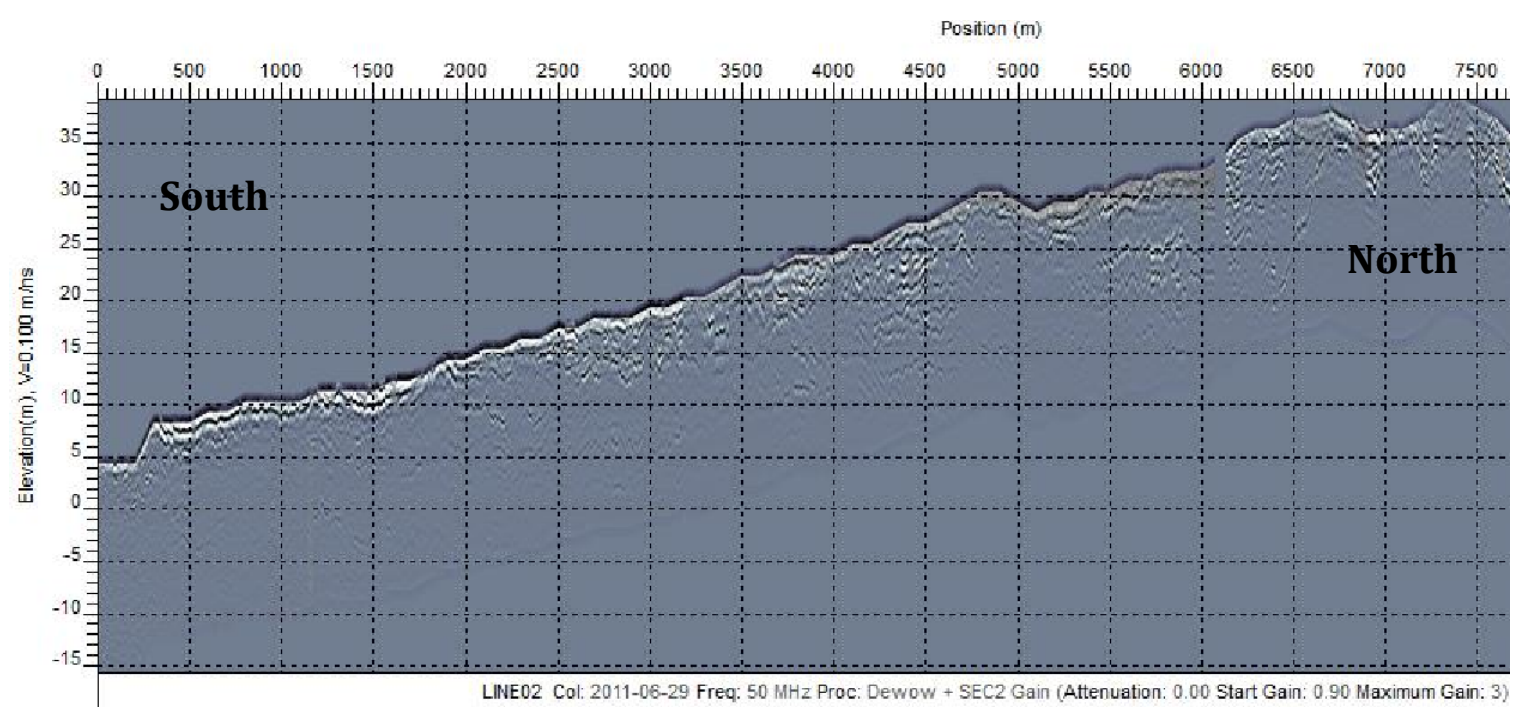

Figure 20: Ground Penetrating Radar image part of Line 14 running south to north along Highway 101 (profile 4 in Figure 5). Most of this tract lacks a strong, continuous reflection, in part, due to the surrounding electromagnetic interference along the highway. However, discontinuous groundwater reflections are apparent at $500 \mathrm{~m}, 1,500 \mathrm{~m}, 3,500 \mathrm{~m}, 4,500 \mathrm{~m}, 5,500 \mathrm{~m}$ and 7,000 m line positions, showing rising groundwater surface from south to north in the North Florence Dune Aquifer.

The $50 \mathrm{mHz}$ and $100 \mathrm{mHz}$ antennae proved to be appropriate wavelengths for penetration to the groundwater surface in the relatively homogenous dune sand aquifer. The $50 \mathrm{mHz}$ antennae provided greater penetration and tended to resolve a single groundwater surface reflection in the study area. The 2 meter wide $50 \mathrm{MHz}$ antennae and antennae guards occupied an entire traffic lane when towed in residential streets and access roads. The shorter $100 \mathrm{mHz}$ antennae ( $1 \mathrm{~m}$ width) were better adapted to towing behind the ATV on narrow tracks through the undeveloped dune fields.

The ground penetrating radar detected changes in saturation of the subsurface, including the vadose zone and/or capillary fringe, within several meters of the ground surface. Multiple reflections are interpreted as detection of water content from a non or partially saturated top reflection to a fully saturated bottom reflection, below which is the fully saturated aquifer. It is expected that during periods of high precipitation this 
saturation gradient would be smaller and fully saturated conditions would occur near/at the surface. This change in saturation could be caused by precipitation draining through the sand, or from groundwater surface drawdown, but in both cases the bottom reflection represents the fully saturated aquifer. Capillary fringe zone height for a sandy aquifer like the North Florence Dunal Aquifer is estimated to range from 4-25cm (Fetter, 1980; Kuo, 1999; Bear, 1979). Spatial resolution in sands using a signal velocity of $0.1 \mathrm{~m} / \mathrm{ns}$ for the 50 and $100 \mathrm{mHz}$ antenna are 50 and $25 \mathrm{~cm}$. Therefore identification of capillary fringe zone is unlikely with the 50 and $100 \mathrm{mHz}$ antennae. For this study both multiple groundwater reflections in the vadose zone (2-4 m depth subsurface in bogs) and single groundwater surface reflections in dune ridges define the groundwater surface elevation in the North Florence dunal aquifer.

\section{Confirmation Of The Window Lakes}

Groundwater surface reflections in the dunal aquifer were traced to surface water bodies and wetlands, confirming that the surface water bodies are windows into the shallow underlying aquifer. LiDAR GIS map data for the North Florence dune fields provided elevation control (resolution better than $3 \mathrm{~m}$ vertical) relative to the NAVD88 datum for both 1) surface water bodies and 2) the ground surface where GPR picks of depth of groundwater surface reflections were made. All of the surface water bodies crossed by GPR profiles in the North Florence Dune Aquifer were found to have similar elevations as those of subsurface groundwater surface reflections in the adjacent dune deposits (Table 3, Figure 15). Table 3 shows the groundwater elevations taken from GPR reflections compared to nearby surface water bodies including larger lakes, wetlands, and ponds. When groundwater elevations from GPR were plotted against surface water 
elevations a correlation coefficient of .98 shows a strong correlation indicating that the two variables have a strong relationship (Figure 21). The regional differences in surface water body elevation (Appendix A) in the dune aquifer are controlled by the regional variability of the groundwater surface in the North Florence study area (Figure 15).

Table 3: Table of groundwater elevations taken from GPR reflections and elevation of surface waterbodies. Measurements taken near the Siuslaw River represent the lowest elevations in the study and measurements near Mussel lake c represent the highest elevations. Surface water elevations were taken from LiDAR.

\begin{tabular}{|c|c|c|c|c|c|c|}
\hline UTM E & UTM N & $\begin{array}{l}\text { Groundwater } \\
\text { Elevation }\end{array}$ & UTM E & UTM N & $\begin{array}{l}\text { Surface Water } \\
\text { Elevation }\end{array}$ & Surface Waterbody \\
\hline 411460 & 4881409 & 18 & 411353 & 4871435 & 19 & Lake Marr \\
\hline 413008 & 4874909 & 36 & 413485 & 4875857 & 37 & Collard Lake \\
\hline 411064 & 4875593 & 34 & 411040 & 4875322 & 31 & Pond \\
\hline 410859 & 4874329 & 35 & 411085 & 4874492 & 34 & Wetland \\
\hline 412449 & 4870515 & 7.5 & 412424 & 4870488 & 10 & Munsel creek \\
\hline 412090 & 4872177 & 20 & 412252 & 4872064 & 19 & Wetland \\
\hline 412127 & 4874989 & 32 & 412104 & 4874817 & 33 & Wetland \\
\hline 413239 & 4871034 & 0 & 413359 & 4870638 & 0 & Siuslaw River \\
\hline 412737 & 4875850 & 35 & 412583 & 4875604 & 37 & Wetland \\
\hline 411921 & 4880667 & 55 & 411720 & 4880578 & 49 & Mussel lake c \\
\hline
\end{tabular}




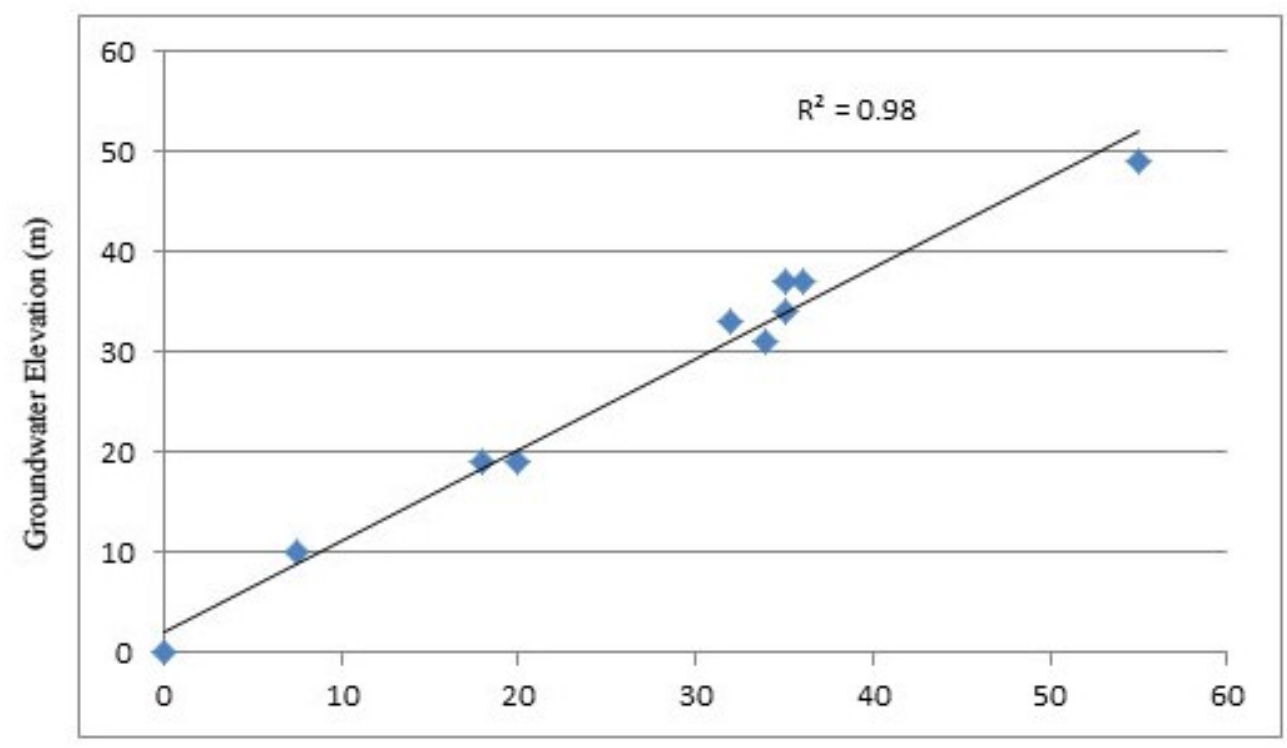

Surface Water Elevation (m)

Figure 21: Groundwater elevations from GPR plotted against surface water elevations from LiDAR show a strong linear relationship. The highest and lowest elevations are shown by the points at $(0,0)$ and $(49,55)$.

A rise or lowering of the local groundwater surface level would have a direct impact on water level in the surface water bodies. Contamination of the local dune aquifer could similarly have an impact on water quality in the connected surface water bodies. Wetlands contained within the North Florence Dunal Aquifer are entirely controlled by local groundwater elevation (Figures 10,11). The barrage lakes to the east (Munsel, Clear and Collard Lake) would certainly experience a lowering in elevation if drawdown in the aquifer occurred, but these lakes most likely receive additional input from surface water to the east. Munsel Creek is an example of a gaining stream, or a 
stream that is fed by groundwater, evidenced by an increase in flow and temperature downstream (City of Florence, unpublished data, 2011) therefore contamination of the groundwater will present itself in gaining creeks. Seasonal variation in stream discharge, as reported for Munsel Creek (City of Florence, unpublished data, 2011) is likely due to seasonal changes in groundwater surface elevation in the dune aquifer. Seasonal variability of groundwater surface reflections in the North Florence dune fields were not performed in this GPR study, but they could be undertaken in future work.

Figures 10 and 11 confirm that at higher elevations a strong single reflection represents that groundwater surface and in lower elevation wetlands multiple reflections from the surface to a depth of about $5 \mathrm{~m}$ subsurface. The multiple reflections in wetlands are interpreted to be detecting changes in saturation. The 50 and $100 \mathrm{mHz}$ antenna did not have the spatial resolution needed to detect capillary fringe which is expected to be between 4 and $25 \mathrm{~cm}$ in medium to coarse grained sand. Both environments can show surface expressions of the aquifer: lakes and ponds in higher elevations and wetlands in lower elevations.

\section{Groundwater Surface Reflection Trends}

GPR profiles in the study area demonstrated relatively horizontal trends of groundwater surface elevation in most areas after topographic processing (see Methods) (Appendix C). Steeper groundwater surface trends occurred on the steeper slopes of the bounding edges of the dune field aquifer (Figure 15). For example, steep gradients of the mapped groundwater surface occur in the southeast margins of the North Florence dune 
field at the North Fork of the Siulsaw River, and in the southwest margins of the dune field where narrow valleys penetrate eastward from the main Siuslaw River (Figure 15). Groundwater monitoring wells located around the margins of the dune field would help to resolve the steeper groundwater surface trends at the edges of the North Florence Dunal Aquifer.

In many GPR profiles a deeper reflection is apparent well below the groundwater surface reflection (Figure 13; Appendix C). The deeper GPR reflections could represent contacts between Holocene dunes and underlying Pleistocene dune deposits or loess paleosols in the Pleistocene dune deposits (Couch et al., 1980; Peterson et al., 2006; Peterson et al. 2007b). In such cases the GPR reflection in the fully saturated media could be caused by changes in the 1) diagenetic cementation of pore spaces, 2) clay mineral abundance, and/or 3) organic content in dunal paleosols (Hampton, 1963; Jol and Bistrow, 2003; Peterson et al., 2006). Nevertheless, the overlying groundwater reflections were continuous and unchanged in elevation or slope by the presence of the underlying features. It is not known whether the underlying Pleistocene deposits serve as deeper aquitards in the mixed Holocene and Pleistocene dune aquifer, but they do not apparently influence the groundwater surface in the overlying Holocene dune deposits.

\section{Creation of Groundwater Surface Map and Trend Assessment}

ArcMap 10.0 Geostatistical Toolpack Simple Kriging tool was used to create a groundwater surface elevation map for the North Florence Dunal Aquifer. The advantage to using a geostatistical method such as kriging is the ability to assess the error associated 
with each prediction. Summary statistics for this process (Table 1) show average standard error (variability from the mean groundwater elevation at each point), root mean error square (variability of the mean groundwater elevation between points) and mean error. The prediction error map (Figure 16) shows less error in areas where more measured values were available, generally less than $2 \mathrm{~m}$ of error elevation (NAVD88). In areas where no surveying was conducted there is possible error of up to almost $6 \mathrm{~m}$ elevation.

In order to assess the flow of groundwater in the North Florence Dunal Aquifer porosity, hydraulic conductivity and boundary conditions would need to be established and entered into a groundwater flow model, such as MODFLOW (Brown et al., 2008). MODFLOW model (GWVista) is in the process of being created from this data by GSI Water Solutions Inc. Although this model is not complete early stages of development are consistent with groundwater surface elevations predicted in this study. Though groundwater flow is not directly addressed in this thesis, it is assumed that shallow groundwater flow should follow general trends or slopes of the groundwater surface.

Groundwater surface trends are shown on the groundwater surface elevation map (Figure 21) indicate that the groundwater elevation generally follows the ground surface topographic elevations in the North Florence Dunal Aquifer. Table 4 shows 55 points throughout Florence whose groundwater elevations mimicked the topography (Table 4). The groundwater surface elevations and ground elevations from Table 4 have a correlation coefficient of .72 indicating a moderate amount of correlation (Figure 23). Combined elevations from both window lakes and ponds (Appendix B) and subsurface 
groundwater surface reflections (Appendix A) demonstrate two elevated mounds of groundwater surface in the north and central dune field areas. The north mound, reaching 50 m elevation (NAVD88) forms a peninsula that slopes downward to the east, west, and south. The northern mound slopes steeply down to the east into barrage lake valleys (5-10 m elevation) and less steeply to the west (Pacific Ocean shoreline) and to a central trough (10-22 m elevation) to the south. 


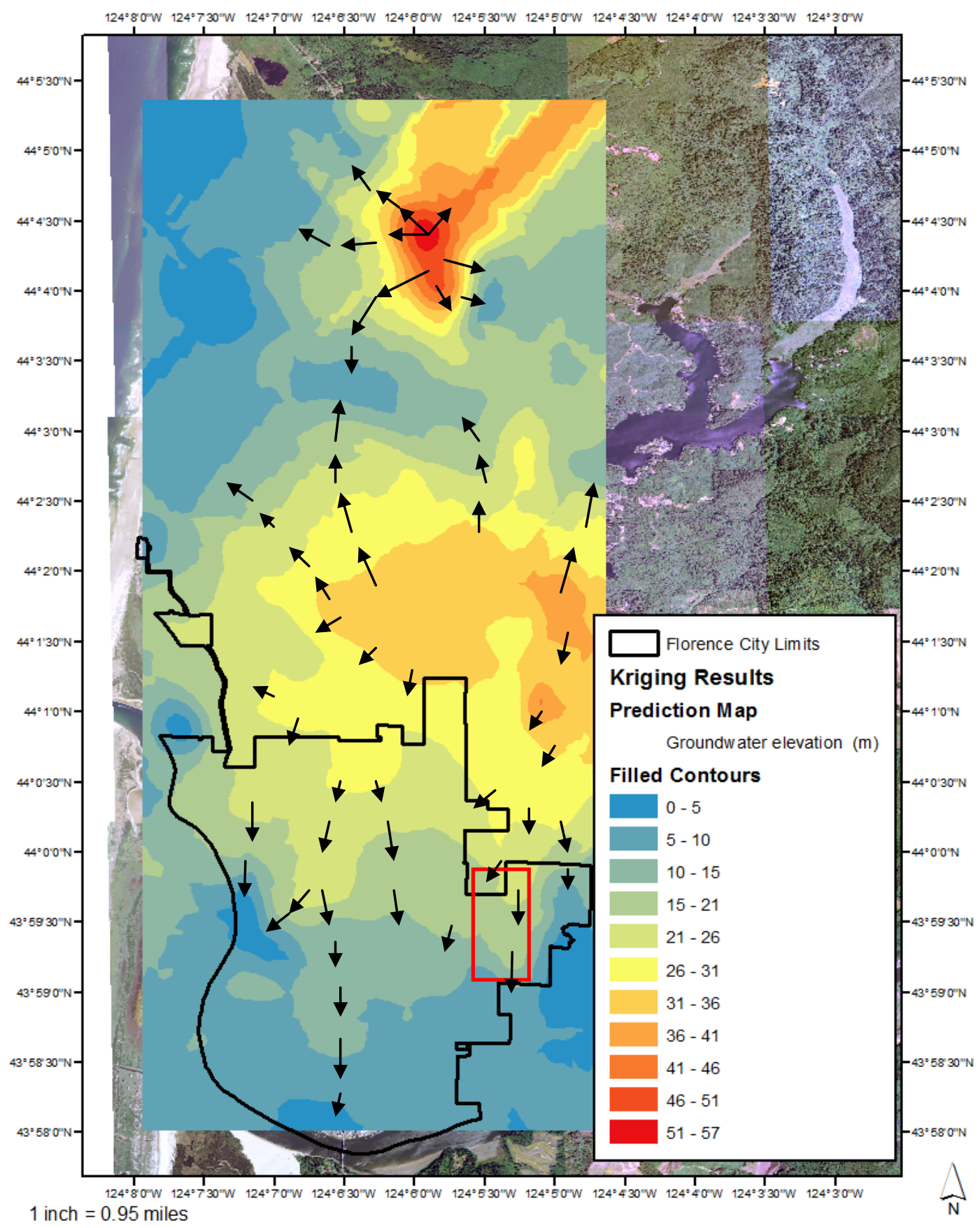

Figure 22: Map of the Predicted Groundwater surface and expected shallow groundwater flow. Since the groundwater gradient regionally follows the ground elevation, shallow groundwater flow is expected to flow radially from two groundwater mounds south to the Siuslaw River, East to Lakes, and west to the Pacific Ocean (predicted flow indicated by arrows). Location of the City wellfield is outlined in the red box, receiving water from up gradient groundwater mounds. 


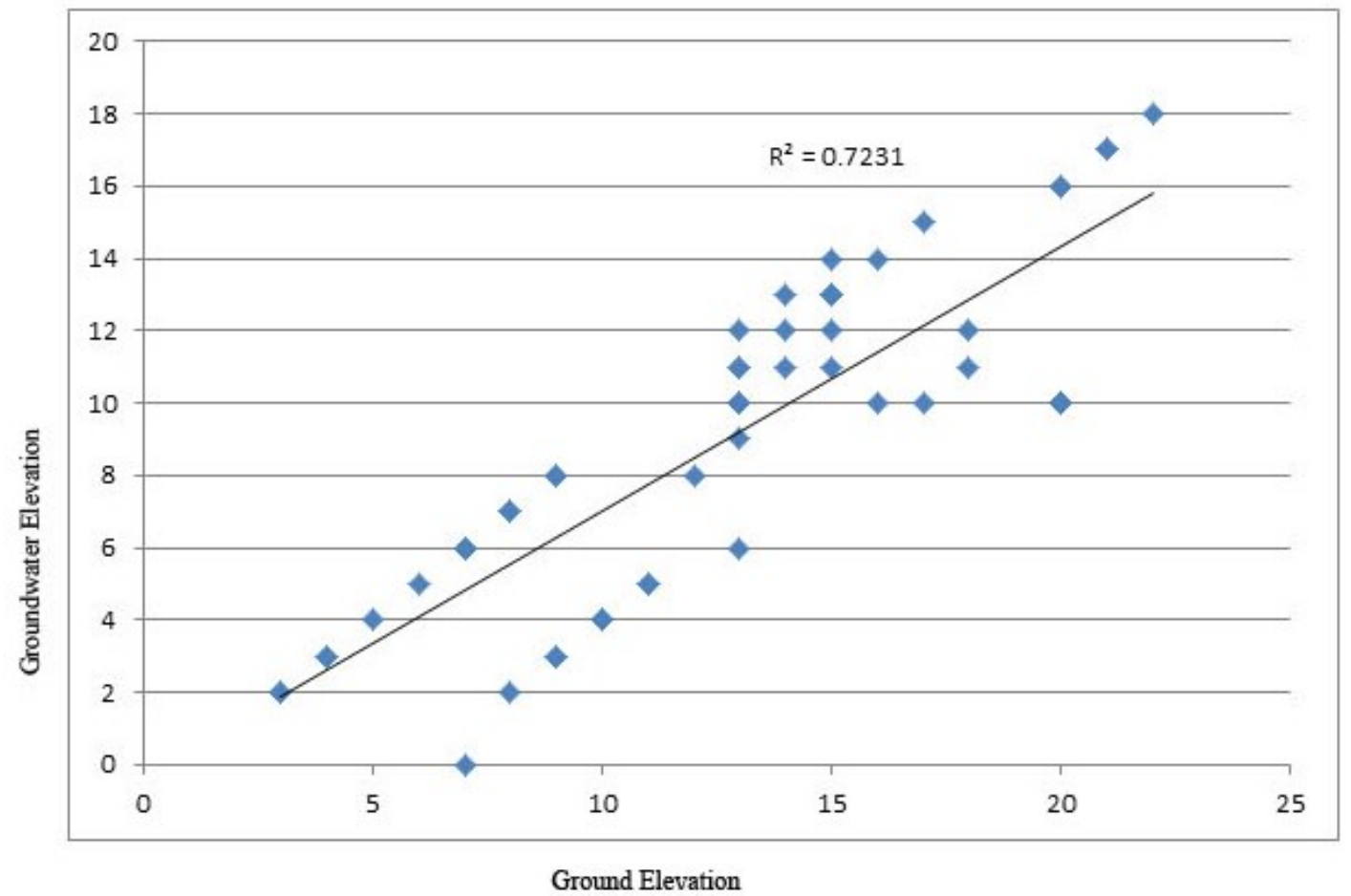

Figure 23: Plot of ground elevations (meters) and groundwater elevations (meters) for 55 points throughout the city of Florence. A correlation coefficient of .72 indicates a linear relationship between the two variables.

The central groundwater surface trough, aligned east to west, separates the north and south groundwater surface mounds in the North Florence Dune Aquifer (Figure 15). The central trough dips from the east end (15-22 m elevation) to the west end (5-10 m elevation). A small creek, ponds, and wetlands are aligned along the central trough, which drains the barraged Sutton Lake and Mercer Lakes (Figure 1).

The south groundwater surface mound in the North Florence Dune aquifer lies below the north end of the City of Florence, and west of the high elevation barrage lakes, Collard Lake, Clear Lake, and Munsel Lake (Figure 1). The south groundwater surface mound reaches elevations of 27-44 m (Figure 15). The south groundwater mound slopes 
downward to the Siuslaw estuary to the south, the central trough to the north, and to the Siuslaw tidal inlet to the west. They city well field (Figure 22) is located down gradient from the southern groundwater mound. The field receives water from this mound and is therefore highly susceptible to any contamination entering the aquifer through larger lakes, creeks or open dune areas located on the groundwater mound. Contaminants could easily enter the North Florence Dunal Aquifer at any location and could affect the quality of drinking water available to the city. However, introducing contaminants to the southern groundwater mound would result in contaminated water flowing directly to the well field. No GPR crossing lines were permitted across the eastside of the dune ridge that separates the City of Florence well field from the North Fork of the Siluslaw River, so groundwater surface trends on the east side of the Cities' well field are not established in this study.

Salinity intrusion reached at least 100-200 m northward of the Siuslaw Bay front at southernmost end of the dunal aquifer, as indicated by abruptly decreased GPR signal penetrations. Such limited salinity intrusion at the south end of the dune aquifer is likely to be prohibited due west of the south groundwater surface mound, which slopes steeply downward to Siuslaw tidal inlet. Groundwater monitoring wells could be installed to confirm the northward extent of shallow salinity intrusion under Old Town at the southernmost end of North Florence Dunal Aquifer. 
Table 4: 55 points from 6 different GPR tracts compared the groundwater elevation and ground elevation. In areas throughout the city the groundwater elevation was observed to mimic the local topography, especially in Holocene dune fields.

\begin{tabular}{rrrrrrrr}
\hline Latitude & Longitude & \multicolumn{1}{c}{$\begin{array}{l}\text { GE } \\
(\mathrm{m})\end{array}$} & $\begin{array}{c}\text { GWE } \\
(\mathrm{m})\end{array}$ & Latitude & Longitude & $\begin{array}{r}\text { GE } \\
(\mathrm{m})\end{array}$ & GWE(m) \\
\hline 44.04981 & -124.1064 & 22 & 18 & 43.97867 & -124.10881 & 13 & 12 \\
44.05016 & -124.1076 & 20 & 16 & 43.97783 & -124.1088 & 15 & 14 \\
44.05053 & -124.1086 & 21 & 17 & 43.97692 & -124.1087 & 17 & 15 \\
44.05134 & -124.1093 & 21 & 17 & 43.97603 & -124.1087 & 14 & 13 \\
44.05214 & -124.1091 & 20 & 16 & 43.97512 & -124.1087 & 9 & 8 \\
44.05278 & -124.1085 & 18 & 11 & 43.97421 & -124.1086 & 9 & 8 \\
44.05347 & -124.1077 & 17 & 10 & 43.9733 & -124.1086 & 8 & 7 \\
44.05435 & -124.1077 & 13 & 6 & 43.97239 & -124.1088 & 8 & 7 \\
44.05368 & -124.1076 & 16 & 10 & 43.97151 & -124.1086 & 7 & 6 \\
44.05292 & -124.1084 & 18 & 12 & 43.97097 & -124.1091 & 7 & 6 \\
44.05298 & -124.110 & 20 & 10 & 43.97095 & -124.1104 & 7 & 6 \\
44.05361 & -124.1118 & 20 & 10 & 43.97063 & -124.1112 & 6 & 5 \\
44.05441 & -124.1123 & 20 & 10 & 43.96978 & -124.1110 & 7 & 6 \\
44.05525 & -124.1128 & 20 & 10 & 43.96917 & -124.1106 & 5 & 4 \\
44.06227 & -124.1193 & 11 & 5 & 43.96842 & -124.1110 & 4 & 3 \\
44.06305 & -124.1199 & 9 & 3 & 43.96782 & -124.1102 & 4 & 3 \\
44.06379 & -124.1204 & 9 & 3 & 43.96709 & -124.1108 & 3 & 2 \\
44.06466 & -124.1207 & 10 & 4 & 43.96677 & -124.1109 & 3 & 2 \\
44.06553 & -124.1212 & 11 & 5 & 43.98794 & -124.0988 & 16 & 14 \\
44.06636 & -124.1216 & 10 & 4 & 43.9876 & -124.0980 & 15 & 13 \\
44.06712 & -124.1220 & 8 & 2 & 43.98768 & -124.0967 & 15 & 12 \\
44.06761 & -124.1230 & 7 & 0 & 43.98763 & -124.0956 & 15 & 13 \\
43.97991 & -124.1028 & 13 & 10 & 43.98758 & -124.0943 & 15 & 13 \\
43.97977 & -124.1040 & 13 & 10 & 43.98757 & -124.0938 & 14 & 12 \\
43.97931 & -124.1051 & 13 & 10 & 43.98673 & -124.0936 & 15 & 11 \\
43.97886 & -124.1063 & 14 & 11 & 43.98629 & -124.0926 & 12 & 8 \\
43.97861 & -124.1073 & 13 & 11 & 43.98544 & -124.0922 & 13 & 9 \\
43.97872 & -124.1086 & 13 & 11 & & & & \\
\hline
\end{tabular}

GE (m)- Ground elevation in meters at specific coordinates taken from Lidar. GWE (m)- Groundwater elevation in meters at specific coordinates taken from GPR. 


\section{Chapter Five-Conclusions}

1) GPR was both successful and efficient in imaging the shallow groundwater surface throughout the large North Florence Dunal Aquifer.

2) The groundwater surface reflections were traced directly to surface water bodies, including lakes, ponds, and bogs in the North Florence dune fields, demonstrating that all of the surface water bodies are windows into the North Florence Dunal Aquifer. Furthermore the wetlands that are contained by the aquifer are entirely controlled by the aquifer while the lakes on the eastern edge of the aquifer receive additional input via surface runoff or spring water

3) The groundwater surface regionally conforms to ground surface elevations produced by dune sand accretion in the North Florence dune fields. 


\section{References Cited}

Bear, Jacob. 1979. Hydraulics of Groundwater. McGraw Hill Publishing Company.

Beckstrand, D. L., 2001. Origin of the Coos Bay and Florence Dune Sheets, South Central Coast, Oregon. M.S. Thesis, Portland State University, 192 p.

Brown, M., 2008. Groundwater Surface Modeling in a coastal dune aquifer. M.S. Thesis, Portland State University, $140 \mathrm{p}$.

Cooper, W.S., 1958. Coastal sand dunes of Oregon and Washington. Geol. Soc. Am. Mem. 72, 169 pp.

Couch, R., Cook, J., Connard, G., Troseth, S., and Standing, W. 1980. Seismic Measurements of the Dunal Aquifer of Florence, Oregon. Geophysics Group, Oregon State University, $40 \mathrm{p}$.

Davis, J.C., 2002. Statistics and Data Analysis in Geology, Third Edition. New York: John Wiley \& Sons.

Doolittle, J. A. 2002. Ground Penetrating Radar Soil Suitability Map of the Conterminous United States. World Wide Web Address: http://soil.usda.gov/research/results/posters.htm\#soil physics.

Fetter, C.W., 2001. Applied Hydrogeology. New York: Prentice Hall, Inc.

Gesch, D.B., 2007. The National Elevation Dataset, in Maune, D., ed., Digital Elevation Model Technologies and Applications: The DEM Users Manual, $2^{\text {nd }}$ Edition: Bethesda, Maryland, American Society for Photogrammetry and Remote Sensing, p. 99-118.

GSI Water Solutions, 2012. Delineation of Drinking Water Protection Areas, City of Florence, Oregon. Unpublished report

Gundogdu, K.S., and Guney, I. 2007. Spatial analyses of groundwater levels using universal kriging, Journal Earth System Science, 116(1), pp. 49-55.

Hampton, E.R, 1963, Ground Water in the Coastal Dune Area Near Florence, Oregon, United States Geological Survey Water-supply paper 1539-K.

Isaaks, E.H., and Srivastava, R.M.1989 Applied Geostatistics. New York: Oxford Univ. Press

Jol, H. M., Bristow, C.S., 2003, Ground Penetrating Radar in Sediments: London, The Geological Society, $330 \mathrm{p}$. 
Kuo, J., 1999. Practical Design Calculations for Groundwater and Soil Remediation. Lewis Publishers, Boca Raton, Florida, pp21

Lund, E., 1971, Coastal Landforms between Florence and Yachats, Oregon, The Ore Bin 33 No. 2.

Newton, V.C.Jr., 1980. Prospects for oil and gas in the Coos Basin, Western Coos, Douglas, and Lake Counties, Oregon. Oil and Gas Investigation No. 6. Oregon Department of Geology and Mineral Industries, 74 p.with maps.

Nielsen, E., 2005. Hydrogeology and groundwater-surface water interactions of the Clatsop Plains aquifer, Clatsop County, Oregon. M.S, Thesis, Portland State University, $377 \mathrm{p}$.

Peterson et al., 2002 C., Baham, J., Beckstrand, D., Clough, C. M., Cloyd, C., Erlandson, J., Grathoff, G., Hart, R., Jol, H., Percy, D., Reckendorf, F., Rosenfeld, C., Smith, T., Steeves, P., and Stock, E., Field guide to the Pleistocene and Holocene dunal landscapes of the central Oregon Coast: Newport to Florence, Oregon., Geological Society of America, Field Trips Guide, Cordillera Meeting: Corvallis, Oregon.

Peterson et al., 2006 Stock, E., Cloyd, C., Beckstrand D., Clough, C., Erlandson, J.M., Hart, R., Murillo-Jimenez, J., Percy, D., Prince, D., Reckendorf, F., and Vanderburgh, S., Dating and Morphostratigraphy of coastal dune sheets from central West Coast of North America. Oregon Sea Grant, Oregon State University, $90 \mathrm{p}$.

Peterson et al., 2007a C.D., H.M. Jol, D. Percy and E.L., Nielsen. Groundwater surface trends from ground penetrating radar (GPR) profiles taken across late-Holocene barriers and beach plains of the Columbia River littoral system, Pacific Northwest coast, USA. Geological Society of America, special paper 432, p. 59-76.

Peterson et al., 2007b C.D. Peterson, E. Stock, D.M. Price, R. Hart, F. Reckendorf, J.M. Erlandson and S.W. Hostetler, Ages, distributions, and origins of upland coastal dune sheets in Oregon, USA, Geomorphology 91, pp. 80-102

Reckendorf, F.F., 1975. Beaches and Dunes of the Oregon coast. US Department of Agriculture, Oregon Department of Soil Conservation Service, and Oregon Coastal Conservation and Development Commision, $161 \mathrm{p}$.

Simpkins, S.B., 2008. Surficial mapping of Lincoln City and Newport dune Sheets of the Oregon coast. M.S. Thesis, Portland State University, 120 p. 
Thomas, B.E., 1995, Groundwater flow and water quality in the sandy aquifer of Long Beach Peninsula, Washington: U.S. Geological Survey, Water Resources Investigations Report 95-4026. 


\section{Appendix A- North Florence Dunal Aquifer Groundwater Elevation Database}

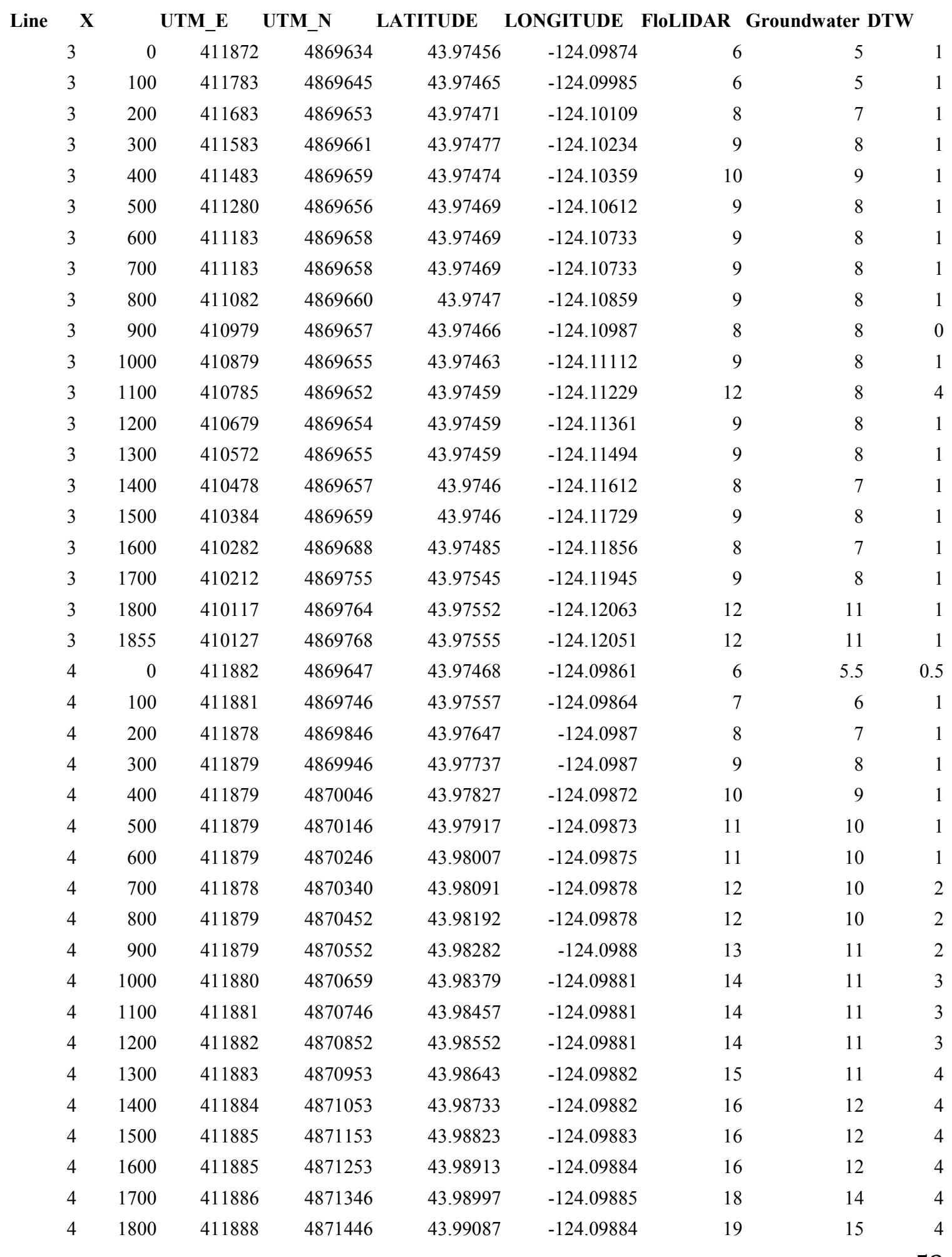




\begin{tabular}{|c|c|c|c|c|c|c|c|}
\hline 4 & 1900 & 411889 & 4871553 & 43.99184 & -124.09884 & 19 & 15 \\
\hline 4 & 2000 & 411890 & 4871647 & 43.99268 & -124.09885 & 20 & 15 \\
\hline 4 & 2100 & 411892 & 4871753 & 43.99364 & -124.09884 & 21 & 16 \\
\hline 4 & 2200 & 411869 & 4871832 & 43.99434 & -124.09914 & 23 & 18 \\
\hline 4 & 2300 & 411791 & 4871865 & 43.99463 & -124.10012 & 20 & 16 \\
\hline 4 & 2400 & 411789 & 4871959 & 43.99548 & -124.10016 & 20 & 16 \\
\hline 4 & 2500 & 411786 & 4872065 & 43.99643 & -124.10021 & 21 & 16 \\
\hline 4 & 2600 & 411822 & 4872128 & 43.997 & -124.09977 & 22 & 17 \\
\hline 4 & 2700 & 411884 & 4872168 & 43.99737 & -124.09901 & 22 & 18 \\
\hline 4 & 2800 & 411884 & 4872268 & 43.99827 & -124.09902 & 22 & 18 \\
\hline 4 & 2900 & 411902 & 4872362 & 43.99912 & -124.09881 & 21 & 17 \\
\hline 4 & 3000 & 411935 & 4872457 & 43.99998 & -124.09842 & 21 & 17 \\
\hline 4 & 3100 & 411937 & 4872545 & 44.00077 & -124.09841 & 22 & 18 \\
\hline 4 & 3200 & 411938 & 4872651 & 44.00172 & -124.09841 & 22 & 18 \\
\hline 4 & 3300 & 411939 & 4872745 & 44.00257 & -124.09842 & 23 & 19 \\
\hline 4 & 3400 & 412010 & 4872800 & 44.00307 & -124.09754 & 24 & 20 \\
\hline 4 & 3500 & 412090 & 4872796 & 44.00305 & -124.09654 & 24 & 20 \\
\hline 4 & 3600 & 412159 & 4872775 & 44.00287 & -124.09568 & 25 & 22 \\
\hline 4 & 3730 & 412168 & 4872776 & 44.00288 & -124.09557 & 25 & 22 \\
\hline 5 & 0 & 411009 & 4868803 & 43.96697 & -124.10935 & 3 & 2 \\
\hline 5 & 100 & 411062 & 4868878 & 43.96766 & -124.10871 & 8 & 5 \\
\hline 5 & 200 & 411074 & 4868980 & 43.96858 & -124.10857 & 5 & 5 \\
\hline 5 & 300 & 411072 & 4869073 & 43.96941 & -124.10861 & 6 & 5 \\
\hline 5 & 400 & 411071 & 4869172 & 43.9703 & -124.10864 & 7 & 5 \\
\hline 5 & 500 & 411070 & 4869272 & 43.9712 & -124.10867 & 7 & 5 \\
\hline 5 & 600 & 411070 & 4869371 & 43.97209 & -124.10869 & 7 & 5 \\
\hline 5 & 700 & 411071 & 4869471 & 43.97299 & -124.10869 & 8 & 5 \\
\hline 5 & 800 & 411071 & 4869576 & 43.97394 & -124.10871 & 9 & 6 \\
\hline 5 & 900 & 411072 & 4869676 & 43.97484 & -124.10871 & 9 & 7 \\
\hline 5 & 1000 & 411073 & 4869781 & 43.97579 & -124.10872 & 11 & 9 \\
\hline 5 & 1100 & 411073 & 4869881 & 43.97669 & -124.10874 & 17 & 15 \\
\hline 5 & 1200 & 411074 & 4869980 & 43.97758 & -124.10874 & 16 & 14 \\
\hline 5 & 1300 & 411075 & 4870080 & 43.97848 & -124.10875 & 13 & 13 \\
\hline 5 & 1400 & 411075 & 4870179 & 43.97937 & -124.10876 & 12 & 12 \\
\hline 5 & 1500 & 411075 & 4870278 & 43.98026 & -124.10878 & 12 & 12 \\
\hline 5 & 1600 & 411075 & 4870378 & 43.98116 & -124.1088 & 13 & 12 \\
\hline 5 & 1700 & 411060 & 4870476 & 43.98204 & -124.109 & 13 & 13 \\
\hline 5 & 1800 & 411051 & 4870575 & 43.98293 & -124.10913 & 14 & 14 \\
\hline 5 & 1900 & 411046 & 4870680 & 43.98387 & -124.10921 & 14 & 14 \\
\hline 5 & 2000 & 411042 & 4870780 & 43.98477 & -124.10927 & 15 & 14 \\
\hline 5 & 2100 & 411028 & 4870872 & 43.9856 & -124.10946 & 15 & 14 \\
\hline 5 & 2200 & 411013 & 4870976 & 43.98654 & -124.10967 & 15 & 14 \\
\hline 5 & 2300 & 411001 & 4871075 & 43.98743 & -124.10983 & 16 & 14 \\
\hline
\end{tabular}




\begin{tabular}{|c|c|c|c|c|c|c|c|}
\hline 5 & 2400 & 410995 & 4871174 & 43.98832 & -124.10993 & 16 & 15 \\
\hline 5 & 2500 & 411002 & 4871273 & 43.98921 & -124.10986 & 17 & 16 \\
\hline 5 & 2600 & 411015 & 4871371 & 43.99009 & -124.10971 & 17 & 16 \\
\hline 5 & 2700 & 410991 & 4871461 & 43.9909 & -124.11002 & 18 & 16 \\
\hline 5 & 2800 & 410956 & 4871554 & 43.99173 & -124.11048 & 18 & 12 \\
\hline 5 & 2900 & 410920 & 4871653 & 43.99262 & -124.11094 & 19 & 17 \\
\hline 5 & 3000 & 410897 & 4871750 & 43.99349 & -124.11124 & 24 & 19 \\
\hline 5 & 3100 & 410908 & 4871854 & 43.99443 & -124.11112 & 29 & 26 \\
\hline 5 & 3200 & 410933 & 4871944 & 43.99524 & -124.11083 & 31 & 26 \\
\hline 5 & 3300 & 411010 & 4872015 & 43.99589 & -124.10988 & 32 & 26 \\
\hline 5 & 3400 & 411077 & 4872078 & 43.99646 & -124.10906 & 32 & 26 \\
\hline 5 & 3500 & 411098 & 4872168 & 43.99728 & -124.10881 & 30 & 25 \\
\hline 5 & 3645 & 411011 & 4872177 & 43.99735 & -124.10989 & 33 & 26 \\
\hline 8 & 0 & 413286 & 4871229 & 43.98908 & -124.08137 & 7 & 0 \\
\hline 8 & 100 & 413258 & 4871133 & 43.98822 & -124.0817 & 7 & 0 \\
\hline 8 & 200 & 413239 & 4871034 & 43.98732 & -124.08192 & 7 & 0 \\
\hline 8 & 300 & 413221 & 4870935 & 43.98643 & -124.08213 & 5 & 0 \\
\hline 8 & 400 & 413206 & 4870836 & 43.98554 & -124.0823 & 4 & 2 \\
\hline 8 & 500 & 413188 & 4870738 & 43.98465 & -124.08251 & 4 & 2 \\
\hline 8 & 600 & 413174 & 4870641 & 43.98378 & -124.08267 & 5 & 0 \\
\hline 8 & 700 & 413178 & 4870538 & 43.98285 & -124.0826 & 4 & 0 \\
\hline 8 & 800 & 413180 & 4870440 & 43.98197 & -124.08256 & 4 & 0 \\
\hline 8 & 900 & 413182 & 4870340 & 43.98107 & -124.08252 & 5 & 2 \\
\hline 8 & 1000 & 413182 & 4870239 & 43.98016 & -124.08251 & 8 & 6 \\
\hline 8 & 1100 & 413176 & 4870137 & 43.97924 & -124.08256 & 7 & 6 \\
\hline 8 & 1200 & 413158 & 4870041 & 43.97838 & -124.08277 & 5 & 5 \\
\hline 8 & 1300 & 413114 & 4869954 & 43.97759 & -124.08331 & 4 & 4 \\
\hline 8 & 1410 & 413042 & 4869838 & 43.97653 & -124.08418 & 6 & 5 \\
\hline 11 & 0 & 410277 & 4872313 & 43.99848 & -124.11907 & 18 & 17 \\
\hline 11 & 100 & 410258 & 4872406 & 43.99932 & -124.11932 & 17 & 17 \\
\hline 11 & 200 & 410217 & 4872494 & 44.0001 & -124.11985 & 17 & 17 \\
\hline 11 & 300 & 410169 & 4872580 & 44.00087 & -124.12046 & 18 & 18 \\
\hline 11 & 400 & 410175 & 4872678 & 44.00175 & -124.1204 & 22 & 20 \\
\hline 11 & 500 & 410157 & 4872782 & 44.00269 & -124.12065 & 23 & 20 \\
\hline 11 & 600 & 410119 & 4872869 & 44.00347 & -124.12114 & 22 & 20 \\
\hline 11 & 700 & 410053 & 4872945 & 44.00414 & -124.12197 & 21 & 20 \\
\hline 11 & 800 & 410041 & 4873039 & 44.00499 & -124.12214 & 22 & 20.5 \\
\hline 11 & 900 & 410080 & 4873124 & 44.00576 & -124.12166 & 24 & 22 \\
\hline 11 & 1000 & 410062 & 4873224 & 44.00666 & -124.12191 & 22 & 21 \\
\hline 11 & 1100 & 410045 & 4873318 & 44.0075 & -124.12213 & 20 & 20 \\
\hline 11 & 1200 & 410018 & 4873415 & 44.00837 & -124.12249 & 20 & 20 \\
\hline 11 & 1300 & 409995 & 4873518 & 44.00929 & -124.12279 & 20 & 20 \\
\hline 11 & 1400 & 409995 & 4873614 & 44.01016 & -124.12281 & 21 & 21 \\
\hline
\end{tabular}




\begin{tabular}{|c|c|c|c|c|c|c|c|}
\hline 11 & 1500 & 410013 & 4873709 & 44.01102 & -124.1226 & 21 & 21 \\
\hline 11 & 1600 & 410045 & 4873806 & 44.01189 & -124.12222 & 21 & 21 \\
\hline 11 & 1700 & 410045 & 4873906 & 44.01279 & -124.12223 & 21 & 21 \\
\hline 11 & 1800 & 410032 & 4874010 & 44.01373 & -124.12241 & 21 & 21 \\
\hline 11 & 1900 & 410023 & 4874107 & 44.0146 & -124.12254 & 21 & 21 \\
\hline 11 & 2000 & 410011 & 4874206 & 44.01549 & -124.12271 & 21 & 21 \\
\hline 11 & 2100 & 410000 & 4874297 & 44.01631 & -124.12286 & 21 & 21 \\
\hline 11 & 2200 & 409988 & 4874402 & 44.01725 & -124.12303 & 21 & 21 \\
\hline 11 & 2300 & 409993 & 4874504 & 44.01817 & -124.12298 & 21 & 20 \\
\hline 11 & 2400 & 410006 & 4874604 & 44.01907 & -124.12284 & 21 & 20 \\
\hline 11 & 2500 & 410022 & 4874701 & 44.01995 & -124.12266 & 21 & 20 \\
\hline 11 & 2600 & 410007 & 4874800 & 44.02084 & -124.12286 & 22 & 22 \\
\hline 11 & 2700 & 409967 & 4874893 & 44.02167 & -124.12337 & 21 & 21 \\
\hline 11 & 2800 & 409940 & 4874986 & 44.0225 & -124.12373 & 21 & 21 \\
\hline 11 & 2900 & 409919 & 4875085 & 44.02339 & -124.12401 & 21 & 21 \\
\hline 11 & 3000 & 409876 & 4875171 & 44.02416 & -124.12456 & 21 & 21 \\
\hline 11 & 3100 & 409813 & 4875257 & 44.02493 & -124.12536 & 20 & 20 \\
\hline 11 & 3200 & 409757 & 4875338 & 44.02565 & -124.12607 & 20 & 20 \\
\hline 11 & 3300 & 409729 & 4875434 & 44.02651 & -124.12644 & 22 & 22 \\
\hline 11 & 3400 & 409707 & 4875536 & 44.02742 & -124.12673 & 24 & 24 \\
\hline 11 & 3500 & 409682 & 4875632 & 44.02829 & -124.12706 & 23 & 20 \\
\hline 11 & 3600 & 409655 & 4875723 & 44.0291 & -124.12741 & 19 & 16 \\
\hline 11 & 3700 & 409620 & 4875818 & 44.02995 & -124.12786 & 17 & 16 \\
\hline 11 & 3800 & 409560 & 4875897 & 44.03066 & -124.12862 & 19 & 18 \\
\hline 11 & 3900 & 409516 & 4875982 & 44.03142 & -124.12919 & 21 & 20 \\
\hline 11 & 4000 & 409520 & 4876085 & 44.03234 & -124.12915 & 18 & 17 \\
\hline 11 & 4100 & 409521 & 4876190 & 44.03329 & -124.12916 & 14 & 13 \\
\hline 11 & 4200 & 409608 & 4876166 & 44.03308 & -124.12807 & 16 & 15 \\
\hline 11 & 4300 & 409707 & 4876127 & 44.03274 & -124.12683 & 18 & 17 \\
\hline 11 & 4400 & 409783 & 4876078 & 44.03231 & -124.12587 & 20 & 19 \\
\hline 11 & 4500 & 409872 & 4876017 & 44.03177 & -124.12475 & 19 & 19 \\
\hline 11 & 4600 & 409953 & 4875961 & 44.03128 & -124.12373 & 20 & 19 \\
\hline 11 & 4700 & 410037 & 4875911 & 44.03084 & -124.12267 & 24 & 23 \\
\hline 11 & 4800 & 410134 & 4875892 & 44.03068 & -124.12146 & 24 & 24 \\
\hline 11 & 4900 & 410219 & 4875848 & 44.0303 & -124.12039 & 26 & 25 \\
\hline 11 & 5000 & 410302 & 4875781 & 44.0297 & -124.11935 & 26 & 26 \\
\hline 11 & 5100 & 410372 & 4875723 & 44.02919 & -124.11846 & 27 & 26 \\
\hline 11 & 5200 & 410453 & 4875650 & 44.02854 & -124.11744 & 26 & 26 \\
\hline 11 & 5300 & 410515 & 4875575 & 44.02787 & -124.11665 & 25 & 25 \\
\hline 11 & 5400 & 410576 & 4875498 & 44.02719 & -124.11588 & 25 & 24 \\
\hline 11 & 5500 & 410638 & 4875420 & 44.02649 & -124.11509 & 26 & 24 \\
\hline 11 & 5600 & 410696 & 4875338 & 44.02576 & -124.11436 & 26 & 24 \\
\hline 11 & 5700 & 410795 & 4875303 & 44.02546 & -124.11311 & 28 & 27 \\
\hline
\end{tabular}




\begin{tabular}{|c|c|c|c|c|c|c|c|}
\hline 11 & 5800 & 410885 & 4875288 & 44.02534 & -124.11199 & 28 & 26 \\
\hline 11 & 5900 & 410972 & 4875247 & 44.02498 & -124.1109 & 28 & 27 \\
\hline 11 & 6000 & 411025 & 4875169 & 44.02428 & -124.11022 & 29 & 28 \\
\hline 11 & 6100 & 411070 & 4875068 & 44.02338 & -124.10964 & 29 & 28 \\
\hline 11 & 6200 & 411096 & 4874973 & 44.02253 & -124.1093 & 28 & 27 \\
\hline 11 & 6300 & 411097 & 4874884 & 44.02172 & -124.10928 & 29 & 27 \\
\hline 11 & 6400 & 411117 & 4874785 & 44.02084 & -124.10901 & 29 & 28 \\
\hline 11 & 6500 & 411187 & 4874715 & 44.02021 & -124.10813 & 28 & 28 \\
\hline 11 & 6600 & 411257 & 4874647 & 44.01961 & -124.10724 & 28 & 28 \\
\hline 11 & 6700 & 411327 & 4874565 & 44.01888 & -124.10635 & 28 & 28 \\
\hline 11 & 6800 & 411395 & 4874482 & 44.01814 & -124.10549 & 30 & 29 \\
\hline 11 & 6900 & 411478 & 4874432 & 44.0177 & -124.10445 & 30 & 29 \\
\hline 11 & 7000 & 411576 & 4874429 & 44.01769 & -124.10323 & 30 & 29 \\
\hline 11 & 7100 & 411699 & 4874431 & 44.01772 & -124.10169 & 32 & 29 \\
\hline 11 & 7200 & 411688 & 4874441 & 44.01781 & -124.10183 & 32 & 29 \\
\hline 12 & 0 & 411698 & 4874441 & 44.01781 & -124.10171 & 32 & 30 \\
\hline 12 & 100 & 411701 & 4874544 & 44.01874 & -124.10168 & 32 & 30 \\
\hline 12 & 200 & 411715 & 4874632 & 44.01953 & -124.10152 & 32 & 30 \\
\hline 12 & 300 & 411721 & 4874753 & 44.02062 & -124.10147 & 33 & 31 \\
\hline 12 & 400 & 411732 & 4874836 & 44.02137 & -124.10135 & 34 & 32 \\
\hline 12 & 500 & 411739 & 4874942 & 44.02232 & -124.10128 & 36 & 35 \\
\hline 12 & 600 & 411749 & 4875034 & 44.02315 & -124.10117 & 36 & 35 \\
\hline 12 & 700 & 411789 & 4875138 & 44.02409 & -124.10069 & 38 & 35 \\
\hline 12 & 800 & 411768 & 4875232 & 44.02494 & -124.10096 & 37 & 36 \\
\hline 12 & 900 & 411779 & 4875346 & 44.02597 & -124.10085 & 38 & 36 \\
\hline 12 & 1000 & 411788 & 4875436 & 44.02678 & -124.10075 & 37 & 36 \\
\hline 12 & 1100 & 411800 & 4875539 & 44.02771 & -124.10062 & 36 & 36 \\
\hline 12 & 1200 & 411807 & 4875628 & 44.02851 & -124.10054 & 36 & 36 \\
\hline 12 & 1300 & 411814 & 4875725 & 44.02938 & -124.10047 & 36 & 36 \\
\hline 12 & 1400 & 411827 & 4875825 & 44.03028 & -124.10033 & 37 & 36 \\
\hline 12 & 1500 & 411834 & 4875925 & 44.03118 & -124.10026 & 38 & 36 \\
\hline 12 & 1600 & 411844 & 4876025 & 44.03209 & -124.10015 & 39 & 37 \\
\hline 12 & 1700 & 411851 & 4876135 & 44.03308 & -124.10008 & 38 & 37 \\
\hline 12 & 1800 & 411855 & 4876239 & 44.03401 & -124.10005 & 37 & 37 \\
\hline 12 & 1900 & 411867 & 4876327 & 44.03481 & -124.09991 & 35 & 35 \\
\hline 12 & 2000 & 411878 & 4876424 & 44.03568 & -124.09979 & 34 & 33 \\
\hline 12 & 2100 & 411885 & 4876531 & 44.03665 & -124.09972 & 33 & 32 \\
\hline 12 & 2200 & 411897 & 4876638 & 44.03761 & -124.09959 & 32 & 32 \\
\hline 12 & 2300 & 411901 & 4876723 & 44.03838 & -124.09955 & 31 & 30 \\
\hline 12 & 2400 & 411915 & 4876829 & 44.03933 & -124.0994 & 30 & 29 \\
\hline 12 & 2500 & 411923 & 4876927 & 44.04021 & -124.09931 & 29 & 28 \\
\hline 12 & 2600 & 411932 & 4877024 & 44.04109 & -124.09922 & 28 & 27 \\
\hline 12 & 2700 & 411944 & 4877118 & 44.04194 & -124.09908 & 28 & 27 \\
\hline
\end{tabular}




\begin{tabular}{|c|c|c|c|c|c|c|c|}
\hline 12 & 2800 & 411953 & 4877221 & 44.04287 & -124.09899 & 28 & 27 \\
\hline 12 & 2900 & 411965 & 4877322 & 44.04378 & -124.09885 & 28 & 27 \\
\hline 12 & 3000 & 411969 & 4877420 & 44.04466 & -124.09882 & 27 & 26 \\
\hline 12 & 3100 & 411986 & 4877526 & 44.04561 & -124.09863 & 24 & 22 \\
\hline 12 & 3200 & 411989 & 4877637 & 44.04661 & -124.09861 & 21 & 18 \\
\hline 12 & 3300 & 412002 & 4877724 & 44.0474 & -124.09846 & 18 & 18 \\
\hline 12 & 3400 & 412079 & 4877746 & 44.04761 & -124.0975 & 19 & 18 \\
\hline 12 & 3500 & 412176 & 4877743 & 44.04759 & -124.09629 & 19 & 18 \\
\hline 12 & 3600 & 412282 & 4877739 & 44.04757 & -124.09497 & 19 & 18 \\
\hline 12 & 3700 & 412380 & 4877736 & 44.04755 & -124.09374 & 21 & 18 \\
\hline 12 & 3800 & 412486 & 4877732 & 44.04753 & -124.09242 & 21 & 18 \\
\hline 12 & 3900 & 412574 & 4877731 & 44.04753 & -124.09132 & 21 & 18 \\
\hline 12 & 4000 & 412680 & 4877734 & 44.04757 & -124.09 & 21 & 20 \\
\hline 12 & 4100 & 412777 & 4877737 & 44.04761 & -124.08879 & 26 & 25 \\
\hline 12 & 4200 & 412882 & 4877750 & 44.04774 & -124.08748 & 30 & 30 \\
\hline 12 & 4300 & 412962 & 4877792 & 44.04813 & -124.08649 & 30 & 26 \\
\hline 12 & 4400 & 413059 & 4877834 & 44.04852 & -124.08528 & 30 & 24 \\
\hline 12 & 4500 & 413164 & 4877830 & 44.04849 & -124.08397 & 28 & 22 \\
\hline 12 & 4600 & 413253 & 4877822 & 44.04843 & -124.08286 & 23 & 15 \\
\hline 12 & 4700 & 413359 & 4877821 & 44.04843 & -124.08154 & 23 & 15 \\
\hline 12 & 4800 & 413445 & 4877813 & 44.04837 & -124.08046 & 26 & 21 \\
\hline 12 & 4900 & 413541 & 4877753 & 44.04784 & -124.07926 & 23 & 17 \\
\hline 12 & 5000 & 413561 & 4877662 & 44.04703 & -124.07899 & 18 & 10 \\
\hline 12 & 5100 & 413704 & 4877553 & 44.04606 & -124.07719 & 16 & 10 \\
\hline 12 & 5200 & 413588 & 4877587 & 44.04635 & -124.07864 & 14 & 12 \\
\hline 13 & 1200 & 412559 & 4878493 & 44.05439 & -124.09163 & 15 & 15 \\
\hline 13 & 1300 & 412477 & 4878437 & 44.05387 & -124.09265 & 16 & 15 \\
\hline 13 & 1400 & 412403 & 4878370 & 44.05326 & -124.09356 & 14 & 14 \\
\hline 13 & 1500 & 412324 & 4878308 & 44.05269 & -124.09454 & 14 & 13 \\
\hline 13 & 1800 & 412063 & 4878157 & 44.0513 & -124.09777 & 17 & 16.5 \\
\hline 13 & 1900 & 412038 & 4878069 & 44.05051 & -124.09807 & 17 & 16.5 \\
\hline 13 & 2000 & 412026 & 4877978 & 44.04969 & -124.0982 & 17 & 16.5 \\
\hline 13 & 2100 & 412013 & 4877871 & 44.04872 & -124.09835 & 17 & 16.5 \\
\hline 13 & 2200 & 412002 & 4877773 & 44.04784 & -124.09847 & 18 & 17 \\
\hline 13 & 2300 & 411993 & 4877672 & 44.04693 & -124.09856 & 20 & 19 \\
\hline 13 & 2400 & 411983 & 4877572 & 44.04603 & -124.09867 & 23 & 22 \\
\hline 13 & 2500 & 411974 & 4877473 & 44.04514 & -124.09877 & 26 & 25 \\
\hline 13 & 2600 & 411909 & 4877470 & 44.0451 & -124.09958 & 29 & 28 \\
\hline 13 & 2700 & 411808 & 4877499 & 44.04535 & -124.10084 & 29 & 28 \\
\hline 13 & 2800 & 411735 & 4877546 & 44.04576 & -124.10176 & 26 & 25 \\
\hline 13 & 2900 & 411681 & 4877630 & 44.04651 & -124.10245 & 24 & 23 \\
\hline 13 & 3000 & 411627 & 4877714 & 44.04726 & -124.10314 & 23 & 22 \\
\hline 13 & 3100 & 411576 & 4877800 & 44.04803 & -124.10379 & 22 & 21 \\
\hline
\end{tabular}




\begin{tabular}{|c|c|c|c|c|c|c|c|}
\hline 13 & 3200 & 411522 & 4877885 & 44.04879 & -124.10448 & 23 & 21 \\
\hline 13 & 3300 & 411461 & 4877513 & 44.04543 & -124.10518 & 29 & 24 \\
\hline 13 & 3400 & 411369 & 4878000 & 44.04981 & -124.10641 & 22 & 18 \\
\hline 13 & 3500 & 411270 & 4878040 & 44.05016 & -124.10765 & 20 & 16 \\
\hline 13 & 3600 & 411189 & 4878083 & 44.05053 & -124.10867 & 21 & 17 \\
\hline 13 & 3700 & 411138 & 4878173 & 44.05134 & -124.10932 & 21 & 17 \\
\hline 13 & 3800 & 411149 & 4878262 & 44.05214 & -124.10919 & 20 & 16 \\
\hline 13 & 3900 & 411206 & 4878332 & 44.05278 & -124.1085 & 18 & 11 \\
\hline 13 & 4000 & 411269 & 4878408 & 44.05347 & -124.10772 & 17 & 10 \\
\hline 13 & 4100 & 411268 & 4878506 & 44.05435 & -124.10775 & 13 & 6 \\
\hline 13 & 4200 & 411275 & 4878431 & 44.05368 & -124.10765 & 16 & 10 \\
\hline 13 & 4300 & 411214 & 4878348 & 44.05292 & -124.1084 & 18 & 12 \\
\hline 13 & 4600 & 411012 & 4878357 & 44.05298 & -124.11092 & 20 & 10 \\
\hline 13 & 4700 & 410942 & 4878428 & 44.05361 & -124.11181 & 20 & 10 \\
\hline 13 & 4800 & 410902 & 4878518 & 44.05441 & -124.11232 & 20 & 10 \\
\hline 13 & 4900 & 410864 & 4878611 & 44.05525 & -124.11281 & 20 & 10 \\
\hline 13 & 5000 & 410811 & 4878695 & 44.056 & -124.11349 & 18 & 10 \\
\hline 13 & 5100 & 410759 & 4878772 & 44.05668 & -124.11415 & 16 & 9 \\
\hline 13 & 5200 & 410698 & 4878861 & 44.05748 & -124.11493 & 16 & 9 \\
\hline 13 & 5300 & 410642 & 4878943 & 44.05821 & -124.11564 & 17 & 12.5 \\
\hline 13 & 5400 & 410583 & 4879024 & 44.05893 & -124.11639 & 16 & 13 \\
\hline 13 & 5500 & 410530 & 4879108 & 44.05968 & -124.11706 & 15 & 11 \\
\hline 13 & 5600 & 410556 & 4879201 & 44.06052 & -124.11676 & 13 & 10 \\
\hline 13 & 5700 & 410521 & 4879283 & 44.06125 & -124.11721 & 12 & 10 \\
\hline 13 & 5800 & 410433 & 4879331 & 44.06167 & -124.11831 & 12 & 8 \\
\hline 13 & 5900 & 410351 & 4879398 & 44.06227 & -124.11935 & 11 & 5 \\
\hline 13 & 6000 & 410308 & 4879486 & 44.06305 & -124.1199 & 9 & 3 \\
\hline 13 & 6100 & 410267 & 4879568 & 44.06379 & -124.12043 & 9 & 3 \\
\hline 13 & 6200 & 410246 & 4879665 & 44.06466 & -124.1207 & 10 & 4 \\
\hline 13 & 6300 & 410202 & 4879762 & 44.06553 & -124.12127 & 11 & 5 \\
\hline 13 & 6400 & 410172 & 4879855 & 44.06636 & -124.12166 & 10 & 4 \\
\hline 13 & 6500 & 410141 & 4879940 & 44.06712 & -124.12206 & 8 & 2 \\
\hline 13 & 6600 & 410066 & 4879995 & 44.06761 & -124.12301 & 7 & 0 \\
\hline 14 & 300 & 411309 & 4869070 & 43.96941 & -124.10566 & 8 & 6 \\
\hline 14 & 400 & 411251 & 4869145 & 43.97008 & -124.10639 & 8 & 7 \\
\hline 14 & 500 & 411280 & 4869228 & 43.97083 & -124.10605 & 8 & 8 \\
\hline 14 & 600 & 411332 & 4869319 & 43.97166 & -124.10541 & 9 & 8 \\
\hline 14 & 700 & 411384 & 4869411 & 43.97249 & -124.10478 & 9 & 9 \\
\hline 14 & 800 & 411428 & 4869495 & 43.97325 & -124.10425 & 10 & 9 \\
\hline 14 & 900 & 411495 & 4869605 & 43.97425 & -124.10343 & 10 & 9 \\
\hline 14 & 1000 & 411527 & 4869680 & 43.97493 & -124.10304 & 10 & 9 \\
\hline 14 & 1100 & 411588 & 4869774 & 43.97578 & -124.1023 & 10 & 9 \\
\hline 14 & 1200 & 411635 & 4869864 & 43.9766 & -124.10173 & 11 & 10 \\
\hline
\end{tabular}




\begin{tabular}{|c|c|c|c|c|c|c|c|}
\hline 14 & 1300 & 411669 & 4869970 & 43.97756 & -124.10132 & 11 & 10 \\
\hline 14 & 1400 & 411678 & 4870068 & 43.97844 & -124.10123 & 11 & 10 \\
\hline 14 & 1500 & 411677 & 4870175 & 43.97941 & -124.10126 & 11 & 10 \\
\hline 14 & 1600 & 411678 & 4870268 & 43.98024 & -124.10126 & 12 & 11 \\
\hline 14 & 1700 & 411679 & 4870369 & 43.98115 & -124.10126 & 12 & 11 \\
\hline 14 & 1800 & 411676 & 4870477 & 43.98212 & -124.10132 & 13 & 12 \\
\hline 14 & 1900 & 411676 & 4870580 & 43.98305 & -124.10134 & 14 & 13.5 \\
\hline 14 & 2000 & 411681 & 4870667 & 43.98383 & -124.10129 & 14 & 13.5 \\
\hline 14 & 2100 & 411681 & 4870766 & 43.98473 & -124.10131 & 15 & 13.5 \\
\hline 14 & 2200 & 411683 & 4870867 & 43.98564 & -124.1013 & 15 & 13.5 \\
\hline 14 & 2300 & 411677 & 4870971 & 43.98657 & -124.10139 & 16 & 14 \\
\hline 14 & 2400 & 411683 & 4871067 & 43.98744 & -124.10133 & 16 & 14 \\
\hline 14 & 2500 & 411677 & 4871158 & 43.98825 & -124.10142 & 17 & 14 \\
\hline 14 & 2600 & 411685 & 4871256 & 43.98914 & -124.10134 & 17 & 14 \\
\hline 14 & 2700 & 411679 & 4871362 & 43.99009 & -124.10143 & 18 & 15 \\
\hline 14 & 2800 & 411686 & 4871456 & 43.99094 & -124.10136 & 18 & 15 \\
\hline 14 & 2900 & 411681 & 4871552 & 43.9918 & -124.10144 & 18 & 15 \\
\hline 14 & 3000 & 411685 & 4871655 & 43.99273 & -124.1014 & 19 & 16 \\
\hline 14 & 3100 & 411684 & 4871760 & 43.99367 & -124.10143 & 19 & 16 \\
\hline 14 & 3200 & 411685 & 4871866 & 43.99463 & -124.10144 & 20 & 17 \\
\hline 14 & 3300 & 411683 & 4871967 & 43.99554 & -124.10148 & 20 & 17 \\
\hline 14 & 3400 & 411689 & 4872055 & 43.99633 & -124.10142 & 21 & 17 \\
\hline 14 & 3500 & 411686 & 4872156 & 43.99724 & -124.10147 & 22 & 18 \\
\hline 14 & 3600 & 411689 & 4872254 & 43.99812 & -124.10145 & 22 & 18 \\
\hline 14 & 3700 & 411687 & 4872365 & 43.99912 & -124.1015 & 23 & 19 \\
\hline 14 & 3800 & 411690 & 4872465 & 44.00002 & -124.10148 & 24 & 20 \\
\hline 14 & 3900 & 411687 & 4872567 & 44.00094 & -124.10153 & 24 & 20 \\
\hline 14 & 4000 & 411688 & 4872664 & 44.00181 & -124.10153 & 24 & 20 \\
\hline 14 & 4100 & 411688 & 4872755 & 44.00263 & -124.10155 & 25 & 21 \\
\hline 14 & 4200 & 411688 & 4872864 & 44.00361 & -124.10157 & 25 & 21 \\
\hline 14 & 4300 & 411690 & 4872965 & 44.00452 & -124.10156 & 26 & 22 \\
\hline 14 & 4400 & 411691 & 4873064 & 44.00541 & -124.10156 & 27 & 23 \\
\hline 14 & 4500 & 411690 & 4873167 & 44.00634 & -124.10159 & 27 & 23 \\
\hline 14 & 4600 & 411692 & 4873253 & 44.00711 & -124.10158 & 28 & 24 \\
\hline 14 & 4700 & 411691 & 4873353 & 44.00801 & -124.10161 & 29 & 25 \\
\hline 14 & 4800 & 411694 & 4873463 & 44.00901 & -124.10159 & 30 & 25 \\
\hline 14 & 4900 & 411691 & 4873567 & 44.00994 & -124.10165 & 30 & 26 \\
\hline 14 & 5000 & 411695 & 4873663 & 44.01081 & -124.10161 & 29 & 26 \\
\hline 14 & 5100 & 411692 & 4873766 & 44.01173 & -124.10167 & 28 & 26 \\
\hline 14 & 5200 & 411695 & 4873863 & 44.01261 & -124.10165 & 29 & 26 \\
\hline 14 & 5300 & 411694 & 4873957 & 44.01345 & -124.10167 & 29 & 26 \\
\hline 14 & 5400 & 411694 & 4874052 & 44.01431 & -124.10169 & 30 & 26 \\
\hline 14 & 5500 & 411696 & 4874164 & 44.01532 & -124.10168 & 30 & 27 \\
\hline
\end{tabular}




\begin{tabular}{|c|c|c|c|c|c|c|c|}
\hline 14 & 5600 & 411699 & 4874251 & 44.0161 & -124.10166 & 31 & 27 \\
\hline 14 & 5700 & 411699 & 4874351 & 44.017 & -124.10168 & 31 & 27 \\
\hline 14 & 5800 & 411702 & 4874457 & 44.01795 & -124.10166 & 32 & 30 \\
\hline 14 & 5900 & 411707 & 4874552 & 44.01881 & -124.10161 & 32 & 30 \\
\hline 14 & 6000 & 411715 & 4874650 & 44.01969 & -124.10153 & 32 & 30 \\
\hline 14 & 6100 & 411721 & 4874742 & 44.02052 & -124.10147 & 33 & 31 \\
\hline 14 & 6200 & 411735 & 4874849 & 44.02149 & -124.10131 & 35 & 34 \\
\hline 14 & 6300 & 411740 & 4874951 & 44.02241 & -124.10127 & 36 & 35 \\
\hline 14 & 6400 & 411754 & 4875048 & 44.02328 & -124.10111 & 36 & 35 \\
\hline 14 & 6500 & 411760 & 4875146 & 44.02416 & -124.10105 & 37 & 36 \\
\hline 14 & 6600 & 411773 & 4875257 & 44.02516 & -124.10091 & 37 & 36 \\
\hline 14 & 6700 & 411778 & 4875352 & 44.02602 & -124.10086 & 38 & 36 \\
\hline 14 & 6800 & 411790 & 4875446 & 44.02687 & -124.10072 & 37 & 36 \\
\hline 14 & 6900 & 411798 & 4875550 & 44.0278 & -124.10064 & 36 & 34 \\
\hline 14 & 7000 & 411808 & 4875645 & 44.02866 & -124.10053 & 36 & 33 \\
\hline 14 & 7100 & 411818 & 4875756 & 44.02966 & -124.10043 & 36 & 33 \\
\hline 14 & 7200 & 411828 & 4875854 & 44.03054 & -124.10032 & 37 & 33 \\
\hline 14 & 7300 & 411839 & 4875948 & 44.03139 & -124.1002 & 39 & 35 \\
\hline 14 & 7400 & 411849 & 4876053 & 44.03234 & -124.10009 & 39 & 35 \\
\hline 14 & 7500 & 411857 & 4876147 & 44.03319 & -124.10001 & 38 & 33 \\
\hline 14 & 7600 & 411864 & 4876241 & 44.03403 & -124.09993 & 37 & 33 \\
\hline 14 & 7700 & 411873 & 4876346 & 44.03498 & -124.09984 & 35 & 33 \\
\hline 14 & 7800 & 411883 & 4876440 & 44.03583 & -124.09973 & 34 & 31 \\
\hline 14 & 7900 & 411893 & 4876545 & 44.03677 & -124.09962 & 33 & 29 \\
\hline 14 & 8000 & 411902 & 4876639 & 44.03762 & -124.09953 & 32 & 28 \\
\hline 14 & 8100 & 411909 & 4876744 & 44.03857 & -124.09946 & 31 & 28 \\
\hline 14 & 8200 & 411922 & 4876848 & 44.0395 & -124.09931 & 30 & 28 \\
\hline 14 & 8300 & 411933 & 4876942 & 44.04035 & -124.09919 & 29 & 27 \\
\hline 14 & 8400 & 411939 & 4877036 & 44.0412 & -124.09913 & 28 & 26 \\
\hline 14 & 8500 & 411948 & 4877141 & 44.04214 & -124.09904 & 28 & 26 \\
\hline 14 & 8600 & 411958 & 4877246 & 44.04309 & -124.09893 & 28 & 26 \\
\hline 14 & 8700 & 411962 & 4877346 & 44.04399 & -124.0989 & 27 & 25 \\
\hline 14 & 8800 & 411973 & 4877445 & 44.04488 & -124.09877 & 26 & 25 \\
\hline 14 & 8900 & 411980 & 4877539 & 44.04573 & -124.0987 & 24 & 22 \\
\hline 14 & 9000 & 411988 & 4877644 & 44.04668 & -124.09862 & 21 & 20 \\
\hline 14 & 9100 & 412001 & 4877749 & 44.04762 & -124.09848 & 18 & 16 \\
\hline 14 & 9200 & 412006 & 4877750 & 44.04763 & -124.09841 & 18 & 16 \\
\hline 15 & 0 & 411999 & 4879112 & 44.05989 & -124.09873 & 21 & 20 \\
\hline 15 & 100 & 412099 & 4879133 & 44.06009 & -124.09748 & 23 & 22 \\
\hline 15 & 200 & 412199 & 4879143 & 44.0602 & -124.09624 & 29 & 25 \\
\hline 15 & 300 & 412295 & 4879138 & 44.06016 & -124.09504 & 24 & 23 \\
\hline 15 & 400 & 412331 & 4879206 & 44.06078 & -124.0946 & 23 & 23 \\
\hline 15 & 500 & 412331 & 4879286 & 44.0615 & -124.09461 & 22 & 20 \\
\hline
\end{tabular}




\begin{tabular}{|c|c|c|c|c|c|c|c|}
\hline 15 & 800 & 412383 & 4879528 & 44.06368 & -124.094 & 17 & 16 \\
\hline 15 & 917 & 412390 & 4879599 & 44.06432 & -124.09393 & 15 & 14 \\
\hline 16 & 0 & 412051 & 4879727 & 44.06544 & -124.09818 & 39 & 38 \\
\hline 16 & 100 & 412155 & 4879740 & 44.06556 & -124.09688 & 45 & 44 \\
\hline 16 & 200 & 412254 & 4879749 & 44.06566 & -124.09565 & 47 & 44 \\
\hline 16 & 307 & 412263 & 4879687 & 44.0651 & -124.09553 & 41 & 40 \\
\hline 17 & 0 & 411879 & 4880204 & 44.06971 & -124.10041 & 46 & 44 \\
\hline 17 & 100 & 411802 & 4880140 & 44.06912 & -124.10136 & 41 & 40 \\
\hline 17 & 200 & 411777 & 4880095 & 44.06871 & -124.10166 & 34 & 33 \\
\hline 17 & 300 & 411711 & 4880167 & 44.06936 & -124.1025 & 30 & 29 \\
\hline 17 & 400 & 411762 & 4880240 & 44.07002 & -124.10187 & 31 & 30 \\
\hline 17 & 505 & 411694 & 4880281 & 44.07038 & -124.10273 & 32 & 31 \\
\hline 18 & 100 & 411921 & 4880667 & 44.07388 & -124.09996 & 58 & 55 \\
\hline 18 & 200 & 412015 & 4880663 & 44.07386 & -124.09879 & 63 & 57 \\
\hline 18 & 300 & 412098 & 4880607 & 44.07336 & -124.09774 & 62 & 54 \\
\hline 18 & 400 & 412154 & 4880533 & 44.0727 & -124.09703 & 55 & 52 \\
\hline 18 & 500 & 412222 & 4880473 & 44.07217 & -124.09617 & 48 & 47 \\
\hline 18 & 600 & 412305 & 4880464 & 44.0721 & -124.09513 & 43 & 40 \\
\hline 18 & 700 & 412391 & 4880424 & 44.07175 & -124.09405 & 39 & 35 \\
\hline 18 & 800 & 412488 & 4880409 & 44.07163 & -124.09284 & 33 & 30 \\
\hline 18 & 900 & 412556 & 4880358 & 44.07118 & -124.09198 & 28 & 23 \\
\hline 18 & 1000 & 412532 & 4880264 & 44.07033 & -124.09226 & 23 & 18 \\
\hline 18 & 1100 & 412581 & 4880204 & 44.06979 & -124.09164 & 18 & 15 \\
\hline 18 & 1200 & 412603 & 4880121 & 44.06905 & -124.09135 & 13 & 11 \\
\hline 18 & 1300 & 412710 & 4880106 & 44.06893 & -124.09002 & 13 & 11 \\
\hline 19 & 200 & 411366 & 4882193 & 44.08755 & -124.10715 & 28 & 25 \\
\hline 19 & 300 & 411290 & 4882162 & 44.08726 & -124.10809 & 17 & 16 \\
\hline 19 & 400 & 411234 & 4882231 & 44.08788 & -124.1088 & 13 & 12 \\
\hline 19 & 500 & 411194 & 4882312 & 44.0886 & -124.10931 & 12 & 10 \\
\hline 19 & 600 & 411095 & 4882308 & 44.08855 & -124.11055 & 10 & 9 \\
\hline 19 & 700 & 410994 & 4882307 & 44.08853 & -124.11181 & 6 & 5 \\
\hline 19 & 1000 & 410695 & 4882303 & 44.08846 & -124.11554 & 9 & 7 \\
\hline 19 & 1100 & 410606 & 4882260 & 44.08806 & -124.11665 & 16 & 15 \\
\hline 19 & 1200 & 410529 & 4882198 & 44.08749 & -124.1176 & 10 & 9 \\
\hline 19 & 1335 & 410488 & 4882238 & 44.08785 & -124.11812 & 8 & 7 \\
\hline 20 & 0 & 411195 & 4882395 & 44.08935 & -124.10932 & 12 & 12 \\
\hline 20 & 100 & 411221 & 4882271 & 44.08824 & -124.10897 & 13 & 12 \\
\hline 20 & 200 & 411250 & 4882172 & 44.08735 & -124.10859 & 14 & 13 \\
\hline 20 & 300 & 411278 & 4882083 & 44.08655 & -124.10823 & 13 & 12 \\
\hline 20 & 400 & 411304 & 4881984 & 44.08566 & -124.10789 & 11 & 11 \\
\hline 20 & 500 & 411329 & 4881891 & 44.08483 & -124.10756 & 10 & 10 \\
\hline 20 & 600 & 411353 & 4881792 & 44.08394 & -124.10724 & 9 & 8 \\
\hline 20 & 700 & 411378 & 4881699 & 44.08311 & -124.10691 & 9 & 8 \\
\hline
\end{tabular}




\begin{tabular}{|c|c|c|c|c|c|c|c|}
\hline 20 & 800 & 411406 & 4881601 & 44.08223 & -124.10655 & 12 & 11 \\
\hline 20 & 900 & 411432 & 4881507 & 44.08138 & -124.10621 & 15 & 14 \\
\hline 20 & 1000 & 411460 & 4881409 & 44.0805 & -124.10584 & 19 & 18 \\
\hline 20 & 3600 & 411957 & 4878986 & 44.05875 & -124.09923 & 15 & 15 \\
\hline 20 & 3700 & 411931 & 4878898 & 44.05796 & -124.09954 & 14 & 14 \\
\hline 20 & 3800 & 411901 & 4878795 & 44.05703 & -124.0999 & 14 & 14 \\
\hline 20 & 3900 & 411901 & 4878705 & 44.05622 & -124.09988 & 14 & 14 \\
\hline 20 & 4000 & 411951 & 4878618 & 44.05544 & -124.09924 & 14 & 14 \\
\hline 20 & 4100 & 412014 & 4878538 & 44.05473 & -124.09844 & 14 & 14 \\
\hline 20 & 4200 & 412062 & 4878455 & 44.05399 & -124.09783 & 15 & 14 \\
\hline 20 & 4300 & 412066 & 4878350 & 44.05304 & -124.09776 & 13 & 12 \\
\hline 20 & 4400 & 412057 & 4878259 & 44.05222 & -124.09786 & 16 & 14 \\
\hline 20 & 4620 & 412037 & 4878155 & 44.05128 & -124.09809 & 17 & 14 \\
\hline 21 & 0 & 412008 & 4877958 & 44.04951 & -124.09842 & 17 & 15 \\
\hline 21 & 100 & 411940 & 4877990 & 44.04979 & -124.09928 & 15 & 14 \\
\hline 21 & 200 & 411890 & 4878051 & 44.05033 & -124.09991 & 15 & 14 \\
\hline 21 & 300 & 411791 & 4878092 & 44.05069 & -124.10115 & 14 & 13 \\
\hline 21 & 400 & 411719 & 4878092 & 44.05068 & -124.10205 & 14 & 14 \\
\hline 21 & 500 & 411649 & 4878157 & 44.05125 & -124.10294 & 13 & 12 \\
\hline 21 & 600 & 411638 & 4878254 & 44.05213 & -124.10309 & 14 & 8 \\
\hline 21 & 700 & 411690 & 4878300 & 44.05255 & -124.10245 & 15 & 9 \\
\hline 21 & 778 & 411746 & 4878295 & 44.05251 & -124.10175 & 16 & 12 \\
\hline 22 & 0 & 411799 & 4878611 & 44.05536 & -124.10114 & 16 & 10 \\
\hline 22 & 100 & 411779 & 4878399 & 44.05345 & -124.10135 & 11 & 10 \\
\hline 22 & 200 & 411949 & 4878551 & 44.05484 & -124.09926 & 15 & 14 \\
\hline 22 & 300 & 411904 & 4878478 & 44.05417 & -124.09981 & 21 & 18 \\
\hline 22 & 400 & 411817 & 4878470 & 44.05409 & -124.10089 & 21 & 18 \\
\hline 22 & 500 & 411780 & 4878551 & 44.05482 & -124.10137 & 15 & 12 \\
\hline 22 & 600 & 411757 & 4878470 & 44.05408 & -124.10164 & 13 & 10 \\
\hline 22 & 700 & 411738 & 4878377 & 44.05325 & -124.10186 & 12 & 9 \\
\hline 22 & 800 & 411646 & 4878374 & 44.05321 & -124.10301 & 12 & 9 \\
\hline 22 & 882 & 411571 & 4878383 & 44.05328 & -124.10395 & 12 & 9 \\
\hline 22 & 900 & 411552 & 4878383 & 44.05328 & -124.10419 & 12 & 9 \\
\hline 22 & 1000 & 411456 & 4878404 & 44.05345 & -124.10539 & 13 & 9 \\
\hline 22 & 1100 & 411371 & 4878433 & 44.05371 & -124.10645 & 13 & 9 \\
\hline 22 & 1200 & 411319 & 4878529 & 44.05456 & -124.10712 & 12 & 9 \\
\hline 22 & 1300 & 411241 & 4878529 & 44.05455 & -124.10809 & 12 & 9 \\
\hline 22 & 1400 & 411234 & 4878630 & 44.05546 & -124.1082 & 13 & 9 \\
\hline 22 & 1500 & 411245 & 4878718 & 44.05626 & -124.10807 & 11 & 8 \\
\hline 22 & 1565 & 411258 & 4878753 & 44.05657 & -124.10792 & 11 & 8 \\
\hline 23 & 0 & 412225 & 4876282 & 44.03444 & -124.09544 & 36 & 35 \\
\hline 23 & 100 & 412144 & 4876276 & 44.03438 & -124.09645 & 36 & 35 \\
\hline 23 & 200 & 412044 & 4876284 & 44.03444 & -124.0977 & 35 & 35 \\
\hline
\end{tabular}




\begin{tabular}{|c|c|c|c|c|c|c|c|}
\hline 23 & 300 & 411944 & 4876293 & 44.03451 & -124.09894 & 34 & 34 \\
\hline 23 & 364 & 411837 & 4876270 & 44.03429 & -124.10028 & 35 & 33 \\
\hline 24 & 0 & 412192 & 4875688 & 44.02909 & -124.09575 & 40 & 36 \\
\hline 24 & 100 & 412096 & 4875705 & 44.02924 & -124.09695 & 40 & 36 \\
\hline 24 & 200 & 412059 & 4875783 & 44.02993 & -124.09742 & 40 & 36 \\
\hline 24 & 300 & 411959 & 4875782 & 44.02991 & -124.09867 & 39 & 37 \\
\hline 24 & 400 & 411859 & 4875794 & 44.03001 & -124.09992 & 38 & 37 \\
\hline 24 & 500 & 411760 & 4875796 & 44.03001 & -124.10116 & 34 & 34 \\
\hline 24 & 600 & 411659 & 4875802 & 44.03006 & -124.10242 & 33 & 32 \\
\hline 24 & 700 & 411563 & 4875816 & 44.03017 & -124.10362 & 33 & 32 \\
\hline 24 & 757 & 411543 & 4875827 & 44.03027 & -124.10387 & 33 & 32 \\
\hline 28 & 0 & 409533 & 4876192 & 44.03331 & -124.12901 & 14 & 13 \\
\hline 28 & 100 & 409432 & 4876190 & 44.03328 & -124.13027 & 13 & 12 \\
\hline 28 & 200 & 409332 & 4876192 & 44.03328 & -124.13152 & 12 & 11 \\
\hline 28 & 300 & 409301 & 4876282 & 44.03409 & -124.13192 & 11 & 10 \\
\hline 28 & 400 & 409304 & 4876381 & 44.03498 & -124.1319 & 11 & 10 \\
\hline 28 & 500 & 409310 & 4876480 & 44.03587 & -124.13184 & 10 & 9 \\
\hline 28 & 600 & 409288 & 4876575 & 44.03673 & -124.13213 & 8 & 7 \\
\hline 28 & 700 & 409276 & 4876644 & 44.03734 & -124.1323 & 9 & 7 \\
\hline 28 & 744 & 409304 & 4876654 & 44.03744 & -124.13195 & 10 & 8 \\
\hline 28 & 797 & 409277 & 4876621 & 44.03714 & -124.13228 & 8 & 7 \\
\hline 31 & 0 & 411701 & 4872825 & 44.00326 & -124.1014 & 25 & 22 \\
\hline 31 & 100 & 411796 & 4872814 & 44.00318 & -124.10021 & 24 & 22 \\
\hline 31 & 200 & 411896 & 4872810 & 44.00315 & -124.09896 & 24 & 23 \\
\hline 31 & 300 & 411997 & 4872801 & 44.00308 & -124.0977 & 24 & 23 \\
\hline 31 & 400 & 412095 & 4872793 & 44.00302 & -124.09648 & 24 & 23 \\
\hline 31 & 500 & 412191 & 4872781 & 44.00293 & -124.09528 & 24 & 23 \\
\hline 31 & 600 & 412293 & 4872779 & 44.00292 & -124.09401 & 23 & 23 \\
\hline 31 & 700 & 412492 & 4872579 & 44.00114 & -124.09149 & 23 & 23 \\
\hline 31 & 800 & 412446 & 4872820 & 44.00331 & -124.09211 & 25 & 24 \\
\hline 31 & 900 & 412458 & 4872889 & 44.00393 & -124.09197 & 27 & 26 \\
\hline 31 & 1000 & 412561 & 4872884 & 44.0039 & -124.09068 & 28 & 26 \\
\hline 31 & 1100 & 412587 & 4872823 & 44.00335 & -124.09035 & 31 & 27 \\
\hline 31 & 1200 & 412524 & 4872770 & 44.00287 & -124.09113 & 29 & 27 \\
\hline 31 & 1300 & 412512 & 4872866 & 44.00373 & -124.09129 & 31 & 26 \\
\hline 31 & 1400 & 412434 & 4872889 & 44.00393 & -124.09227 & 25 & 24 \\
\hline 31 & 1500 & 412370 & 4872851 & 44.00358 & -124.09306 & 24 & 24 \\
\hline 31 & 1600 & 412277 & 4872859 & 44.00364 & -124.09422 & 24 & 24 \\
\hline 32 & 0 & 412293 & 4873100 & 44.00581 & -124.09406 & 26 & 25 \\
\hline 32 & 100 & 412255 & 4873185 & 44.00657 & -124.09455 & 27 & 25 \\
\hline 32 & 200 & 412160 & 4873198 & 44.00668 & -124.09574 & 26 & 25 \\
\hline 32 & 300 & 412060 & 4873202 & 44.0067 & -124.09698 & 25 & 24 \\
\hline 32 & 400 & 411983 & 4873232 & 44.00696 & -124.09795 & 26 & 23 \\
\hline
\end{tabular}




\begin{tabular}{|c|c|c|c|c|c|c|c|}
\hline 32 & 500 & 411992 & 4873330 & 44.00784 & -124.09785 & 26 & 23 \\
\hline 32 & 600 & 411977 & 4873428 & 44.00872 & -124.09806 & 27 & 23 \\
\hline 32 & 700 & 412046 & 4873457 & 44.00899 & -124.0972 & 27 & 24 \\
\hline 32 & 800 & 412144 & 4873438 & 44.00883 & -124.09598 & 27 & 24 \\
\hline 32 & 900 & 412238 & 4873410 & 44.00859 & -124.0948 & 26 & 25 \\
\hline 32 & 1000 & 412241 & 4873310 & 44.00769 & -124.09474 & 26 & 24 \\
\hline 32 & 1153 & 412236 & 4873201 & 44.00671 & -124.09479 & 25 & 23 \\
\hline 33 & 0 & 412417 & 4873110 & 44.00591 & -124.09252 & 27 & 25 \\
\hline 33 & 100 & 412325 & 4873100 & 44.00581 & -124.09366 & 27 & 25 \\
\hline 33 & 200 & 412239 & 4873053 & 44.00538 & -124.09473 & 25 & 24 \\
\hline 33 & 300 & 412172 & 4872990 & 44.0048 & -124.09555 & 24 & 23 \\
\hline 33 & 400 & 412198 & 4872897 & 44.00397 & -124.09521 & 24 & 23 \\
\hline 33 & 500 & 412276 & 4872837 & 44.00344 & -124.09423 & 23 & 22 \\
\hline 33 & 600 & 412291 & 4872740 & 44.00257 & -124.09403 & 23 & 22 \\
\hline 33 & 700 & 412293 & 4872644 & 44.0017 & -124.09399 & 22 & 21 \\
\hline 33 & 800 & 412286 & 4872539 & 44.00076 & -124.09406 & 22 & 21 \\
\hline 33 & 900 & 412288 & 4872440 & 43.99987 & -124.09401 & 23 & 21 \\
\hline 33 & 1000 & 412279 & 4872340 & 43.99897 & -124.09411 & 21 & 20 \\
\hline 33 & 1100 & 412214 & 4872282 & 43.99844 & -124.09491 & 23 & 21 \\
\hline 33 & 1200 & 412123 & 4872272 & 43.99834 & -124.09604 & 21 & 20 \\
\hline 33 & 1300 & 412090 & 4872177 & 43.99748 & -124.09644 & 21 & 20 \\
\hline 33 & 1400 & 412067 & 4872082 & 43.99662 & -124.09671 & 20 & 19 \\
\hline 33 & 1500 & 412063 & 4871987 & 43.99576 & -124.09674 & 20 & 19 \\
\hline 33 & 1600 & 412055 & 4871890 & 43.99489 & -124.09683 & 19 & 18 \\
\hline 33 & 1700 & 412044 & 4871782 & 43.99392 & -124.09695 & 19 & 18 \\
\hline 33 & 1800 & 412006 & 4871719 & 43.99334 & -124.09741 & 22 & 20 \\
\hline 33 & 1961 & 411916 & 4871731 & 43.99344 & -124.09854 & 22 & 20 \\
\hline 34 & 0 & 412007 & 4871631 & 43.99255 & -124.09738 & 24 & 18 \\
\hline 34 & 100 & 411943 & 4871592 & 43.99219 & -124.09818 & 21 & 18 \\
\hline 34 & 200 & 411889 & 4871649 & 43.9927 & -124.09886 & 20 & 18 \\
\hline 34 & 300 & 411787 & 4871650 & 43.9927 & -124.10013 & 19 & 16 \\
\hline 34 & 400 & 411688 & 4871649 & 43.99268 & -124.10136 & 19 & 15 \\
\hline 34 & 500 & 411588 & 4871651 & 43.99268 & -124.10261 & 19 & 15 \\
\hline 34 & 600 & 411487 & 4871650 & 43.99266 & -124.10387 & 19 & 16 \\
\hline 34 & 700 & 411407 & 4871692 & 43.99303 & -124.10488 & 19 & 16 \\
\hline 34 & 800 & 411310 & 4871711 & 43.99319 & -124.10609 & 19 & 17 \\
\hline 34 & 900 & 411231 & 4871656 & 43.99268 & -124.10706 & 19 & 16 \\
\hline 34 & 977 & 411214 & 4871625 & 43.9924 & -124.10727 & 19 & 16 \\
\hline 39 & 0 & 412642 & 4870176 & 43.97953 & -124.08923 & 12 & 10 \\
\hline 39 & 100 & 412560 & 4870175 & 43.97951 & -124.09025 & 11 & 9 \\
\hline 39 & 200 & 412460 & 4870171 & 43.97946 & -124.09149 & 11 & 9 \\
\hline 39 & 300 & 412374 & 4870124 & 43.97903 & -124.09256 & 11 & 9 \\
\hline 39 & 400 & 412285 & 4870077 & 43.9786 & -124.09366 & 11 & 9 \\
\hline
\end{tabular}




\begin{tabular}{|c|c|c|c|c|c|c|c|}
\hline 39 & 500 & 412198 & 4870023 & 43.9781 & -124.09474 & 10 & 9 \\
\hline 39 & 600 & 412161 & 4869946 & 43.9774 & -124.09518 & 11 & 9 \\
\hline 39 & 700 & 412060 & 4869950 & 43.97743 & -124.09644 & 9 & 8 \\
\hline 39 & 800 & 411957 & 4869948 & 43.9774 & -124.09773 & 9 & 8 \\
\hline 39 & 900 & 411877 & 4869964 & 43.97753 & -124.09873 & 9 & 8 \\
\hline 39 & 1000 & 411879 & 4870065 & 43.97844 & -124.09872 & 10 & 9 \\
\hline 39 & 1100 & 411880 & 4870159 & 43.97929 & -124.09872 & 11 & 10 \\
\hline 39 & 1200 & 411849 & 4870233 & 43.97995 & -124.09912 & 11 & 10 \\
\hline 39 & 1300 & 411744 & 4870233 & 43.97994 & -124.10043 & 11 & 10 \\
\hline 39 & 1400 & 411655 & 4870233 & 43.97992 & -124.10154 & 12 & 10 \\
\hline 39 & 1500 & 411549 & 4870233 & 43.97991 & -124.10286 & 13 & 10 \\
\hline 39 & 1600 & 411452 & 4870218 & 43.97977 & -124.10407 & 13 & 10 \\
\hline 39 & 1700 & 411361 & 4870169 & 43.97931 & -124.10519 & 13 & 10 \\
\hline 39 & 1800 & 411271 & 4870120 & 43.97886 & -124.10631 & 14 & 11 \\
\hline 39 & 1900 & 411188 & 4870093 & 43.97861 & -124.10734 & 13 & 11 \\
\hline 39 & 2059 & 411085 & 4870107 & 43.97872 & -124.10863 & 13 & 11 \\
\hline 40 & 0 & 411070 & 4870102 & 43.97867 & -124.10881 & 13 & 12 \\
\hline 40 & 100 & 411070 & 4870008 & 43.97783 & -124.1088 & 15 & 14 \\
\hline 40 & 200 & 411074 & 4869907 & 43.97692 & -124.10873 & 17 & 15 \\
\hline 40 & 300 & 411074 & 4869808 & 43.97603 & -124.10871 & 14 & 13 \\
\hline 40 & 400 & 411074 & 4869707 & 43.97512 & -124.1087 & 9 & 8 \\
\hline 40 & 500 & 411074 & 4869606 & 43.97421 & -124.10868 & 9 & 8 \\
\hline 40 & 600 & 411072 & 4869505 & 43.9733 & -124.10869 & 8 & 7 \\
\hline 40 & 700 & 411071 & 4869404 & 43.97239 & -124.10868 & 8 & 7 \\
\hline 40 & 800 & 411072 & 4869306 & 43.97151 & -124.10865 & 7 & 6 \\
\hline 40 & 900 & 411030 & 4869247 & 43.97097 & -124.10917 & 7 & 6 \\
\hline 40 & 1000 & 410925 & 4869246 & 43.97095 & -124.11048 & 7 & 6 \\
\hline 40 & 1100 & 410865 & 4869211 & 43.97063 & -124.11122 & 6 & 5 \\
\hline 40 & 1200 & 410875 & 4869116 & 43.96978 & -124.11108 & 7 & 6 \\
\hline 40 & 1300 & 410911 & 4869048 & 43.96917 & -124.11062 & 5 & 4 \\
\hline 40 & 1400 & 410874 & 4868965 & 43.96842 & -124.11106 & 4 & 3 \\
\hline 40 & 1500 & 410941 & 4868898 & 43.96782 & -124.11022 & 4 & 3 \\
\hline 40 & 1600 & 410889 & 4868818 & 43.96709 & -124.11085 & 3 & 2 \\
\hline 40 & 1700 & 410879 & 4868782 & 43.96677 & -124.11097 & 3 & 2 \\
\hline 44 & 0 & 412276 & 4872334 & 43.99891 & -124.09415 & 21 & 19 \\
\hline 44 & 100 & 412283 & 4872242 & 43.99808 & -124.09404 & 19 & 18 \\
\hline 44 & 200 & 412289 & 4872143 & 43.99719 & -124.09395 & 18 & 18 \\
\hline 44 & 300 & 412295 & 4872044 & 43.9963 & -124.09386 & 18 & 17 \\
\hline 44 & 400 & 412304 & 4871942 & 43.99539 & -124.09373 & 17 & 16 \\
\hline 44 & 500 & 412375 & 4871884 & 43.99487 & -124.09284 & 16 & 16 \\
\hline 44 & 600 & 412458 & 4871829 & 43.99439 & -124.09179 & 17 & 16 \\
\hline 44 & 700 & 412539 & 4871768 & 43.99385 & -124.09077 & 17 & 16 \\
\hline 6 & 0 & 410271 & 4872310 & 43.99845 & -124.11915 & 18 & 16 \\
\hline
\end{tabular}




\begin{tabular}{|c|c|c|c|c|c|c|c|c|}
\hline 6 & 50 & 410328 & 4872291 & 43.99829 & -124.11843 & 18 & 16 & 2 \\
\hline 6 & 150 & 410409 & 4872242 & 43.99786 & -124.11741 & 19 & 18 & 1 \\
\hline 6 & 250 & 410510 & 4872242 & 43.99787 & -124.11615 & 21 & 19 & 2 \\
\hline 6 & 350 & 410603 & 4872212 & 43.99761 & -124.11499 & 21 & 19 & 2 \\
\hline 6 & 450 & 410696 & 4872240 & 43.99788 & -124.11383 & 21 & 19 & 2 \\
\hline 6 & 550 & 410271 & 4872310 & 43.99845 & -124.11915 & 18 & 17 & 1 \\
\hline 6 & 650 & 410890 & 4872252 & 43.99801 & -124.11142 & 31 & 28 & 3 \\
\hline 6 & 750 & 410927 & 4872222 & 43.99774 & -124.11095 & 34 & 26 & 8 \\
\hline 6 & 850 & 411070 & 4872182 & 43.9974 & -124.10916 & 31 & 24 & 7 \\
\hline 6 & 950 & 411168 & 4872160 & 43.99721 & -124.10793 & 24 & 21 & 3 \\
\hline 6 & 1050 & 411263 & 4872126 & 43.99692 & -124.10674 & 21 & 20 & 1 \\
\hline 6 & 1150 & 411315 & 4872009 & 43.99587 & -124.10608 & 20 & 18 & 2 \\
\hline 6 & 1250 & 411462 & 4872125 & 43.99693 & -124.10426 & 21 & 18 & 3 \\
\hline 6 & 1350 & 411563 & 4872123 & 43.99693 & -124.103 & 22 & 18 & 4 \\
\hline 6 & 1450 & 411625 & 4872003 & 43.99585 & -124.10221 & 21 & 18 & 3 \\
\hline 6 & 1550 & 411766 & 4872123 & 43.99695 & -124.10047 & 21 & 18 & 3 \\
\hline 6 & 1650 & 411861 & 4872126 & 43.99699 & -124.09929 & 22 & 18 & 4 \\
\hline 25 & 50 & 411580 & 4874890 & 44.02184 & -124.10325 & 34 & 31 & 3 \\
\hline 25 & 150 & 411492 & 4874863 & 44.02158 & -124.10435 & 31 & 31 & 0 \\
\hline 25 & 250 & 411413 & 4874919 & 44.02208 & -124.10534 & 30 & 30 & 0 \\
\hline 25 & 350 & 411379 & 4875013 & 44.02292 & -124.10578 & 33 & 30 & 3 \\
\hline 25 & 450 & 411361 & 4875104 & 44.02374 & -124.10602 & 31 & 31 & 0 \\
\hline 25 & 550 & 411299 & 4875181 & 44.02442 & -124.10681 & 32 & 31 & 1 \\
\hline 25 & 650 & 411252 & 4875269 & 44.02521 & -124.10741 & 31 & 31 & 0 \\
\hline 25 & 750 & 411196 & 4875359 & 44.02601 & -124.10812 & 33 & 33 & 0 \\
\hline 25 & 850 & 411301 & 4875032 & 44.02308 & -124.10676 & 30 & 30 & 0 \\
\hline 25 & 950 & 411093 & 4875516 & 44.02741 & -124.10943 & 34 & 33 & 1 \\
\hline 25 & 1050 & 411079 & 4875551 & 44.02773 & -124.10961 & 34 & 32.5 & 1.5 \\
\hline 25 & 1150 & 411072 & 4875575 & 44.02794 & -124.1097 & 35 & 34 & 1 \\
\hline 25 & 1217 & 411064 & 4875593 & 44.0281 & -124.10981 & 36 & 34 & 2 \\
\hline 26 & 0 & 411056 & 4875084 & 44.02352 & -124.10982 & 29 & 26 & 3 \\
\hline 26 & 100 & 410964 & 4875059 & 44.02328 & -124.11097 & 31 & 26 & 5 \\
\hline 26 & 200 & 410866 & 4875066 & 44.02333 & -124.11219 & 30 & 25 & 5 \\
\hline 26 & 300 & 410803 & 4875020 & 44.02291 & -124.11297 & 29 & 24 & 5 \\
\hline 26 & 400 & 410841 & 4874927 & 44.02208 & -124.11248 & 31 & 24 & 7 \\
\hline 26 & 500 & 410762 & 4874866 & 44.02152 & -124.11345 & 31 & 24 & 7 \\
\hline 27 & 583 & 411056 & 4875084 & 44.02327 & -124.11289 & 29 & 24 & 5 \\
\hline 27 & 0 & 410810 & 4875059 & 44.02327 & -124.11289 & 29 & 23 & 6 \\
\hline 27 & 100 & 410778 & 4875156 & 44.02413 & -124.1133 & 29 & 24 & 5 \\
\hline 27 & 200 & 410706 & 4875209 & 44.0246 & -124.11421 & 32 & 23 & 9 \\
\hline 27 & 300 & 410622 & 4875254 & 44.025 & -124.11526 & 28 & 24 & 4 \\
\hline 27 & 400 & 410363 & 4875314 & 44.02551 & -124.11851 & 29 & 25 & 4 \\
\hline 27 & 500 & 410530 & 4875366 & 44.02599 & -124.11643 & 27 & 24 & 3 \\
\hline
\end{tabular}




\begin{tabular}{|c|c|c|c|c|c|c|c|}
\hline 27 & 600 & 410429 & 4875367 & 44.02599 & -124.11769 & 26 & 25 \\
\hline 27 & 700 & 410362 & 4875402 & 44.0263 & -124.11853 & 26 & 25 \\
\hline 27 & 800 & 410782 & 4875181 & 44.02436 & -124.11326 & 30 & 24 \\
\hline 27 & 900 & 410363 & 4875599 & 44.02807 & -124.11855 & 28 & 22 \\
\hline 27 & 1000 & 410424 & 4875680 & 44.02881 & -124.11781 & 27 & 24 \\
\hline 29 & 200 & 410005 & 4874799 & 44.02083 & -124.12288 & 21 & 20 \\
\hline 29 & 300 & 410054 & 4874733 & 44.02024 & -124.12226 & 21 & 21 \\
\hline 29 & 400 & 410149 & 4874734 & 44.02026 & -124.12108 & 22 & 22 \\
\hline 29 & 500 & 410249 & 4874752 & 44.02043 & -124.11983 & 24 & 24 \\
\hline 29 & 600 & 410350 & 4874763 & 44.02054 & -124.11857 & 24 & 24 \\
\hline 29 & 700 & 410452 & 4874764 & 44.02057 & -124.1173 & 26 & 25 \\
\hline 29 & 800 & 410524 & 4874712 & 44.02011 & -124.1164 & 30 & 29 \\
\hline 29 & 900 & 410609 & 4874649 & 44.01955 & -124.11532 & 28 & 27 \\
\hline 29 & 1000 & 410663 & 4874598 & 44.0191 & -124.11464 & 26 & 26 \\
\hline 29 & 1100 & 410657 & 4874497 & 44.01819 & -124.1147 & 26 & 26 \\
\hline 29 & 1200 & 410575 & 4874467 & 44.01791 & -124.11572 & 30 & 29 \\
\hline 29 & 1300 & 410472 & 4874468 & 44.0179 & -124.117 & 27 & 25 \\
\hline 29 & 1400 & 410438 & 4874405 & 44.01733 & -124.11742 & 25 & 25 \\
\hline 29 & 1500 & 410387 & 4874331 & 44.01666 & -124.11804 & 29 & 28 \\
\hline 29 & 1600 & 410290 & 4874316 & 44.01651 & -124.11925 & 28 & 26 \\
\hline 29 & 1700 & 410186 & 4874323 & 44.01656 & -124.12055 & 23 & 22 \\
\hline 29 & 1800 & 410095 & 4874343 & 44.01673 & -124.12168 & 23 & 23 \\
\hline 29 & 1900 & 410002 & 4874305 & 44.01638 & -124.12284 & 21 & 21 \\
\hline 29 & 2000 & 409960 & 4874369 & 44.01695 & -124.12337 & 20 & 20 \\
\hline 29 & 2200 & 409858 & 4874373 & 44.01697 & -124.12465 & 20 & 19 \\
\hline 29 & 2300 & 409758 & 4874362 & 44.01686 & -124.12589 & 15 & 15 \\
\hline 29 & 2400 & 409694 & 4874232 & 44.01568 & -124.12667 & 4 & 4 \\
\hline 29 & 2466 & 409691 & 4874239 & 44.01575 & -124.12671 & 2 & 2 \\
\hline 30 & 0 & 410185 & 4873903 & 44.01278 & -124.12049 & 22 & 22 \\
\hline 30 & 100 & 410152 & 4873903 & 44.01278 & -124.1209 & 22 & 21 \\
\hline 30 & 200 & 409989 & 4873901 & 44.01274 & -124.12293 & 20 & 19 \\
\hline 30 & 266 & 409936 & 4873895 & 44.01268 & -124.12359 & 20 & 18 \\
\hline 35 & 0 & 410875 & 4871355 & 43.98993 & -124.11145 & 18 & 14 \\
\hline 35 & 100 & 410977 & 4871366 & 43.99004 & -124.11018 & 17 & 14 \\
\hline 35 & 200 & 411073 & 4871362 & 43.99002 & -124.10899 & 17 & 13 \\
\hline 35 & 300 & 411180 & 4871362 & 43.99003 & -124.10765 & 18 & 14 \\
\hline 35 & 400 & 411276 & 4871364 & 43.99006 & -124.10645 & 19 & 15 \\
\hline 35 & 500 & 411336 & 4871322 & 43.98969 & -124.1057 & 18 & 15 \\
\hline 35 & 600 & 411334 & 4871223 & 43.9888 & -124.10571 & 17 & 15 \\
\hline 35 & 700 & 411335 & 4871121 & 43.98788 & -124.10568 & 17 & 15 \\
\hline 35 & 800 & 410394 & 4871076 & 43.98736 & -124.1174 & 19 & 15 \\
\hline 35 & 900 & 411480 & 4871094 & 43.98765 & -124.10387 & 17 & 15 \\
\hline 35 & 1000 & 411483 & 4871196 & 43.98857 & -124.10385 & 17 & 15 \\
\hline
\end{tabular}




\begin{tabular}{|c|c|c|c|c|c|c|c|}
\hline 35 & 1100 & 411510 & 4871270 & 43.98924 & -124.10352 & 18 & 15 \\
\hline 35 & 1200 & 411603 & 4871271 & 43.98926 & -124.10236 & 18 & 15 \\
\hline 35 & 1300 & 411688 & 4871286 & 43.98941 & -124.1013 & 17 & 15 \\
\hline 35 & 1400 & 411686 & 4871385 & 43.9903 & -124.10135 & 18 & 15 \\
\hline 35 & 1500 & 411686 & 4871490 & 43.99124 & -124.10136 & 18 & 15 \\
\hline 35 & 1600 & 411721 & 4871556 & 43.99184 & -124.10094 & 19 & 15 \\
\hline 35 & 1700 & 411814 & 4871554 & 43.99184 & -124.09978 & 19 & 16 \\
\hline 35 & 1800 & 411887 & 4871520 & 43.99154 & -124.09886 & 19 & 16 \\
\hline 35 & 1900 & 411885 & 4871422 & 43.99066 & -124.09887 & 19 & 16 \\
\hline 35 & 2000 & 411886 & 4871323 & 43.98976 & -124.09884 & 17 & 15 \\
\hline 35 & 2100 & 411885 & 4871230 & 43.98893 & -124.09884 & 16 & 15 \\
\hline 35 & 2200 & 411881 & 4871120 & 43.98794 & -124.09887 & 16 & 14 \\
\hline 35 & 2300 & 411949 & 4871082 & 43.9876 & -124.09802 & 15 & 13 \\
\hline 35 & 2400 & 412051 & 4871089 & 43.98768 & -124.09675 & 15 & 12 \\
\hline 35 & 2500 & 412143 & 4871083 & 43.98763 & -124.0956 & 15 & 13 \\
\hline 35 & 2600 & 412247 & 4871076 & 43.98758 & -124.0943 & 15 & 13 \\
\hline 35 & 2700 & 412284 & 4871074 & 43.98757 & -124.09384 & 14 & 12 \\
\hline 36 & 100 & 412297 & 4870981 & 43.98673 & -124.09366 & 15 & 11 \\
\hline 36 & 200 & 412378 & 4870930 & 43.98629 & -124.09264 & 12 & 8 \\
\hline 36 & 300 & 412407 & 4870836 & 43.98544 & -124.09227 & 13 & 9 \\
\hline 36 & 400 & 412472 & 4870761 & 43.98478 & -124.09144 & 11 & 8 \\
\hline 36 & 500 & 412573 & 4870760 & 43.98478 & -124.09018 & 11 & 9 \\
\hline 36 & 600 & 412654 & 4870720 & 43.98443 & -124.08917 & 13 & 7 \\
\hline 36 & 637 & 412657 & 4870717 & 43.9844 & -124.08913 & 13 & 8 \\
\hline 37 & 0 & 412473 & 4870765 & 43.98481 & -124.09143 & 11 & 8 \\
\hline 37 & 100 & 412508 & 4870664 & 43.98391 & -124.09098 & 11 & 7 \\
\hline 37 & 200 & 412499 & 4870568 & 43.98304 & -124.09107 & 10 & 6 \\
\hline 37 & 300 & 412449 & 4870515 & 43.98256 & -124.09169 & 11 & 7.5 \\
\hline 37 & 400 & 412347 & 4870515 & 43.98255 & -124.09296 & 12 & 7 \\
\hline 37 & 500 & 412246 & 4870512 & 43.98251 & -124.09422 & 13 & 8.5 \\
\hline 37 & 600 & 412148 & 4870512 & 43.9825 & -124.09544 & 12 & 9 \\
\hline 37 & 700 & 412043 & 4870513 & 43.98249 & -124.09675 & 13 & 10 \\
\hline 37 & 800 & 411942 & 4870513 & 43.98248 & -124.09801 & 13 & 9.5 \\
\hline 37 & 900 & 411842 & 4870515 & 43.98249 & -124.09926 & 13 & 9 \\
\hline 37 & 1000 & 411747 & 4870515 & 43.98247 & -124.10044 & 14 & 9 \\
\hline 37 & 1100 & 411648 & 4870516 & 43.98247 & -124.10167 & 14 & 9 \\
\hline 37 & 1200 & 411541 & 4870515 & 43.98245 & -124.10301 & 14 & 9 \\
\hline 37 & 1300 & 411444 & 4870515 & 43.98244 & -124.10422 & 14 & 9.5 \\
\hline 37 & 1364 & 411435 & 4870523 & 43.98251 & -124.10433 & 14 & 10.5 \\
\hline 38 & 0 & 412215 & 4870699 & 43.98419 & -124.09464 & 13 & 11 \\
\hline 38 & 100 & 412137 & 4870701 & 43.9842 & -124.09561 & 13 & 12 \\
\hline 38 & 200 & 412037 & 4870704 & 43.98421 & -124.09686 & 13 & 12 \\
\hline 38 & 300 & 411939 & 4870706 & 43.98422 & -124.09808 & 14 & 13 \\
\hline
\end{tabular}




\begin{tabular}{|c|c|c|c|c|c|c|c|}
\hline 38 & 400 & 411883 & 4870749 & 43.9846 & -124.09878 & 14 & 13 \\
\hline 38 & 500 & 411827 & 4870797 & 43.98502 & -124.09949 & 15 & 14 \\
\hline 38 & 600 & 411727 & 4871799 & 43.99403 & -124.1009 & 20 & 15 \\
\hline 38 & 700 & 411679 & 4870747 & 43.98455 & -124.10133 & 15 & 14 \\
\hline 38 & 800 & 411617 & 4870707 & 43.98419 & -124.10209 & 14 & 13 \\
\hline 38 & 900 & 411520 & 4870708 & 43.98418 & -124.1033 & 15 & 14 \\
\hline 38 & 1000 & 411417 & 4870709 & 43.98418 & -124.10459 & 15 & 13 \\
\hline 38 & 1100 & 411312 & 4870710 & 43.98418 & -124.1059 & 15 & 12.5 \\
\hline 38 & 1200 & 411220 & 4870711 & 43.98417 & -124.10704 & 15 & 11 \\
\hline 38 & 1300 & 411123 & 4870713 & 43.98418 & -124.10825 & 14 & 12 \\
\hline 38 & 1368 & 411081 & 4870716 & 43.9842 & -124.10878 & 14 & 12.5 \\
\hline 41 & 0 & 410878 & 4868782 & 43.96677 & -124.11098 & 3 & 2.5 \\
\hline 41 & 100 & 410925 & 4868876 & 43.96762 & -124.11041 & 4 & 3 \\
\hline 41 & 300 & 410820 & 4869002 & 43.96874 & -124.11174 & 4 & 4 \\
\hline 41 & 400 & 410740 & 4869060 & 43.96925 & -124.11275 & 5 & 4 \\
\hline 41 & 500 & 410717 & 4869150 & 43.97006 & -124.11305 & 5 & 5 \\
\hline 41 & 600 & 410720 & 4869248 & 43.97094 & -124.11303 & 8 & 5 \\
\hline 41 & 700 & 410622 & 4869248 & 43.97093 & -124.11425 & 6 & 6 \\
\hline 41 & 800 & 410520 & 4869247 & 43.97091 & -124.11552 & 5 & 5 \\
\hline 41 & 900 & 410421 & 4869249 & 43.97092 & -124.11676 & 7 & 6 \\
\hline 41 & 1000 & 410322 & 4869285 & 43.97123 & -124.118 & 10 & 7 \\
\hline 41 & 1100 & 410256 & 4869344 & 43.97175 & -124.11883 & 12 & 9 \\
\hline 41 & 1200 & 410190 & 4869423 & 43.97246 & -124.11967 & 11 & 9 \\
\hline 41 & 1300 & 410138 & 4869501 & 43.97315 & -124.12033 & 5 & 5 \\
\hline 41 & 1400 & 410095 & 4869598 & 43.97402 & -124.12088 & 8 & 4.5 \\
\hline 41 & 1500 & 410103 & 4869687 & 43.97482 & -124.1208 & 12 & 9.5 \\
\hline 41 & 1600 & 410128 & 4869791 & 43.97576 & -124.1205 & 12 & 10 \\
\hline 41 & 1700 & 410146 & 4869892 & 43.97667 & -124.12029 & 11 & 10 \\
\hline 41 & 1800 & 410176 & 4869984 & 43.9775 & -124.11994 & 10 & 10 \\
\hline 41 & 1900 & 410202 & 4870081 & 43.97838 & -124.11963 & 9 & 9 \\
\hline 41 & 2000 & 410210 & 4870184 & 43.97931 & -124.11955 & 9 & 9 \\
\hline 41 & 2100 & 410224 & 4870289 & 43.98026 & -124.11939 & 9 & 9 \\
\hline 41 & 2200 & 410240 & 4870378 & 43.98106 & -124.1192 & 10 & 10 \\
\hline 41 & 2300 & 410240 & 4870480 & 43.98198 & -124.11922 & 10 & 10 \\
\hline 41 & 2400 & 410239 & 4870583 & 43.9829 & -124.11925 & 10 & 10 \\
\hline 41 & 2500 & 410243 & 4870678 & 43.98376 & -124.11922 & 10 & 10 \\
\hline 41 & 2600 & 410246 & 4870776 & 43.98464 & -124.1192 & 13 & 13 \\
\hline 41 & 2700 & 410249 & 4870879 & 43.98557 & -124.11918 & 15 & 14 \\
\hline 41 & 2800 & 410258 & 4870981 & 43.98649 & -124.11908 & 12 & 8 \\
\hline 41 & 2900 & 410260 & 4871075 & 43.98733 & -124.11907 & 6 & 3 \\
\hline 41 & 3000 & 410250 & 4871177 & 43.98825 & -124.11922 & 5 & 4 \\
\hline 41 & 3100 & 410533 & 4870139 & 43.97894 & -124.11551 & 12 & 5.5 \\
\hline 41 & 3200 & 410252 & 4871374 & 43.99003 & -124.11922 & 5 & 4 \\
\hline
\end{tabular}




\begin{tabular}{|c|c|c|c|c|c|c|c|}
\hline 41 & 3300 & 410259 & 4871476 & 43.99094 & -124.11915 & 5 & 1 \\
\hline 41 & 3400 & 410309 & 4871434 & 43.99057 & -124.11852 & 12 & 9 \\
\hline 41 & 3500 & 410357 & 4871347 & 43.9898 & -124.11791 & 16 & 10 \\
\hline 41 & 3600 & 410371 & 4871250 & 43.98892 & -124.11772 & 19 & 2.5 \\
\hline 41 & 3700 & 410386 & 4871257 & 43.98899 & -124.11753 & 19 & 1 \\
\hline 41 & 3800 & 410376 & 4871295 & 43.98933 & -124.11766 & 18 & 2 \\
\hline 41 & 3900 & 410356 & 4871375 & 43.99005 & -124.11793 & 16 & 2 \\
\hline 41 & 4000 & 410259 & 4871510 & 43.99125 & -124.11916 & 5 & 2 \\
\hline 41 & 4100 & 410262 & 4871611 & 43.99216 & -124.11914 & 5 & 2.5 \\
\hline 41 & 4200 & 410264 & 4871710 & 43.99305 & -124.11913 & 6 & 4 \\
\hline 41 & 4300 & 410265 & 4871810 & 43.99395 & -124.11914 & 6 & 4 \\
\hline 41 & 4400 & 410251 & 4871909 & 43.99484 & -124.11933 & 6 & 4 \\
\hline 41 & 4500 & 410226 & 4872004 & 43.99569 & -124.11965 & 9 & 7.5 \\
\hline 41 & 4600 & 410234 & 4872101 & 43.99657 & -124.11957 & 13 & 9 \\
\hline 41 & 4700 & 410259 & 4872199 & 43.99745 & -124.11928 & 17 & 9.5 \\
\hline 41 & 4800 & 410271 & 4872292 & 43.99829 & -124.11914 & 18 & 6 \\
\hline 41 & 4905 & 410278 & 4872297 & 43.99834 & -124.11906 & 18 & 4 \\
\hline 47 & 0 & 411631 & 4873901 & 44.01294 & -124.10245 & 28 & 27 \\
\hline 47 & 100 & 411592 & 4873860 & 44.01257 & -124.10293 & 29 & 27 \\
\hline 47 & 200 & 411493 & 4873864 & 44.01259 & -124.10417 & 30 & 30 \\
\hline 47 & 300 & 411398 & 4873841 & 44.01237 & -124.10535 & 32 & 31 \\
\hline 47 & 400 & 411298 & 4873828 & 44.01224 & -124.10659 & 32 & 31 \\
\hline 47 & 500 & 411199 & 4873815 & 44.01211 & -124.10782 & 37 & 33 \\
\hline 47 & 600 & 411101 & 4873803 & 44.01199 & -124.10905 & 27 & 26 \\
\hline 47 & 700 & 411052 & 4873871 & 44.0126 & -124.10967 & 26 & 26 \\
\hline 47 & 800 & 411021 & 4873967 & 44.01346 & -124.11007 & 26 & 26 \\
\hline 47 & 900 & 410997 & 4874062 & 44.01431 & -124.11039 & 26 & 26 \\
\hline 47 & 1000 & 410977 & 4874161 & 44.0152 & -124.11065 & 26 & 26 \\
\hline 47 & 1100 & 410946 & 4874120 & 44.01483 & -124.11103 & 26 & 26 \\
\hline 47 & 1200 & 410864 & 4874196 & 44.0155 & -124.11207 & 27 & 26.5 \\
\hline 47 & 1300 & 410889 & 4874293 & 44.01638 & -124.11177 & 29 & 29 \\
\hline 47 & 1350 & 410859 & 4874329 & 44.0167 & -124.11215 & 35 & 35 \\
\hline 48 & 0 & 410909 & 4871934 & 43.99515 & -124.11113 & 31 & 25 \\
\hline 48 & 100 & 410831 & 4871916 & 43.99497 & -124.1121 & 29 & 25 \\
\hline 48 & 200 & 410773 & 4871834 & 43.99423 & -124.1128 & 25 & 23 \\
\hline 48 & 300 & 410715 & 4871755 & 43.99351 & -124.11351 & 23 & 20 \\
\hline 48 & 400 & 410625 & 4871726 & 43.99324 & -124.11463 & 21 & 19.5 \\
\hline 48 & 500 & 410527 & 4871732 & 43.99328 & -124.11586 & 18 & 17 \\
\hline 48 & 600 & 410425 & 4871706 & 43.99304 & -124.11712 & 17 & 16 \\
\hline 48 & 700 & 410441 & 4871709 & 43.99306 & -124.11692 & 18 & 17 \\
\hline 48 & 800 & 410532 & 4871727 & 43.99324 & -124.11579 & 18 & 17 \\
\hline 48 & 900 & 410635 & 4871724 & 43.99322 & -124.11451 & 23 & 22.5 \\
\hline 48 & 964 & 410673 & 4871732 & 43.9933 & -124.11403 & 23 & 21 \\
\hline
\end{tabular}




\begin{tabular}{|c|c|c|c|c|c|c|c|c|}
\hline 49 & 0 & 411773 & 4875127 & 44.02399 & -124.10088 & 37 & 36 & 1 \\
\hline 49 & 100 & 411856 & 4875115 & 44.0239 & -124.09985 & 37 & 36 & 1 \\
\hline 49 & 200 & 411949 & 4875085 & 44.02364 & -124.09868 & 36 & 36 & 0 \\
\hline 49 & 300 & 412041 & 4875038 & 44.02322 & -124.09753 & 34 & 34 & 0 \\
\hline 49 & 400 & 412127 & 4874989 & 44.02279 & -124.09644 & 33 & 32 & 1 \\
\hline 49 & 500 & 412213 & 4874940 & 44.02236 & -124.09536 & 32 & 32 & 0 \\
\hline 49 & 600 & 412309 & 4874904 & 44.02205 & -124.09416 & 32 & 32 & 0 \\
\hline 49 & 700 & 412406 & 4874881 & 44.02186 & -124.09295 & 32 & 32 & 0 \\
\hline 49 & 800 & 412505 & 4874874 & 44.0218 & -124.09171 & 32 & 32 & 0 \\
\hline 49 & 900 & 412603 & 4874865 & 44.02173 & -124.09049 & 32 & 32 & 0 \\
\hline 49 & 1000 & 412705 & 4874850 & 44.02161 & -124.08921 & 33 & 32 & 1 \\
\hline 49 & 1100 & 412784 & 4874886 & 44.02195 & -124.08823 & 32 & 32 & 0 \\
\hline 49 & 1200 & 412847 & 4874967 & 44.02268 & -124.08746 & 36 & 36 & 0 \\
\hline 49 & 1300 & 412921 & 4874980 & 44.02281 & -124.08654 & 42 & 39 & 3 \\
\hline 49 & 1400 & 413004 & 4874924 & 44.02231 & -124.08549 & 37 & 35.5 & 1.5 \\
\hline 49 & 1500 & 413065 & 4874849 & 44.02165 & -124.08472 & 30 & 30 & 0 \\
\hline 49 & 1600 & 413008 & 4874909 & 44.02218 & -124.08544 & 37 & 36 & 1 \\
\hline 49 & 1700 & 413025 & 4875016 & 44.02314 & -124.08525 & 37 & 36.5 & 0.5 \\
\hline 49 & 1800 & 413029 & 4875108 & 44.02397 & -124.08521 & 36 & 36 & 0 \\
\hline 49 & 1900 & 413028 & 4875207 & 44.02486 & -124.08524 & 34 & 34 & 0 \\
\hline 49 & 2000 & 413014 & 4875305 & 44.02574 & -124.08543 & 37 & 34 & 3 \\
\hline 49 & 2100 & 413036 & 4875393 & 44.02654 & -124.08517 & 38 & 32 & 6 \\
\hline 49 & 2200 & 413102 & 4875466 & 44.0272 & -124.08436 & 40 & 34 & 6 \\
\hline 49 & 2300 & 413169 & 4875539 & 44.02787 & -124.08354 & 43 & 42 & 1 \\
\hline 49 & 2400 & 413239 & 4875615 & 44.02856 & -124.08267 & 42 & 40 & 2 \\
\hline 49 & 2500 & 413311 & 4875693 & 44.02927 & -124.08179 & 48 & 41 & 7 \\
\hline 49 & 2600 & 413262 & 4875733 & 44.02963 & -124.08241 & 49 & 44 & 5 \\
\hline 49 & 2700 & 413163 & 4875767 & 44.02992 & -124.08365 & 46 & 42.5 & 3.5 \\
\hline 49 & 2800 & 413076 & 4875797 & 44.03018 & -124.08474 & 40 & 40 & 0 \\
\hline 49 & 2900 & 412975 & 4875832 & 44.03048 & -124.086 & 36 & 36 & 0 \\
\hline 49 & 3000 & 412879 & 4875868 & 44.0308 & -124.08721 & 37 & 37 & 0 \\
\hline 49 & 3100 & 412787 & 4875865 & 44.03076 & -124.08836 & 36 & 35 & 1 \\
\hline 49 & 3168 & 412737 & 4875850 & 44.03062 & -124.08898 & 36 & 35 & 1 \\
\hline 50 & 100 & 413014 & 4875817 & 44.03035 & -124.08552 & 36 & 34 & 2 \\
\hline 50 & 200 & 413012 & 4875715 & 44.02943 & -124.08552 & 36 & 33 & 3 \\
\hline 50 & 300 & 413011 & 4875616 & 44.02854 & -124.08552 & 36 & 33 & 3 \\
\hline 50 & 500 & 413007 & 4875419 & 44.02677 & -124.08554 & 36 & 34 & 2 \\
\hline 50 & 800 & 412880 & 4875191 & 44.0247 & -124.08708 & 35 & 28 & 7 \\
\hline 50 & 900 & 412850 & 4875096 & 44.02384 & -124.08744 & 34 & 27 & 7 \\
\hline 50 & 1000 & 412820 & 4875002 & 44.02299 & -124.0878 & 33 & 27 & 6 \\
\hline 50 & 1100 & 412800 & 4874909 & 44.02215 & -124.08804 & 32 & 26 & 6 \\
\hline 50 & 1300 & 412776 & 4874722 & 44.02047 & -124.0883 & 33 & 28 & 5 \\
\hline 50 & 1500 & 412785 & 4874531 & 44.01875 & -124.08816 & 32 & 27 & 5 \\
\hline
\end{tabular}




\begin{tabular}{|c|c|c|c|c|c|c|c|c|}
\hline 50 & 1600 & 412801 & 4874435 & 44.01789 & -124.08795 & 31 & 26 & 5 \\
\hline 50 & 1700 & 412800 & 4874336 & 44.017 & -124.08794 & 34 & 27 & 7 \\
\hline 50 & 1800 & 412792 & 4874230 & 44.01604 & -124.08802 & 36 & 31 & 5 \\
\hline 50 & 1886 & 412853 & 4874106 & 44.01493 & -124.08724 & 32 & 27 & 5 \\
\hline 51 & 0 & 412853 & 4874106 & 44.01493 & -124.08724 & 32 & 31 & 1 \\
\hline 51 & 100 & 412914 & 4874188 & 44.01568 & -124.08649 & 34 & 33 & 1 \\
\hline 51 & 200 & 412965 & 4874274 & 44.01646 & -124.08587 & 44 & 41 & 3 \\
\hline 51 & 300 & 413000 & 4874363 & 44.01726 & -124.08545 & 53 & 43 & 10 \\
\hline 51 & 400 & 413001 & 4874464 & 44.01817 & -124.08545 & 55 & 44.5 & 10.5 \\
\hline 51 & 500 & 413078 & 4874522 & 44.0187 & -124.0845 & 42 & 40 & 2 \\
\hline 51 & 600 & 413102 & 4874517 & 44.01866 & -124.0842 & 37 & 36 & 1 \\
\hline 51 & 700 & 413015 & 4874486 & 44.01837 & -124.08528 & 55 & 44 & 11 \\
\hline 51 & 800 & 412999 & 4874389 & 44.0175 & -124.08547 & 53 & 42 & 11 \\
\hline 51 & 900 & 412975 & 4874295 & 44.01665 & -124.08575 & 47 & 41 & 6 \\
\hline 51 & 1000 & 412930 & 4874206 & 44.01584 & -124.0863 & 35 & 34 & 1 \\
\hline 51 & 1100 & 412868 & 4874130 & 44.01515 & -124.08706 & 32 & 31 & 1 \\
\hline 51 & 1200 & 412815 & 4874041 & 44.01434 & -124.08771 & 31 & 30 & 1 \\
\hline 51 & 1300 & 412773 & 4873958 & 44.01359 & -124.08822 & 31 & 30 & 1 \\
\hline 51 & 1400 & 412764 & 4873851 & 44.01263 & -124.08831 & 31 & 30 & 1 \\
\hline 51 & 1500 & 412766 & 4873756 & 44.01177 & -124.08827 & 31 & 30 & 1 \\
\hline 51 & 1600 & 412766 & 4873660 & 44.01091 & -124.08825 & 30 & 29 & 1 \\
\hline 51 & 1700 & 412763 & 4873556 & 44.00997 & -124.08827 & 31 & 29 & 2 \\
\hline 51 & 1800 & 412666 & 4873548 & 44.00989 & -124.08948 & 30 & 29 & 1 \\
\hline 51 & 1900 & 412602 & 4873477 & 44.00924 & -124.09027 & 32 & 30 & 2 \\
\hline 51 & 1977 & 412594 & 4873406 & 44.0086 & -124.09036 & 29 & 28 & 1 \\
\hline 52 & 0 & 410088 & 4874103 & 44.01457 & -124.12173 & 21 & 21 & 0 \\
\hline 52 & 100 & 410194 & 4874102 & 44.01458 & -124.12041 & 22 & 21 & 1 \\
\hline 52 & 200 & 410294 & 4874097 & 44.01454 & -124.11916 & 23 & 22 & 1 \\
\hline 52 & 300 & 410389 & 4874064 & 44.01426 & -124.11797 & 24 & 23 & 1 \\
\hline 52 & 400 & 410484 & 4874047 & 44.01412 & -124.11678 & 25 & 24 & 1 \\
\hline 52 & 500 & 410586 & 4874046 & 44.01412 & -124.11551 & 26 & 25 & 1 \\
\hline 52 & 600 & 410652 & 4874089 & 44.01451 & -124.11469 & 27 & 25 & 2 \\
\hline 52 & 700 & 410595 & 4874171 & 44.01525 & -124.11542 & 28 & 26 & 2 \\
\hline 52 & 800 & 410531 & 4874248 & 44.01593 & -124.11623 & 28 & 27 & 1 \\
\hline 52 & 900 & 410467 & 4874325 & 44.01662 & -124.11704 & 29 & 28 & 1 \\
\hline 52 & 1000 & 410395 & 4874340 & 44.01674 & -124.11794 & 29 & 28 & 1 \\
\hline 52 & 1100 & 410299 & 4874314 & 44.0165 & -124.11914 & 28 & 27 & 1 \\
\hline 52 & 1200 & 410201 & 4874319 & 44.01653 & -124.12036 & 24 & 23 & 1 \\
\hline 52 & 1300 & 410196 & 4874219 & 44.01563 & -124.1204 & 22 & 22 & 0 \\
\hline 53 & 0 & 413068 & 4871963 & 43.99567 & -124.08421 & 13 & 12 & 1 \\
\hline 53 & 100 & 412956 & 4871943 & 43.99547 & -124.0856 & 19 & 18 & 1 \\
\hline 53 & 200 & 412909 & 4872015 & 43.99612 & -124.0862 & 25 & 23 & 2 \\
\hline 53 & 300 & 412874 & 4872118 & 43.99704 & -124.08665 & 27 & 24 & 3 \\
\hline
\end{tabular}




\begin{tabular}{|c|c|c|c|c|c|c|c|}
\hline 53 & 400 & 412871 & 4872206 & 43.99783 & -124.08671 & 27 & 25 \\
\hline 53 & 500 & 412874 & 4872116 & 43.99702 & -124.08665 & 27 & 24 \\
\hline 53 & 600 & 412906 & 4872021 & 43.99617 & -124.08624 & 25 & 22 \\
\hline 53 & 700 & 412955 & 4871943 & 43.99547 & -124.08561 & 19 & 18 \\
\hline 53 & 800 & 412960 & 4871871 & 43.99483 & -124.08554 & 19 & 18 \\
\hline 53 & 900 & 412930 & 4871784 & 43.99404 & -124.0859 & 18 & 18 \\
\hline 53 & 1000 & 412935 & 4871682 & 43.99312 & -124.08582 & 18 & 18 \\
\hline 53 & 1100 & 412943 & 4871651 & 43.99284 & -124.08572 & 19 & 18 \\
\hline 53 & 1200 & 412931 & 4871750 & 43.99373 & -124.08588 & 18 & 18 \\
\hline 53 & 1300 & 412937 & 4871847 & 43.99461 & -124.08582 & 18 & 18 \\
\hline 53 & 1400 & 411937 & 4871932 & 43.99525 & -124.09831 & 26 & 25 \\
\hline 53 & 1500 & 413058 & 4871950 & 43.99555 & -124.08433 & 13 & 12 \\
\hline 53 & 1579 & 413065 & 4871951 & 43.99556 & -124.08424 & 13 & 12 \\
\hline 54 & 0 & 412699 & 4870737 & 43.98459 & -124.08861 & 17 & 16 \\
\hline 54 & 100 & 412685 & 4870843 & 43.98554 & -124.0888 & 17 & 16 \\
\hline 54 & 200 & 412684 & 4870937 & 43.98638 & -124.08883 & 19 & 16 \\
\hline 54 & 300 & 412694 & 4871034 & 43.98726 & -124.08872 & 22 & 18 \\
\hline 54 & 400 & 412698 & 4871135 & 43.98817 & -124.08869 & 26 & 18 \\
\hline 54 & 500 & 412696 & 4871234 & 43.98906 & -124.08873 & 32 & 18 \\
\hline 54 & 600 & 412699 & 4871333 & 43.98995 & -124.08871 & 31 & 17 \\
\hline 54 & 700 & 412699 & 4871432 & 43.99084 & -124.08872 & 32 & 18 \\
\hline 54 & 800 & 412692 & 4871530 & 43.99172 & -124.08883 & 30 & 18 \\
\hline 54 & 900 & 412688 & 4871635 & 43.99267 & -124.08889 & 26 & 15 \\
\hline 54 & 1000 & 412687 & 4871728 & 43.9935 & -124.08892 & 26 & 18 \\
\hline 54 & 1100 & 412706 & 4871823 & 43.99436 & -124.0887 & 34 & 27 \\
\hline 54 & 1200 & 412695 & 4871927 & 43.9953 & -124.08885 & 33 & 22 \\
\hline 54 & 1300 & 412694 & 4872024 & 43.99617 & -124.08888 & 31 & 20 \\
\hline 54 & 1400 & 412698 & 4872119 & 43.99703 & -124.08885 & 30 & 21 \\
\hline 54 & 1500 & 412706 & 4872221 & 43.99795 & -124.08877 & 34 & 27 \\
\hline 54 & 1600 & 412742 & 4872166 & 43.99874 & -124.08893 & 29 & 25 \\
\hline 54 & 1700 & 412737 & 4872072 & 43.99823 & -124.0881 & 29 & 21 \\
\hline 54 & 1800 & 412738 & 4871971 & 43.99834 & -124.08726 & 30 & 27 \\
\hline 54 & 1900 & 412745 & 4871866 & 43.99774 & -124.08763 & 32 & 25 \\
\hline 54 & 2000 & 412692 & 4871781 & 43.9971 & -124.08838 & 29 & 21 \\
\hline 54 & 2100 & 412738 & 4871971 & 43.99834 & -124.08726 & 20 & 16 \\
\hline 54 & 2300 & 412736 & 4872127 & 43.9971 & -124.08838 & 29 & 26 \\
\hline 54 & 2400 & 412721 & 4871977 & 43.99575 & -124.08854 & 32 & 27 \\
\hline 54 & 2500 & 412695 & 4871796 & 43.99412 & -124.08883 & 30 & 24 \\
\hline 54 & 2600 & 412690 & 4871582 & 43.99219 & -124.08886 & 26 & 17 \\
\hline 54 & 2700 & 412683 & 4871421 & 43.99074 & -124.08892 & 34 & 23 \\
\hline 54 & 2800 & 412681 & 4871254 & 43.98924 & -124.08892 & 29 & 19 \\
\hline 54 & 2900 & 412693 & 4871156 & 43.98836 & -124.08875 & 27 & 20 \\
\hline 54 & 3000 & 412692 & 4871869 & 43.99477 & -124.08888 & 31 & 24 \\
\hline
\end{tabular}




\section{Appendix B- Groundwater Groundtruthing Locations and Elevations}

\begin{tabular}{|c|c|c|c|c|c|c|}
\hline ID & UTM E & UTM N & DTW(m) & $\mathbf{Z}$ & Latitude & Longitude \\
\hline 1 & 411829 & 4869625 & 3.7 & 4 & 43.97447 & -124.099 \\
\hline 2 & 411881 & 4869930 & 6 & 6 & 43.97722 & -124.099 \\
\hline 3 & 411881 & 4869979 & 3.3 & 5 & 43.97767 & -124.099 \\
\hline 4 & 411894 & 4872320 & 3.5 & 21 & 43.99874 & -124.099 \\
\hline 5 & 411941 & 4872405 & 3 & 22 & 43.99951 & -124.098 \\
\hline 6 & 411009 & 4868803 & 2 & 3 & 43.96697 & -124.109 \\
\hline 7 & 412626 & 4873393 & 2.4 & 30 & 44.00849 & -124.09 \\
\hline 8 & 412972 & 4872772 & 1.5 & 26 & 44.00294 & -124.086 \\
\hline 9 & 413195 & 4870802 & 1.5 & 5 & 43.98523 & -124.082 \\
\hline 10 & 412339 & 4871184 & 2 & 13 & 43.98857 & -124.093 \\
\hline 11 & 412282 & 4871079 & 3 & 15 & 43.98762 & -124.094 \\
\hline 12 & 410870 & 4871355 & 3 & 22 & 43.98993 & -124.112 \\
\hline 15 & 410628 & 4875418 & 1.5 & 30 & 44.02647 & -124.115 \\
\hline 16 & 411053 & 4875083 & 3.5 & 31 & 44.02351 & -124.11 \\
\hline 17 & 411114 & 4874779 & 1.5 & 33 & 44.02078 & -124.109 \\
\hline 18 & 413588 & 4877587 & 4 & 17 & 44.04635 & -124.079 \\
\hline 19 & 412590 & 4878505 & 3.7 & 15 & 44.0545 & -124.091 \\
\hline 20 & 411184 & 4878285 & 1.5 & 21 & 44.05235 & -124.109 \\
\hline 21 & 411281 & 4878505 & 1.2 & 21 & 44.05434 & -124.108 \\
\hline 23 & 411420 & 4868823 & 3 & 6 & 43.9672 & -124.104 \\
\hline 24 & 411703 & 4869753 & 6.8 & 5 & 43.97561 & -124.101 \\
\hline 27 & 412390 & 4869599 & 2.5 & 25 & 43.97431 & -124.092 \\
\hline 28 & 411694 & 4870281 & 4.6 & 38 & 43.98036 & -124.101 \\
\hline 29 & 410858 & 4882317 & 1 & 6 & 44.08861 & -124.114 \\
\hline 30 & 410779 & 4872314 & 1 & 6 & 43.99855 & -124.113 \\
\hline 31 & 411285 & 4872024 & 3 & 11 & 43.996 & -124.106 \\
\hline 32 & 411379 & 4871684 & 2 & 10 & 43.99295 & -124.105 \\
\hline 33 & 411808 & 4870646 & 7 & 53 & 43.98366 & -124.1 \\
\hline 34 & 411819 & 4879899 & 4 & 37 & 44.06696 & -124.101 \\
\hline 35 & 411936 & 4878906 & 4 & 16 & 44.05803 & -124.099 \\
\hline 37 & 412056 & 4878352 & 5.7 & 11 & 44.05306 & -124.098 \\
\hline 38 & 411886 & 4878050 & 3 & 26 & 44.05032 & -124.1 \\
\hline 39 & 411585 & 4875805 & 3 & 35 & 44.03007 & -124.103 \\
\hline 40 & 410399 & 4875648 & 2 & 30 & 44.02852 & -124.118 \\
\hline 41 & 409691 & 4874239 & 1.8 & 5 & 44.01575 & -124.127 \\
\hline 42 & 412220 & 4872779 & 2 & 23 & 44.00291 & -124.095 \\
\hline
\end{tabular}




\begin{tabular}{|c|c|c|c|c|c|c|c|}
\hline 43 & 412253 & 4873192 & 2.8 & 25 & 44.00663 & -124.095 & \\
\hline 44 & 412070 & 4872137 & 2 & 19 & 43.99711 & -124.097 & \\
\hline 45 & 412285 & 4871069 & 3 & 15 & 43.98753 & -124.094 & \\
\hline 46 & 412306 & 4870967 & 3.7 & 13 & 43.98661 & -124.094 & \\
\hline 47 & 412435 & 4870520 & 2.9 & 10 & 43.9826 & -124.092 & \\
\hline 48 & 410879 & 4868782 & 2 & 0 & 43.96677 & -124.111 & \\
\hline 49 & 410266 & 4861484 & 4.2 & 6 & 43.901 & -124.117 & \\
\hline 50 & 412325 & 4871185 & 2.8 & 13 & 43.98857 & -124.093 & \\
\hline 51 & 411077 & 4873805 & 1 & 36 & 44.01201 & -124.109 & \\
\hline 52 & 413059 & 4874839 & 1 & 31 & 44.02155 & -124.085 & \\
\hline 53 & 411819 & 4879899 & & 37 & 44.06696 & -124.101 & Dune Lake \\
\hline 54 & 411353 & 4871435 & & 19 & 43.99071 & -124.106 & Lake Marr \\
\hline 55 & 411595 & 4870820 & & 30 & 43.9852 & -124.102 & $\begin{array}{l}\text { Nott Lake } \\
\text { Mussel Lake }\end{array}$ \\
\hline 56 & 411560 & 4870596 & & 43 & 43.98318 & -124.103 & $\begin{array}{l}\text { a } \\
\text { Mussel Lake }\end{array}$ \\
\hline 57 & 411560 & 4870543 & & 44 & 43.9827 & -124.103 & $\begin{array}{l}\mathrm{b} \\
\text { Mussel Lake }\end{array}$ \\
\hline 58 & 411720 & 4870575 & & 48 & 43.98301 & -124.101 & $\mathrm{c}$ \\
\hline 59 & 411633 & 4870345 & & 37 & 43.98093 & -124.102 & Alder Lake \\
\hline 60 & 411930 & 4879712 & & 37 & 44.06529 & -124.1 & Buck Lake \\
\hline 61 & 412211 & 4878773 & & 10 & 44.05687 & -124.096 & Sutton Lake \\
\hline 62 & 413818 & 4877772 & & 10 & 44.04805 & -124.076 & $\begin{array}{l}\text { Mercer Lake } \\
\text { North Collard }\end{array}$ \\
\hline 63 & 413604 & 4876813 & & 36 & 44.03939 & -124.078 & $\begin{array}{l}\text { Lake } \\
\text { Centeral }\end{array}$ \\
\hline 64 & 413575 & 4876518 & & 37 & 44.03673 & -124.079 & $\begin{array}{l}\text { Collard Lake } \\
\text { South Collard }\end{array}$ \\
\hline 65 & 413594 & 4876166 & & 37 & 44.03356 & -124.078 & Lake \\
\hline 66 & 413442 & 4874949 & & 30 & 44.02259 & -124.08 & Clear Lake \\
\hline 67 & 413269 & 4874014 & & 30 & 44.01415 & -124.082 & Ackerly Lake \\
\hline 68 & 413019 & 4873206 & & 28 & 44.00685 & -124.085 & $\begin{array}{l}\text { Munsel Lake } \\
\text { Golf Course }\end{array}$ \\
\hline 69 & 410526 & 4872662 & & 21 & 44.00165 & -124.116 & $\begin{array}{l}\text { Lake } 1 \\
\text { Golf Course }\end{array}$ \\
\hline 70 & 410814 & 4872516 & & 25 & 44.00037 & -124.112 & $\begin{array}{l}\text { Lake } 2 \\
\text { Heceta Beach }\end{array}$ \\
\hline 71 & 410935 & 4874761 & & 37 & 44.0206 & -124.111 & $\begin{array}{l}\text { Road } \\
\text { Lake Point }\end{array}$ \\
\hline 72 & 411056 & 4875277 & & 32 & 44.02526 & -124.11 & $\begin{array}{l}\text { Drive } \\
\text { Unnamed }\end{array}$ \\
\hline 73 & 410261 & 4876033 & & 29 & 44.03197 & -124.12 & Lake \\
\hline
\end{tabular}




\section{Appendix C- GPR Line Metadata}

\begin{tabular}{|c|c|c|c|}
\hline \multirow[t]{2}{*}{ Line } & Distance (m) & \multirow{2}{*}{$\begin{array}{l}\text { Date Colleced } \\
\text { June } 132011\end{array}$} & \multirow{2}{*}{$\begin{array}{l}\text { Antennae } \\
\text { Frequency } \\
50 \mathrm{mHz}\end{array}$} \\
\hline & 1855 & & \\
\hline 4 & 3730 & June 132011 & $50 \mathrm{mHz}$ \\
\hline 5 & 3645 & June 132011 & $50 \mathrm{mHz}$ \\
\hline 6 & 1650 & June 132011 & $50 \mathrm{mHz}$ \\
\hline 8 & 1410 & June 132011 & $50 \mathrm{mHz}$ \\
\hline 11 & 7200 & June 132011 & $50 \mathrm{mHz}$ \\
\hline 12 & 5200 & June 132011 & $50 \mathrm{mHz}$ \\
\hline 13 & 6600 & June 132011 & $50 \mathrm{mHz}$ \\
\hline 14 & 9200 & June 292011 & $50 \mathrm{mHz}$ \\
\hline 15 & 917 & June 292011 & $50 \mathrm{mHz}$ \\
\hline 16 & 307 & June 292011 & $50 \mathrm{mHz}$ \\
\hline 17 & 505 & June 292011 & $50 \mathrm{mHz}$ \\
\hline 18 & 1300 & June 292011 & $50 \mathrm{mHz}$ \\
\hline 19 & 1335 & June 292011 & $50 \mathrm{mHz}$ \\
\hline 20 & 4620 & June 292011 & $50 \mathrm{mHz}$ \\
\hline 21 & 778 & June 292011 & $50 \mathrm{mHz}$ \\
\hline 22 & 1565 & June 292011 & $50 \mathrm{mHz}$ \\
\hline 23 & 364 & June 292011 & $50 \mathrm{mHz}$ \\
\hline 24 & 757 & June 292011 & $50 \mathrm{mHz}$ \\
\hline 25 & 1217 & June 292011 & $50 \mathrm{mHz}$ \\
\hline 26 & 583 & June 292011 & $50 \mathrm{mHz}$ \\
\hline 27 & 1000 & June 292011 & $50 \mathrm{mHz}$ \\
\hline 28 & 797 & June 292011 & $50 \mathrm{mHz}$ \\
\hline 29 & 2466 & June 292011 & $50 \mathrm{mHz}$ \\
\hline 30 & 266 & June 292011 & $50 \mathrm{mHz}$ \\
\hline 31 & 1600 & June 292011 & $50 \mathrm{mHz}$ \\
\hline 32 & 1153 & June 292011 & $50 \mathrm{mHz}$ \\
\hline 33 & 1961 & June 292011 & $50 \mathrm{mHz}$ \\
\hline 34 & 977 & June 292011 & $50 \mathrm{mHz}$ \\
\hline 35 & 2700 & June 292011 & $50 \mathrm{mHz}$ \\
\hline 37 & 1364 & June 292011 & $50 \mathrm{mHz}$ \\
\hline 38 & 1368 & June 292011 & $50 \mathrm{mHz}$ \\
\hline 39 & 2059 & June 292011 & $50 \mathrm{mHz}$ \\
\hline 40 & 1700 & June 292011 & $50 \mathrm{mHz}$ \\
\hline 41 & 4905 & September 62011 & $100 \mathrm{mHz}$ \\
\hline 44 & 700 & September 62011 & $100 \mathrm{mHz}$ \\
\hline 47 & 1350 & September 62011 & $100 \mathrm{mHz}$ \\
\hline 48 & 964 & September 72011 & $100 \mathrm{mHz}$ \\
\hline 49 & 3168 & September 72011 & $100 \mathrm{mHz}$ \\
\hline 50 & 1886 & September 72011 & $100 \mathrm{mHz}$ \\
\hline 51 & 1977 & September 72011 & $100 \mathrm{mHz}$ \\
\hline 52 & 1300 & September 72011 & $100 \mathrm{mHz}$ \\
\hline 53 & 1579 & September 72011 & $100 \mathrm{mHz}$ \\
\hline 54 & 3000 & September 72011 & $100 \mathrm{mHz}$ \\
\hline
\end{tabular}




\section{Appendix D- GPR Subsurface Images}

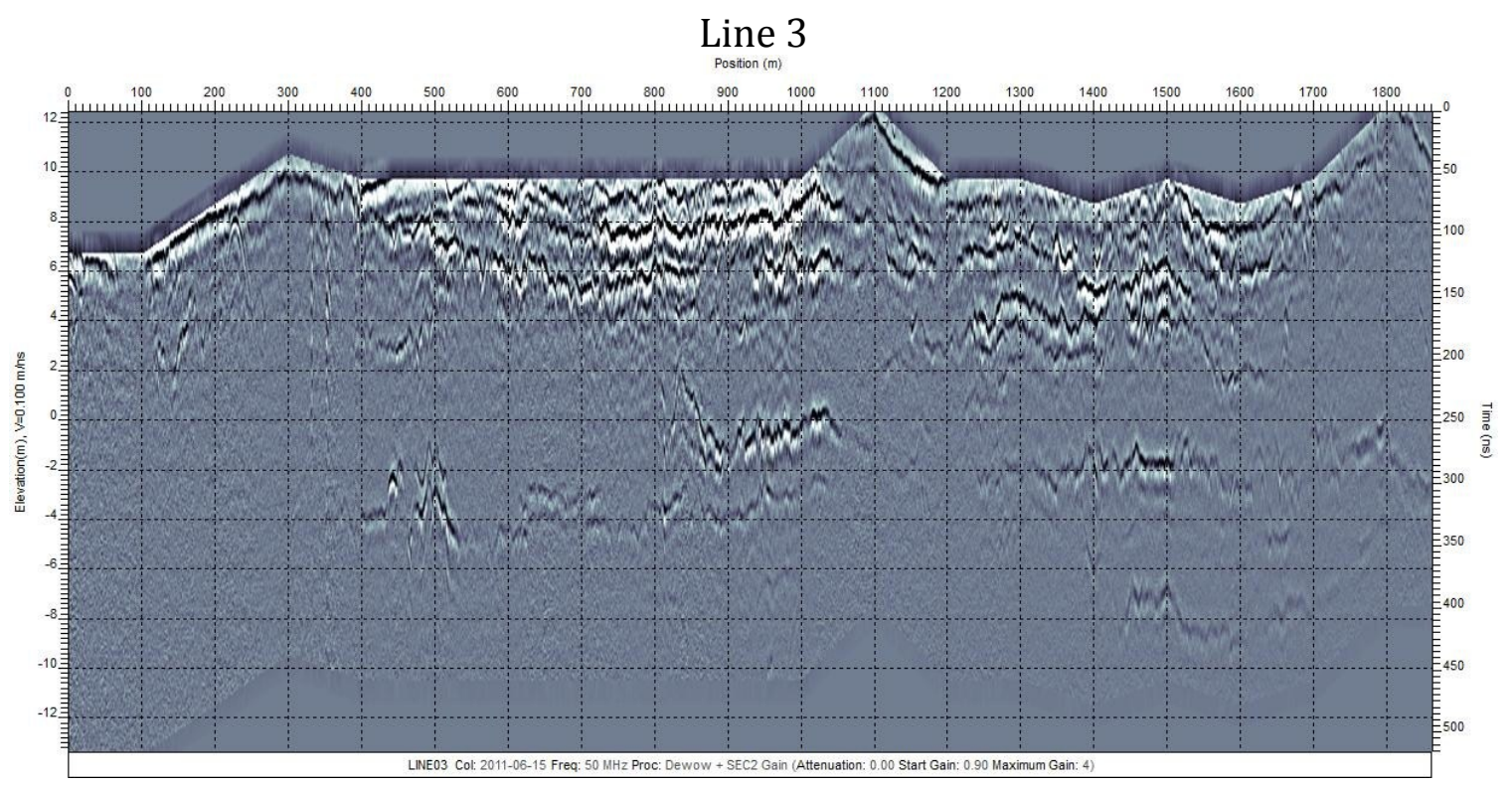

Line 4

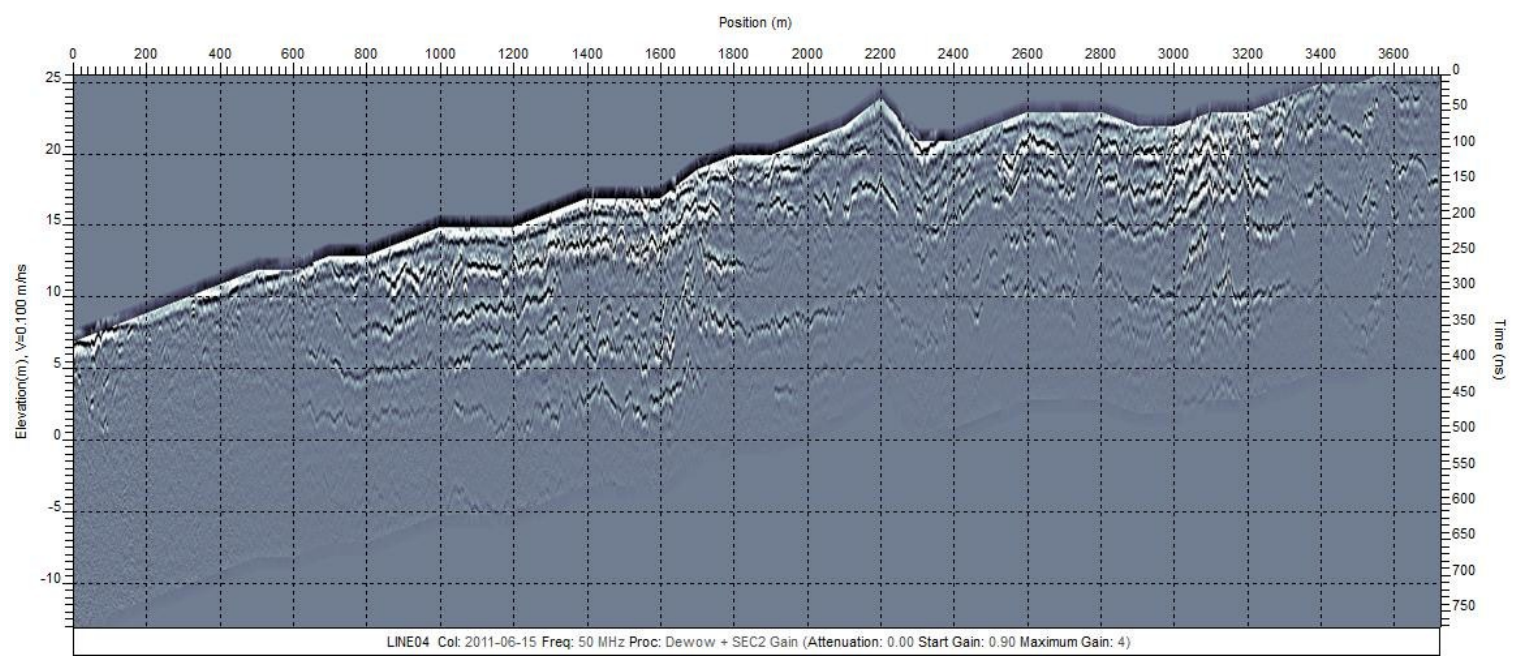


Line 5

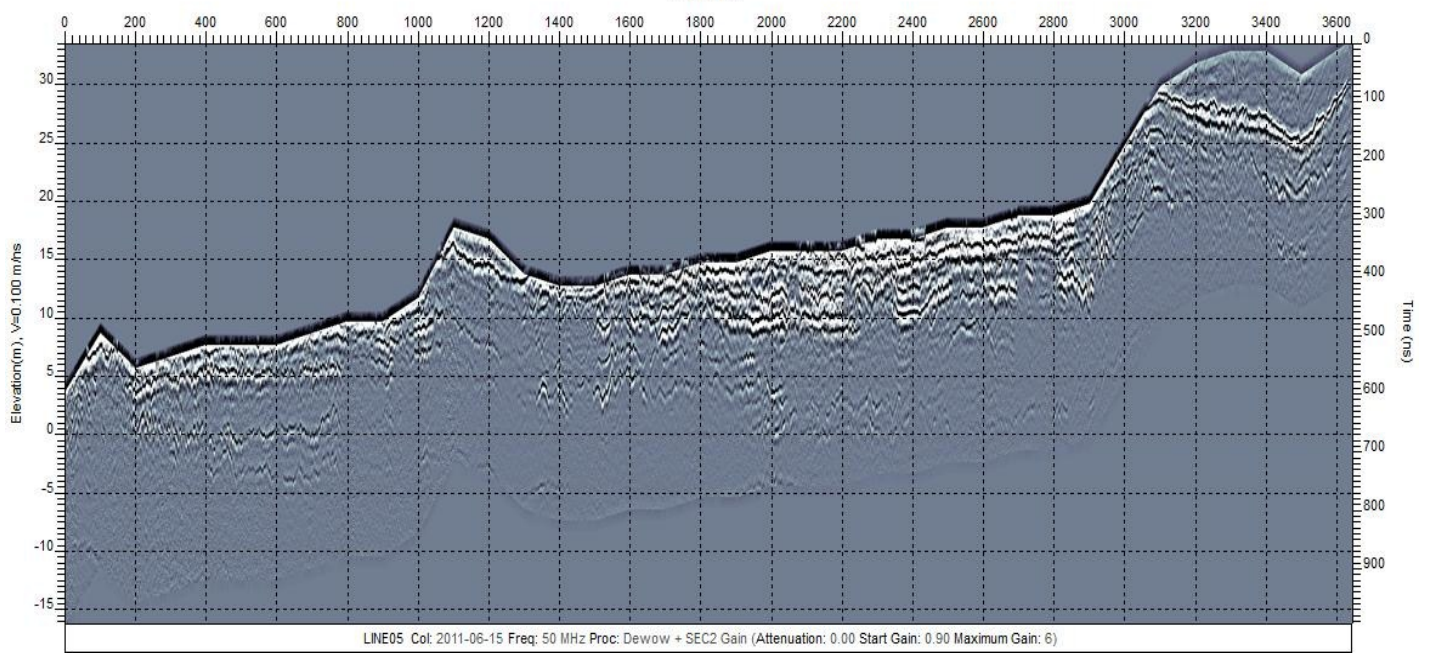

Line 6

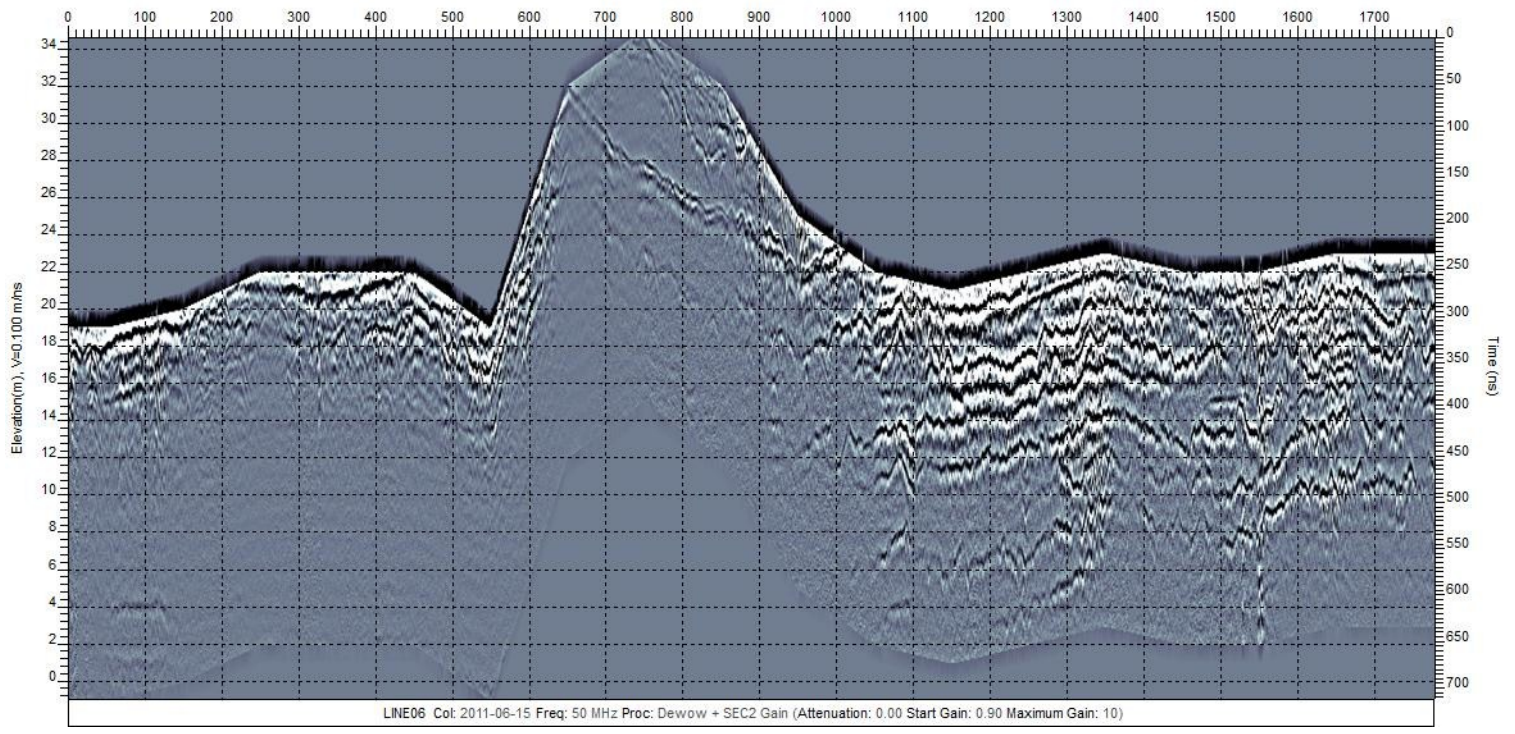



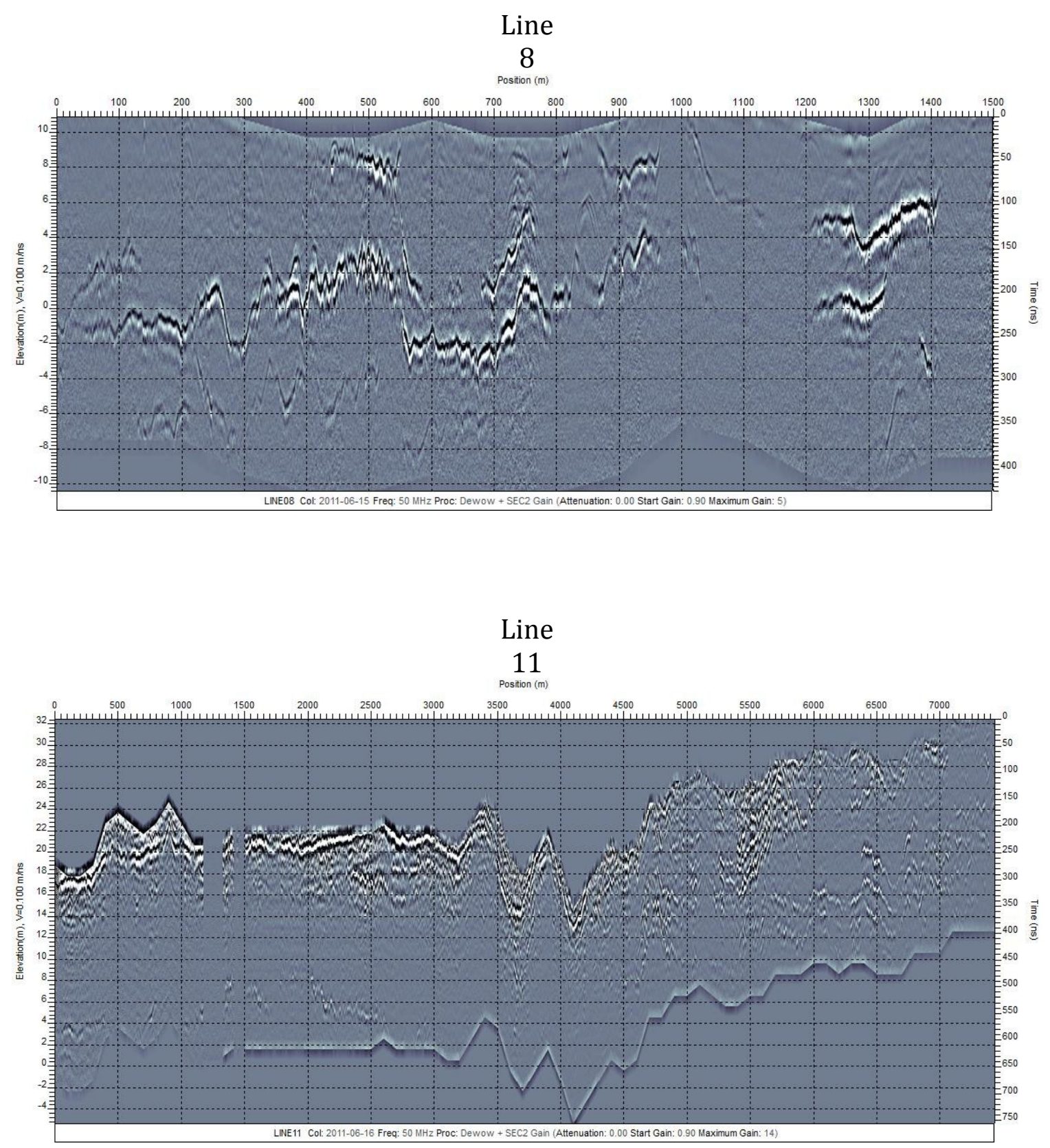


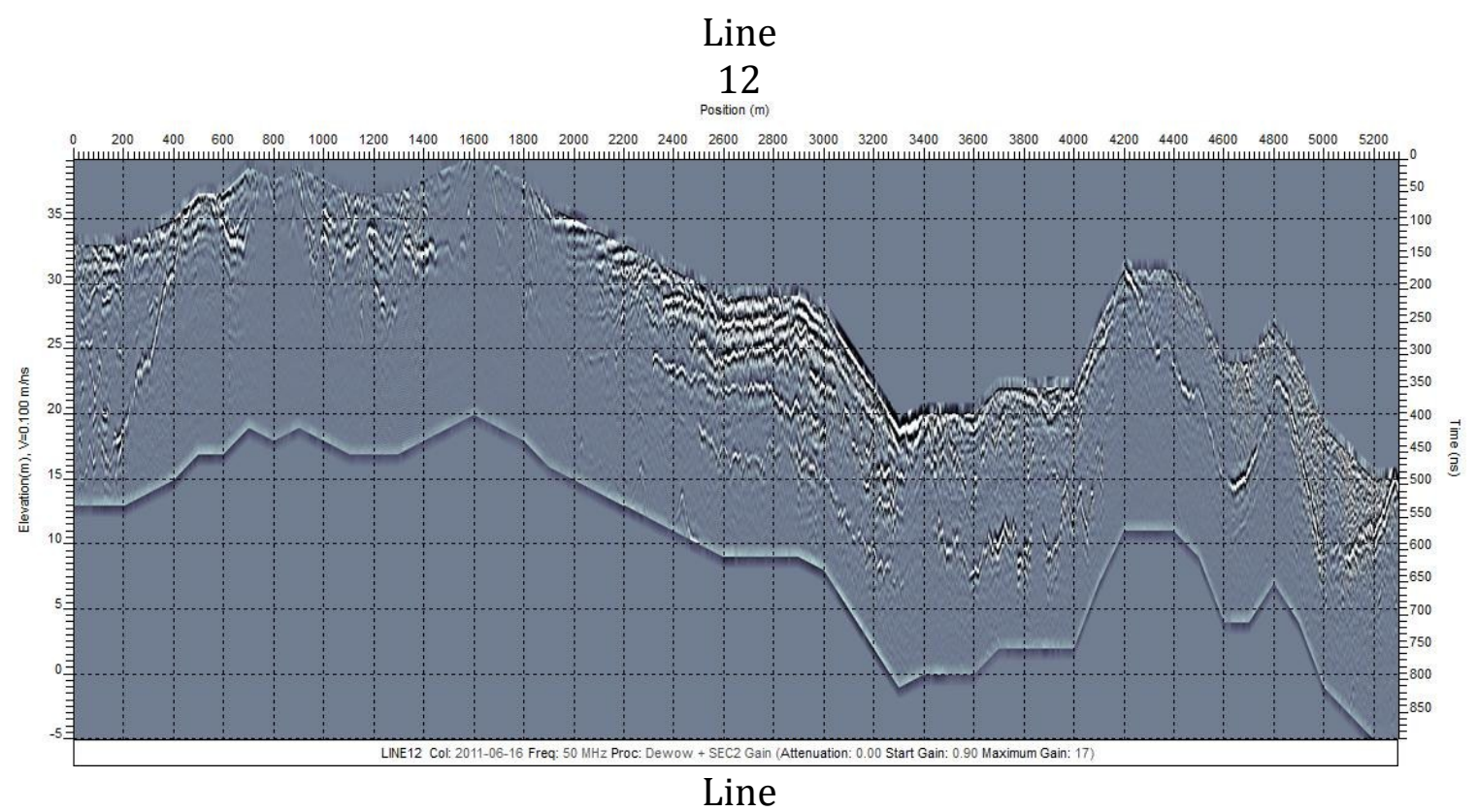

13

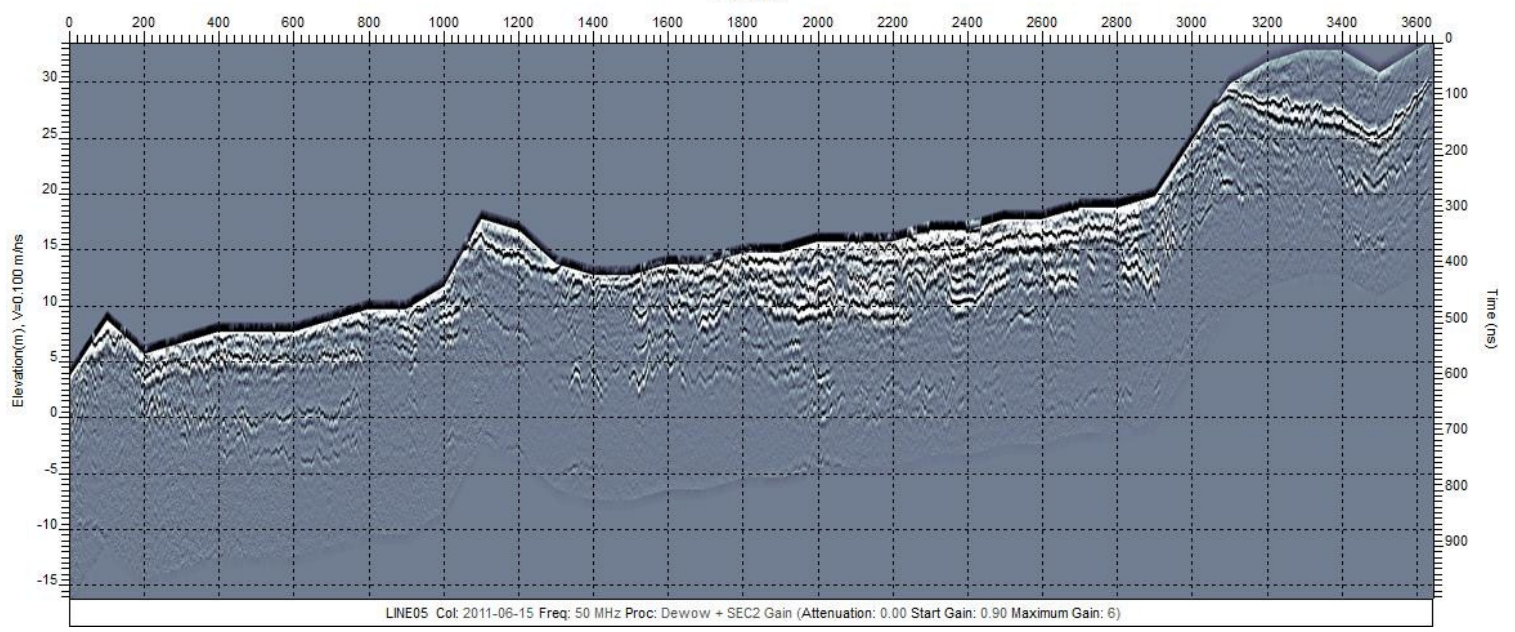




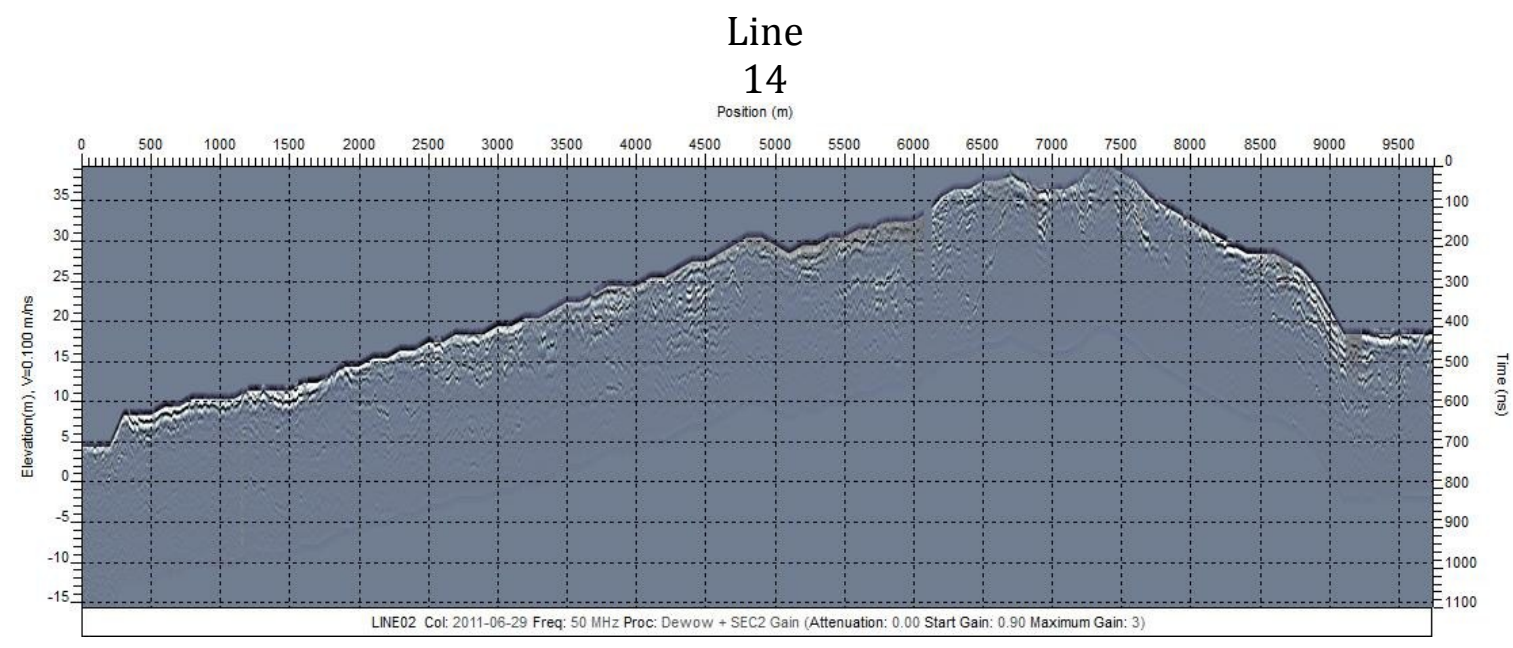

Line 15

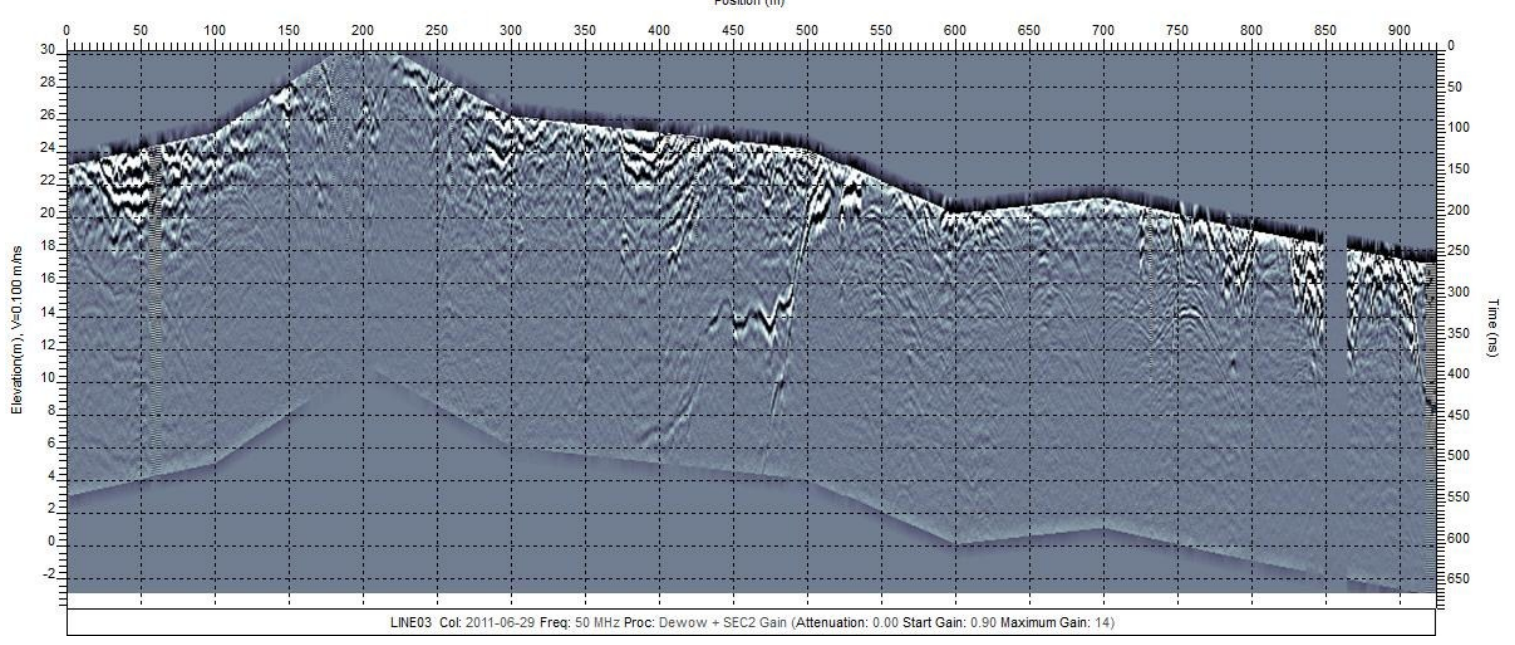




\section{Line 16}
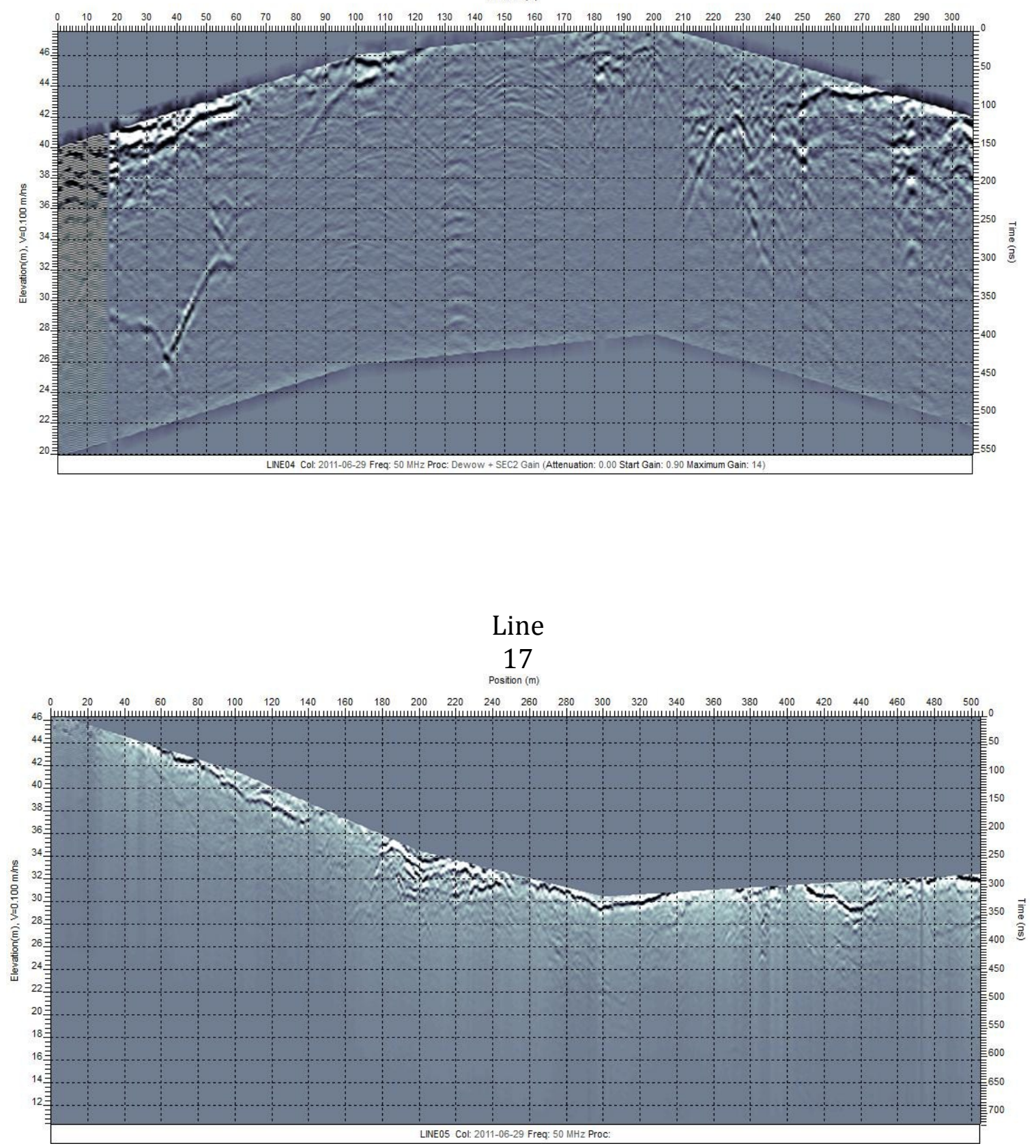

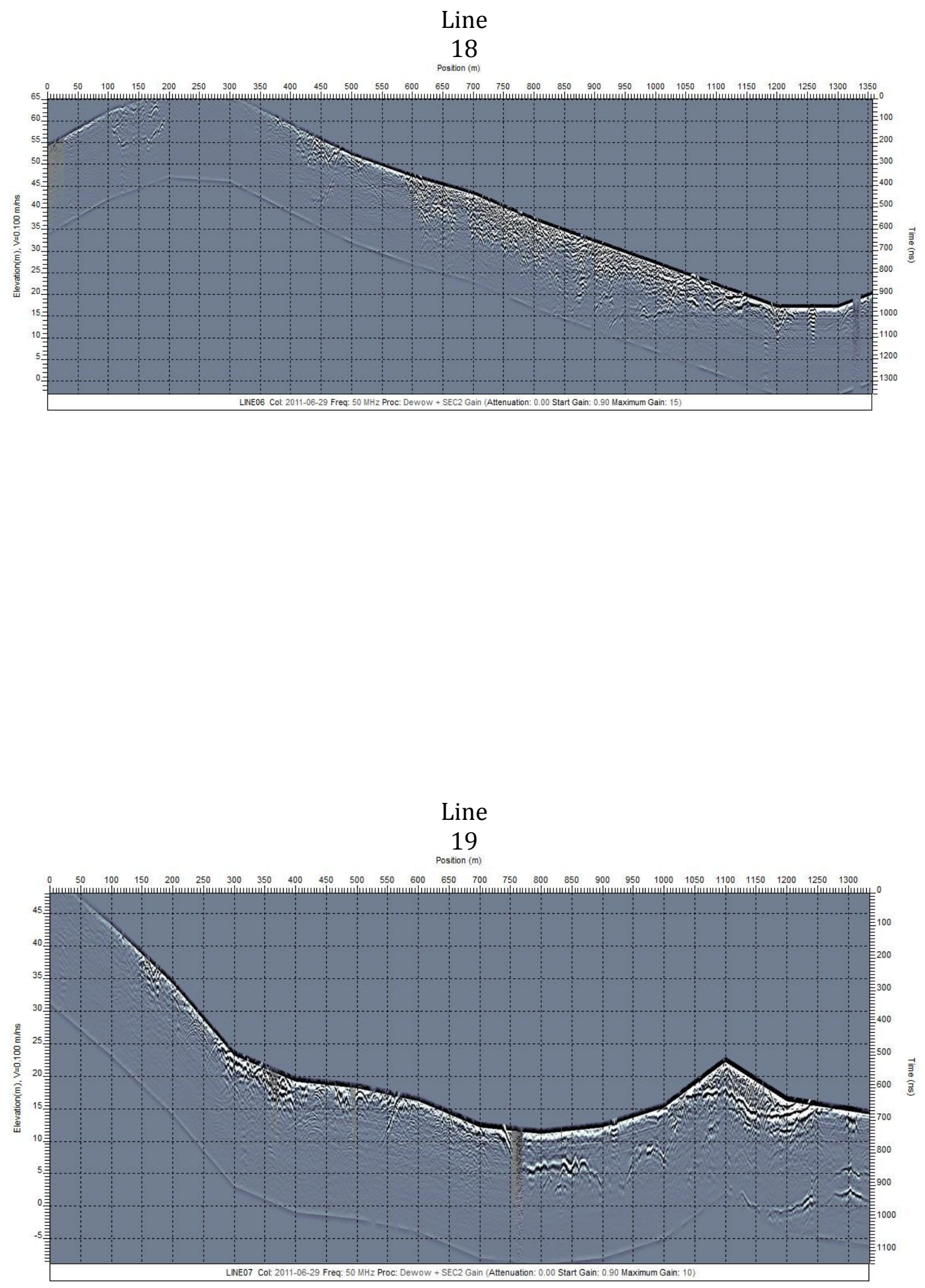


\section{Line}

20

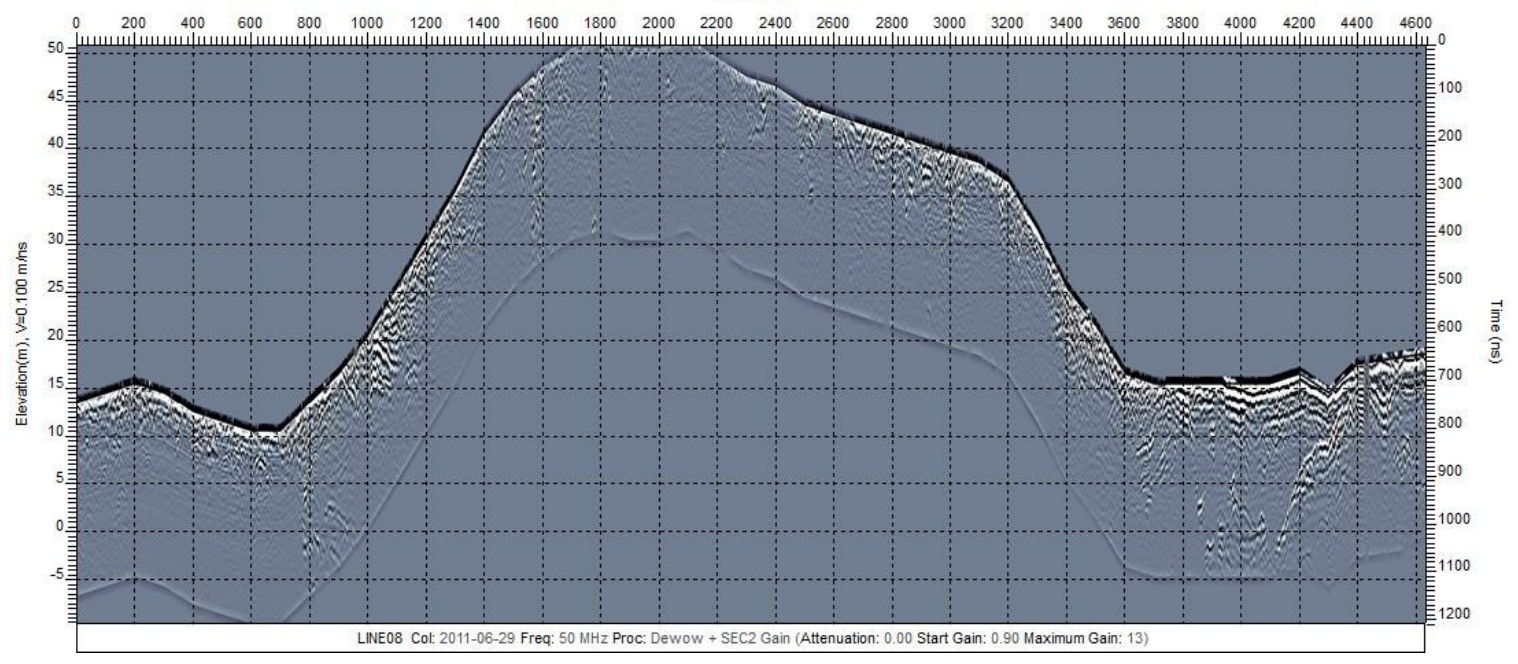



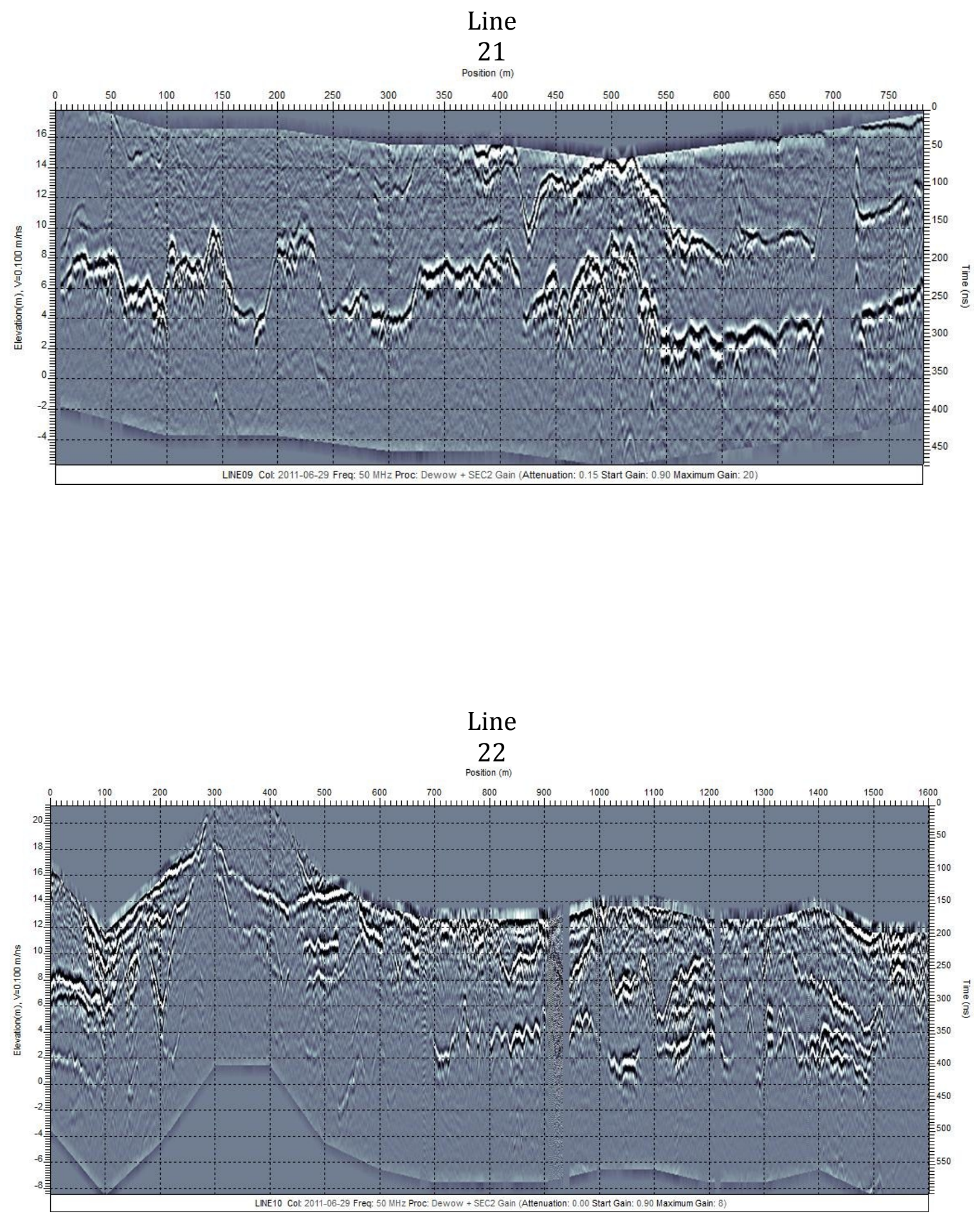
Line

23
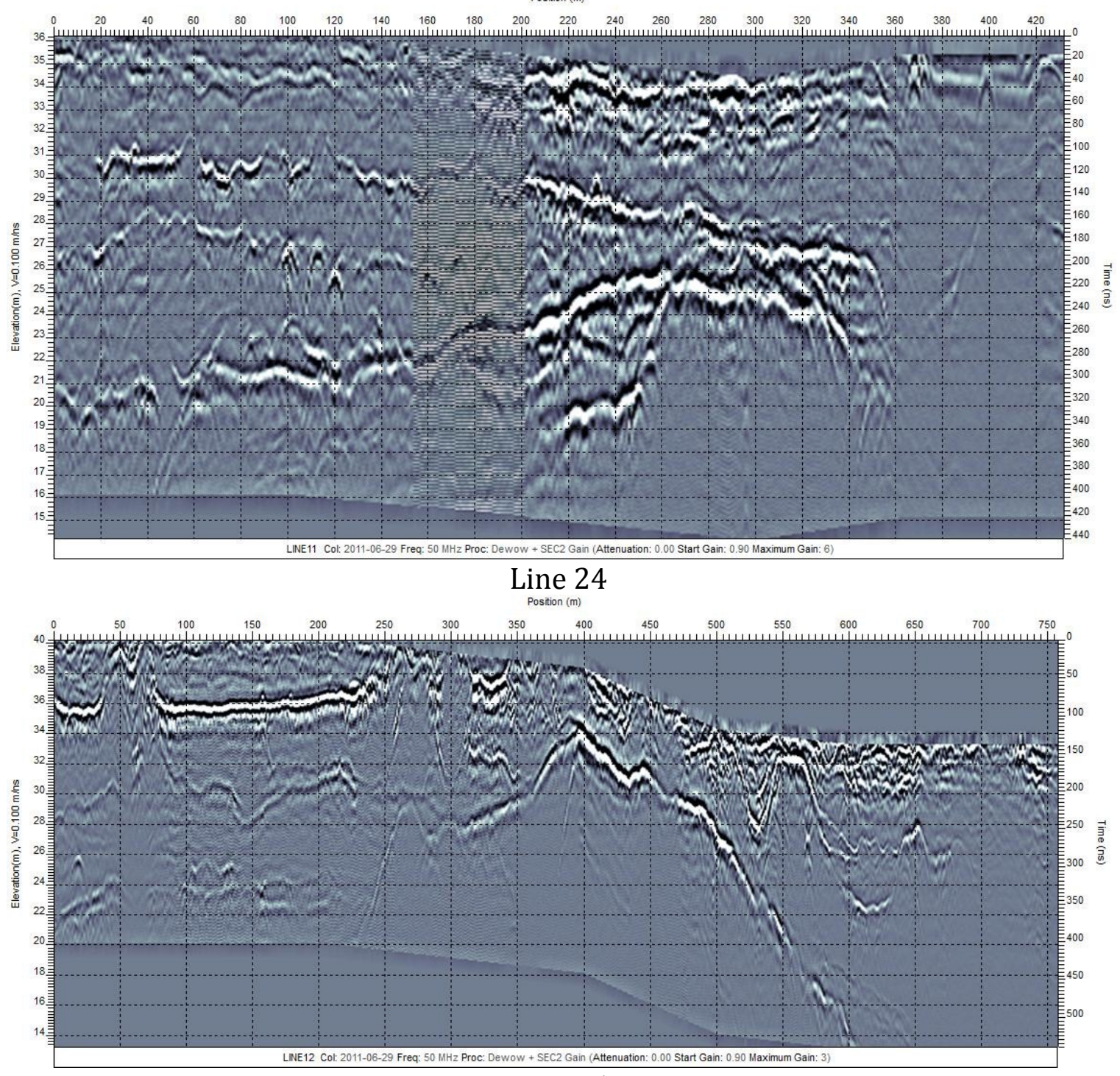

Line 25 


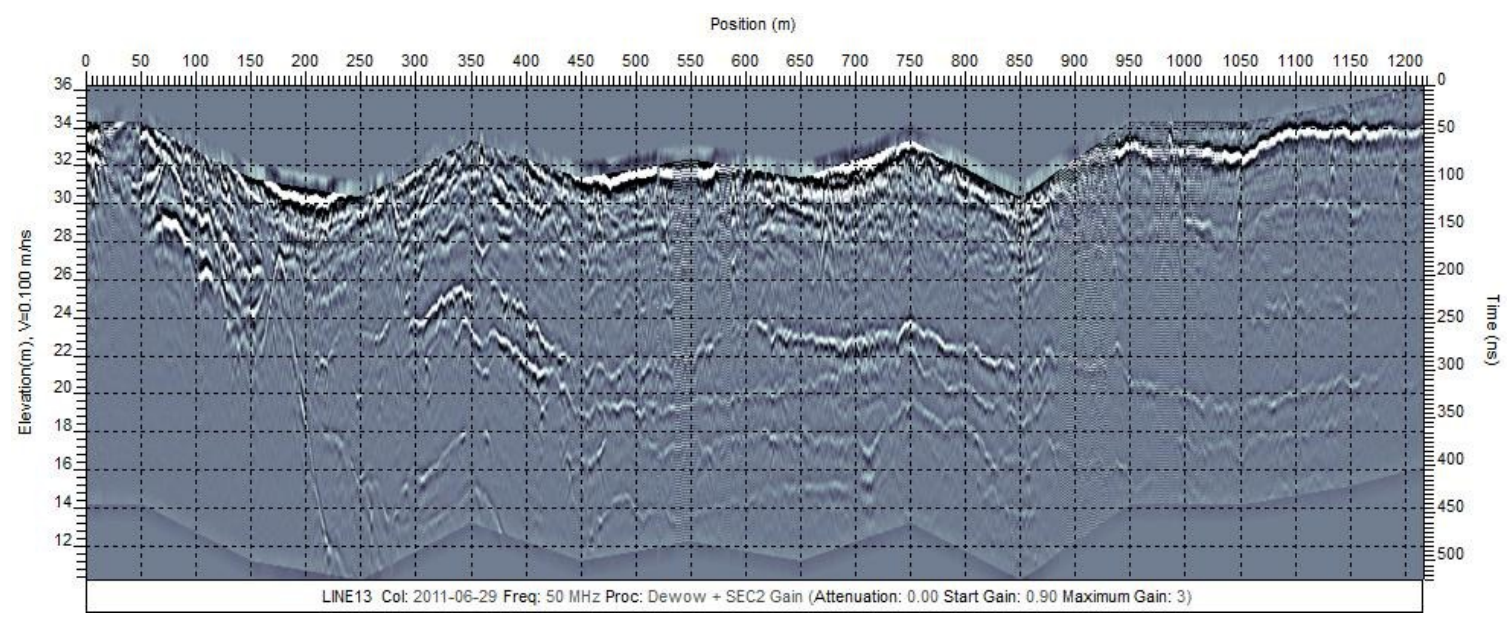

\section{Line}

26

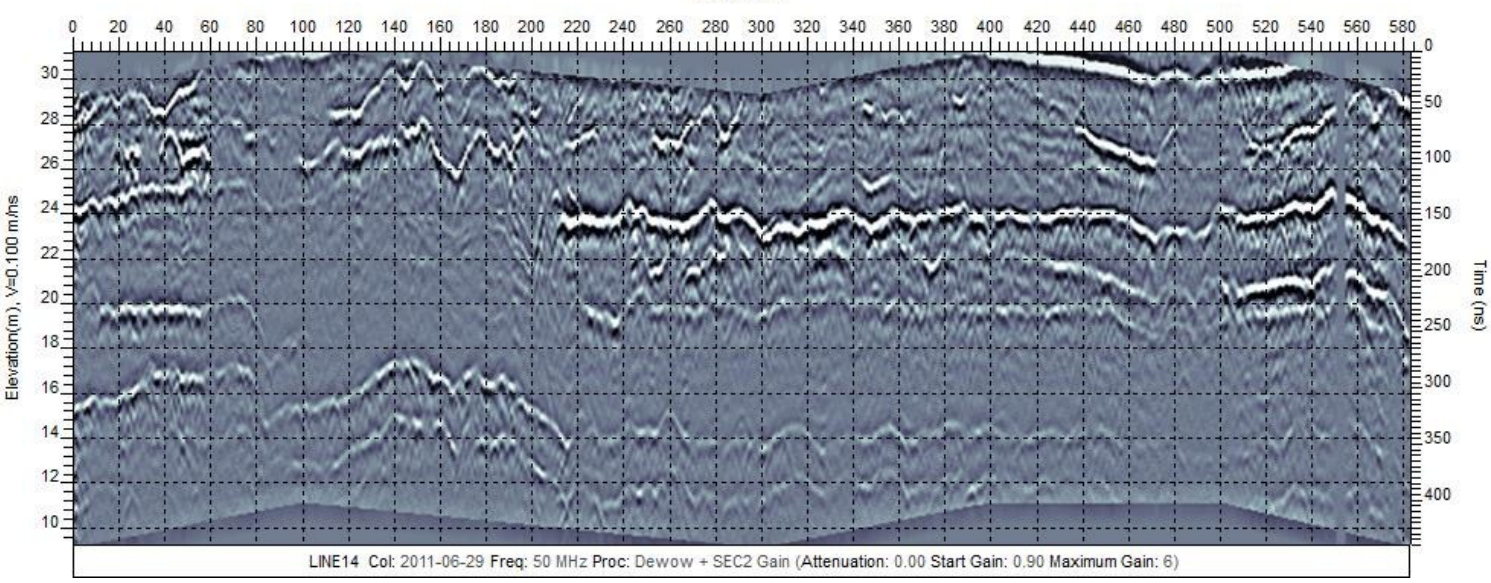

\section{Line 27}

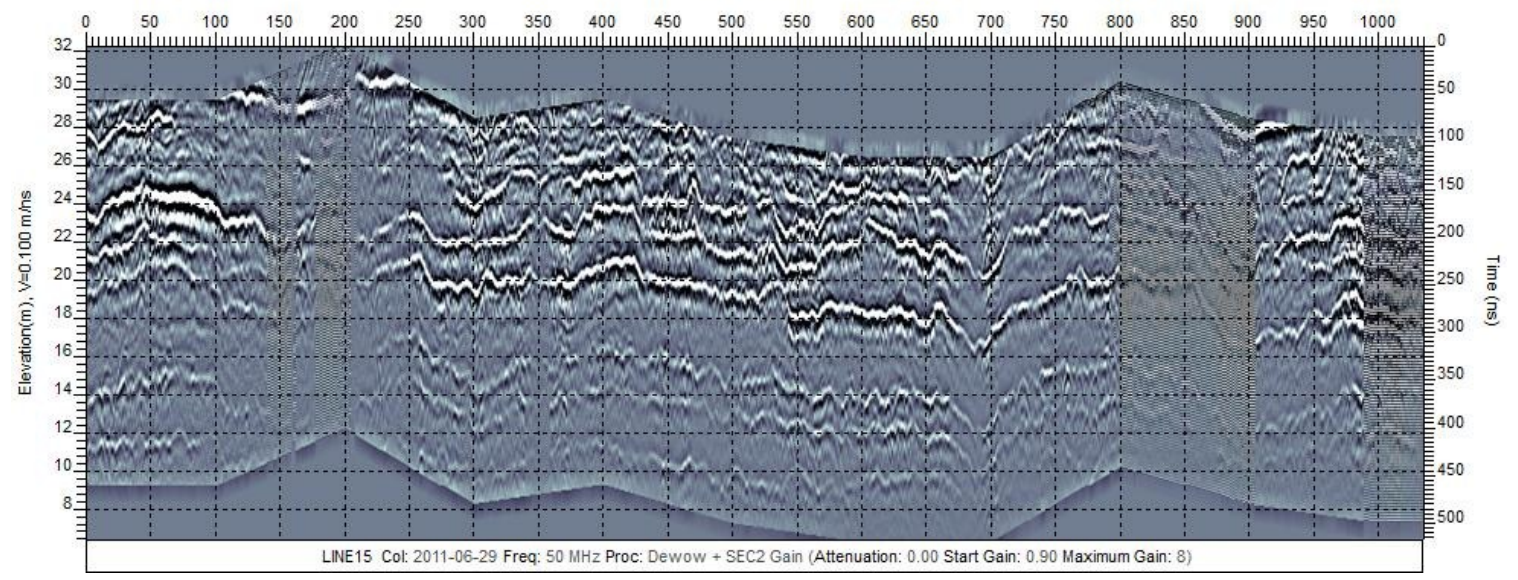



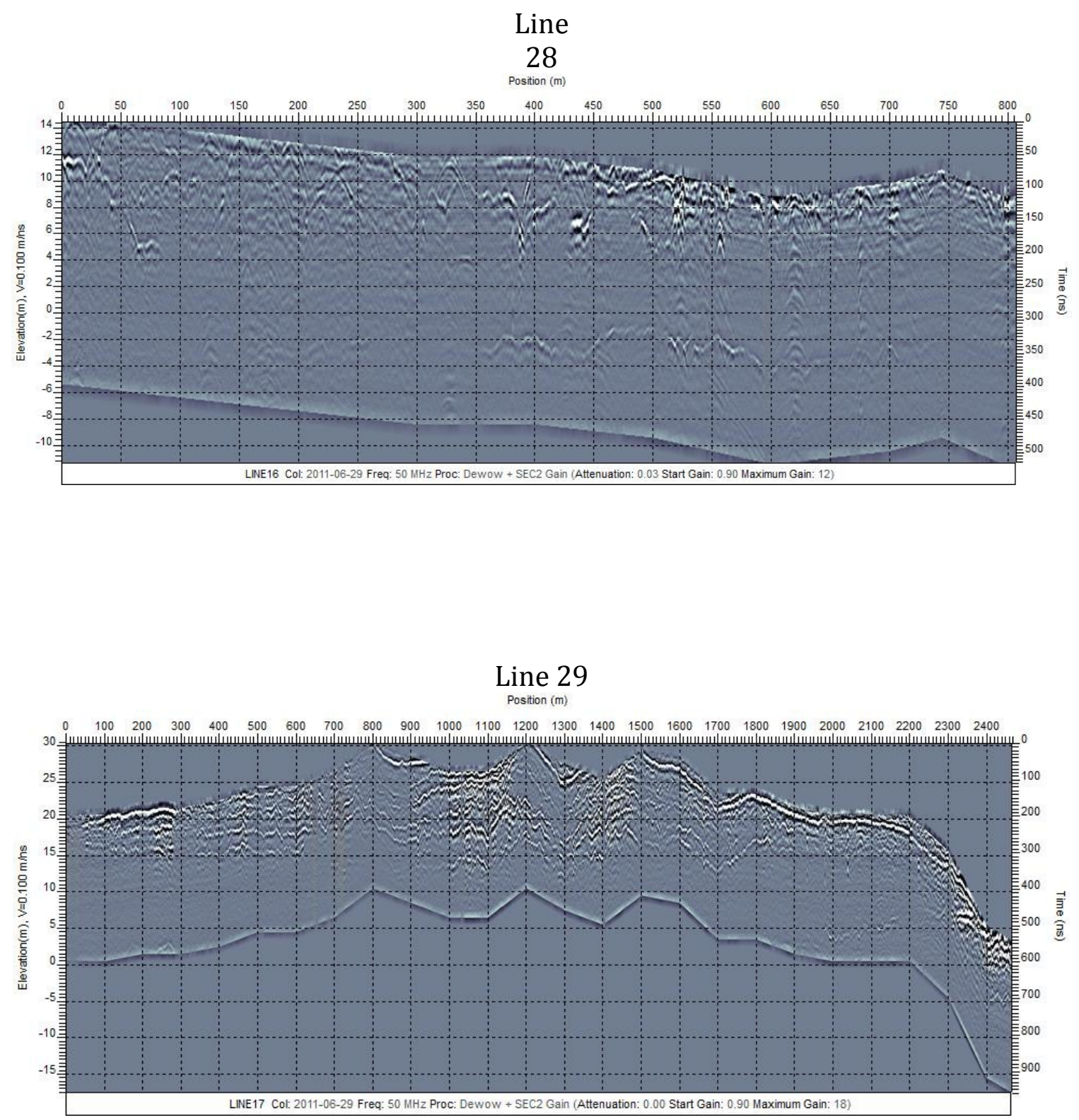


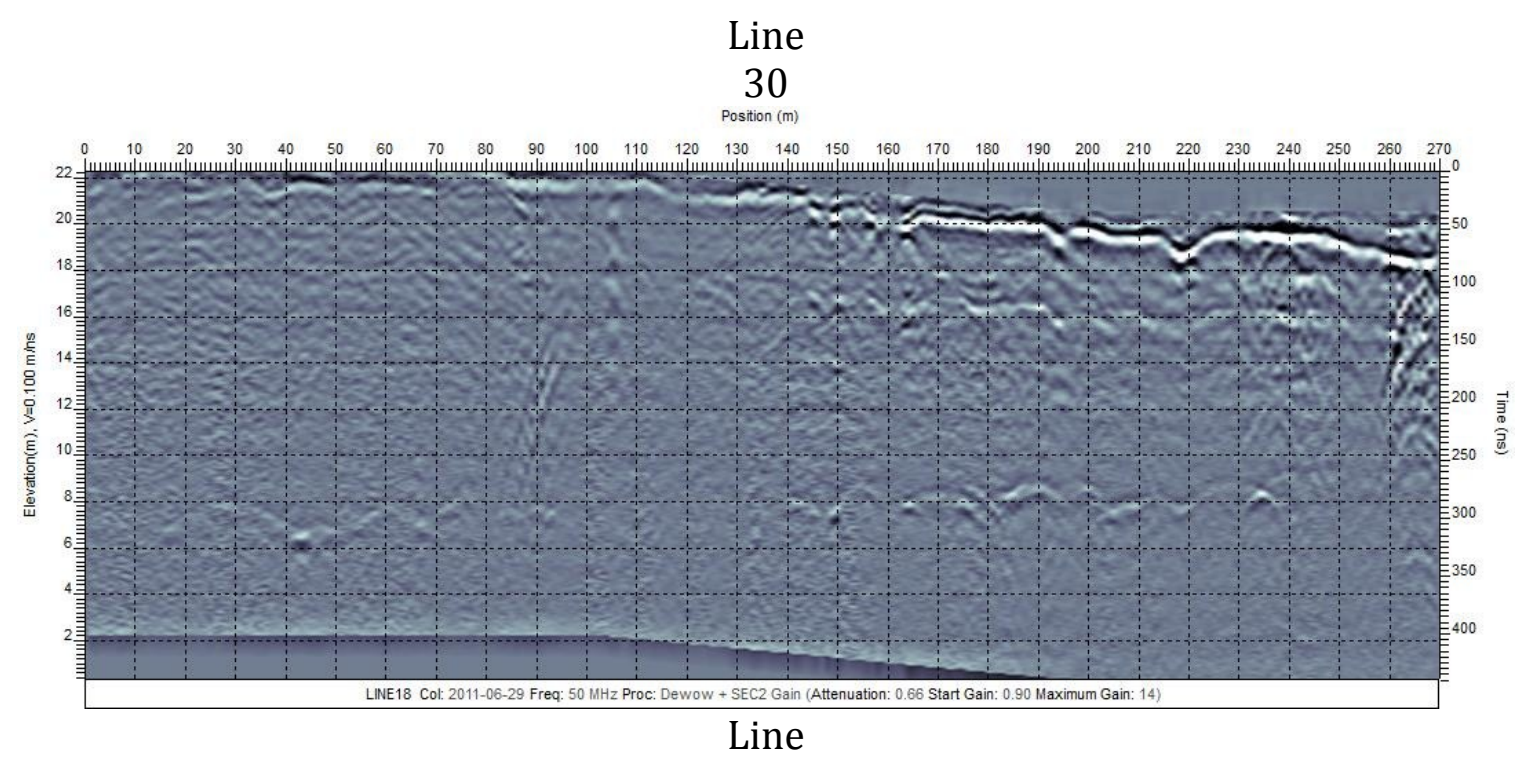

31

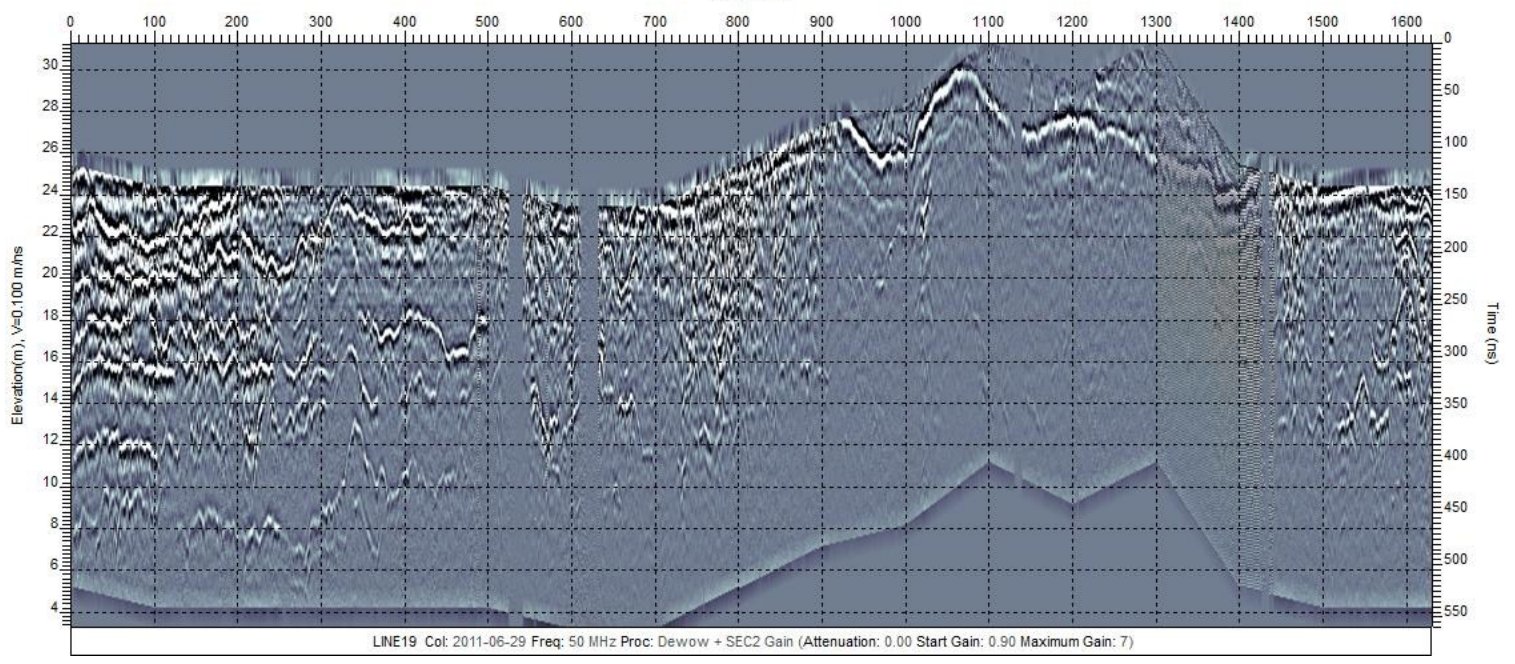




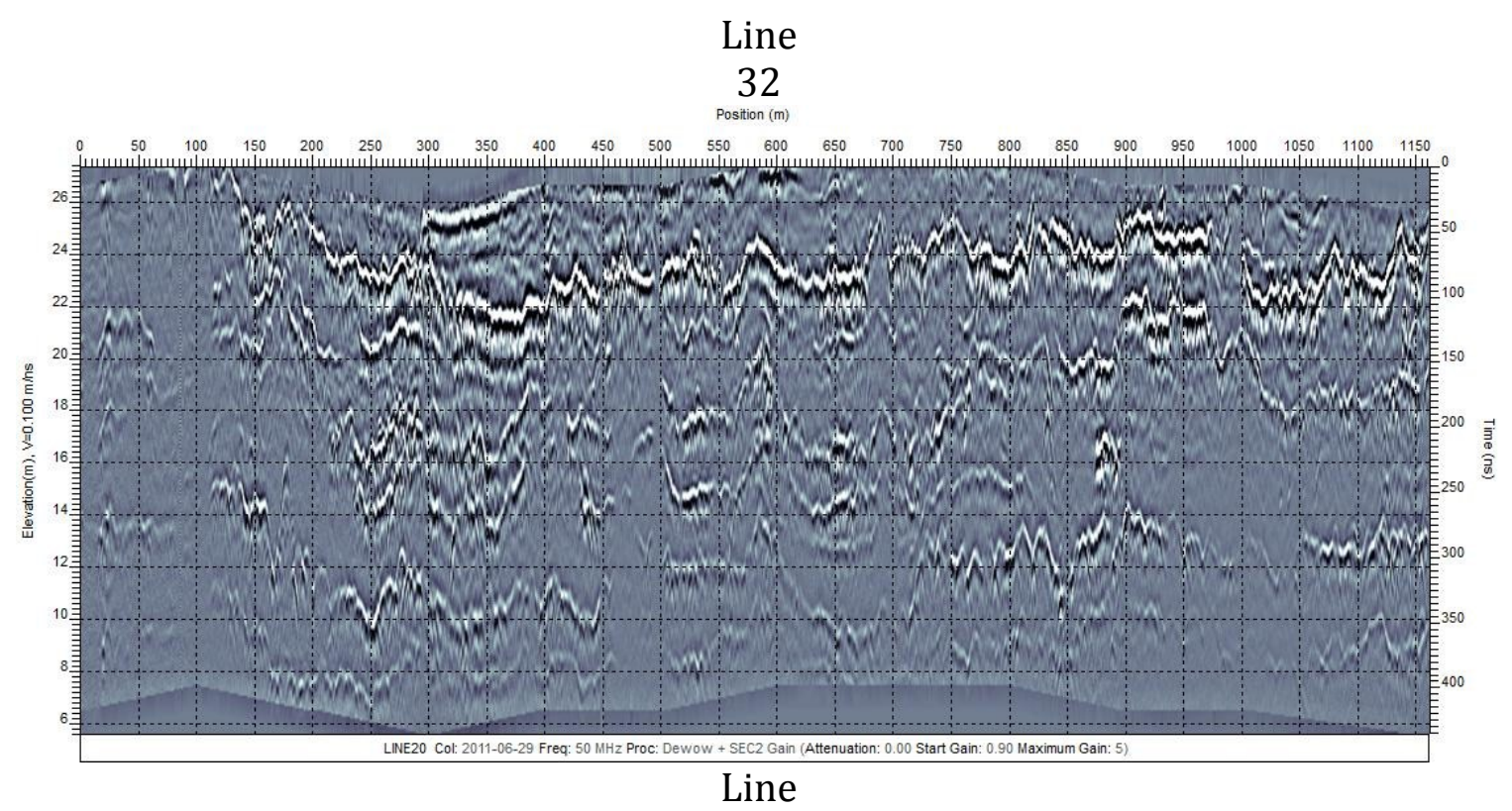

33

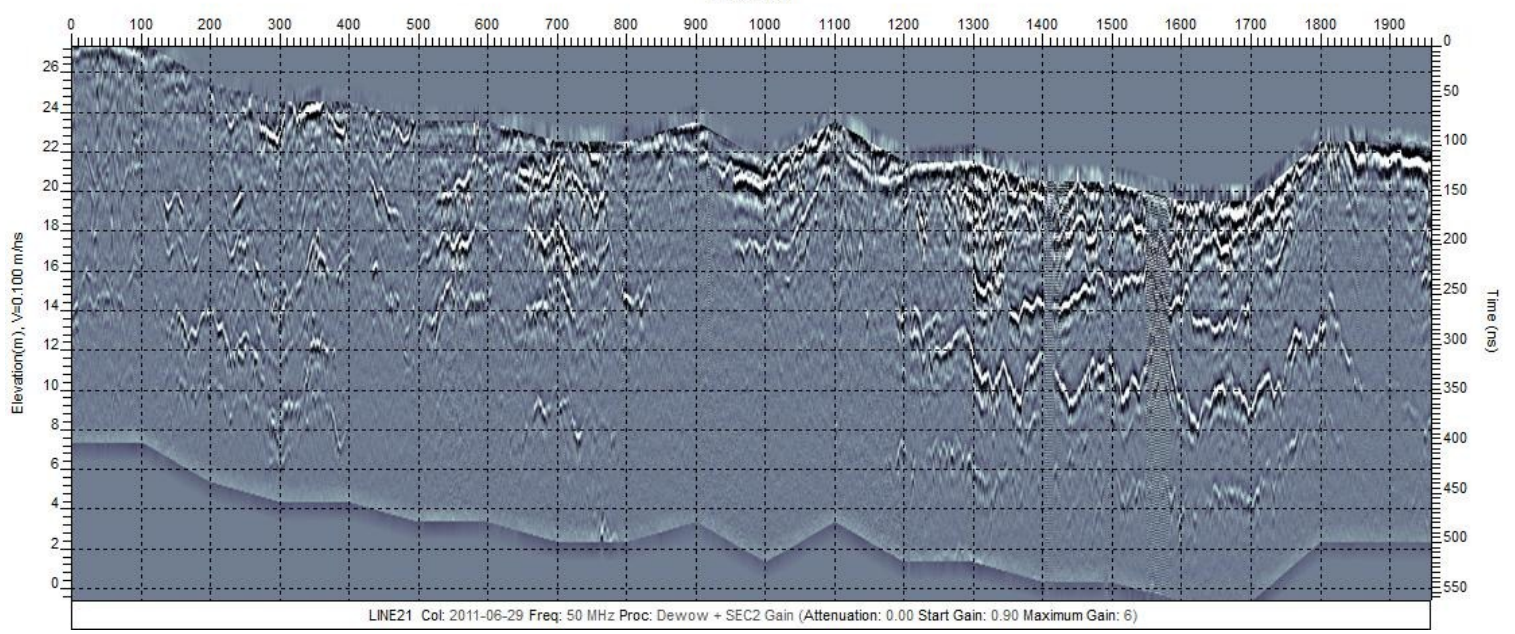




\section{Line 34}
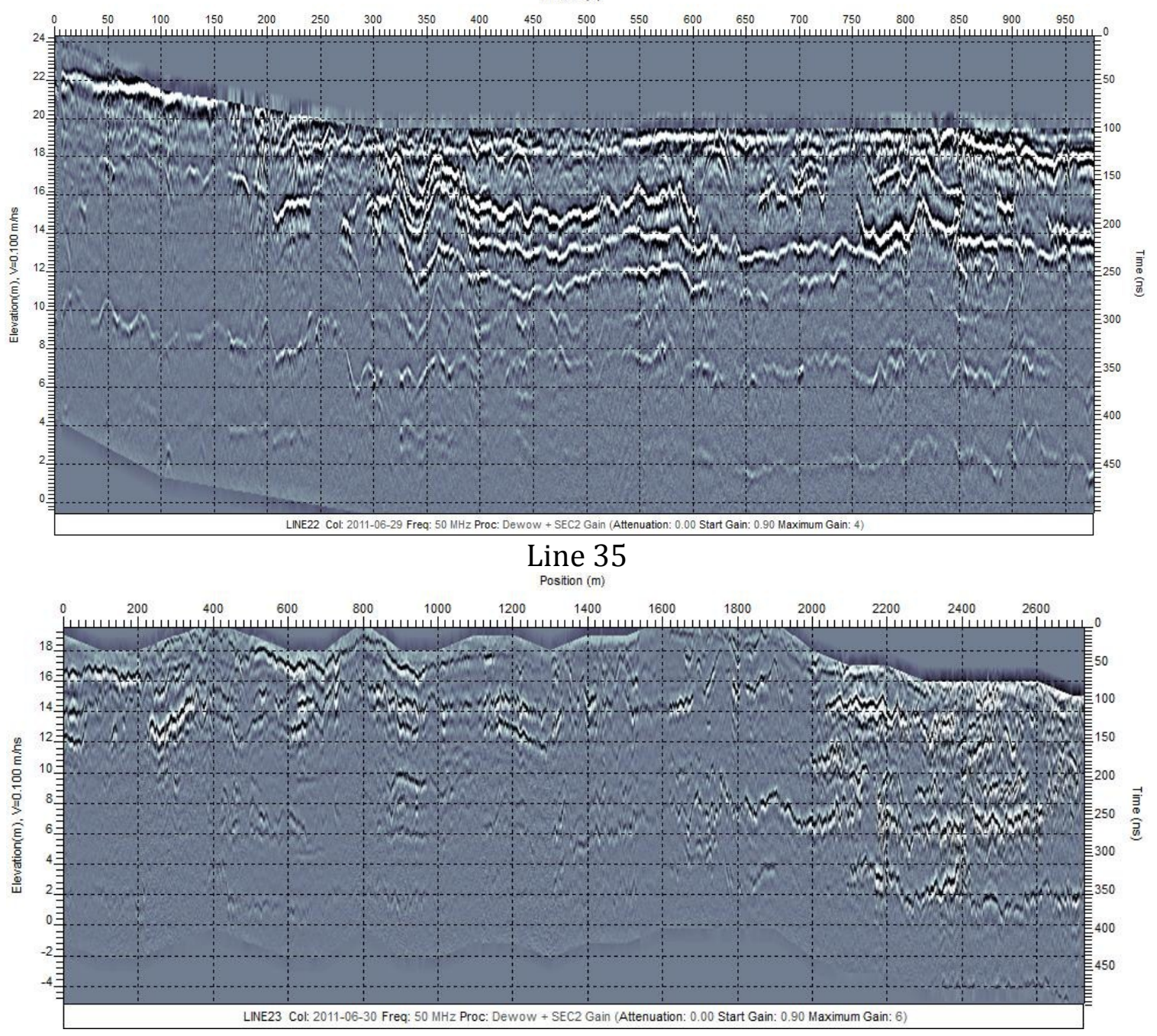


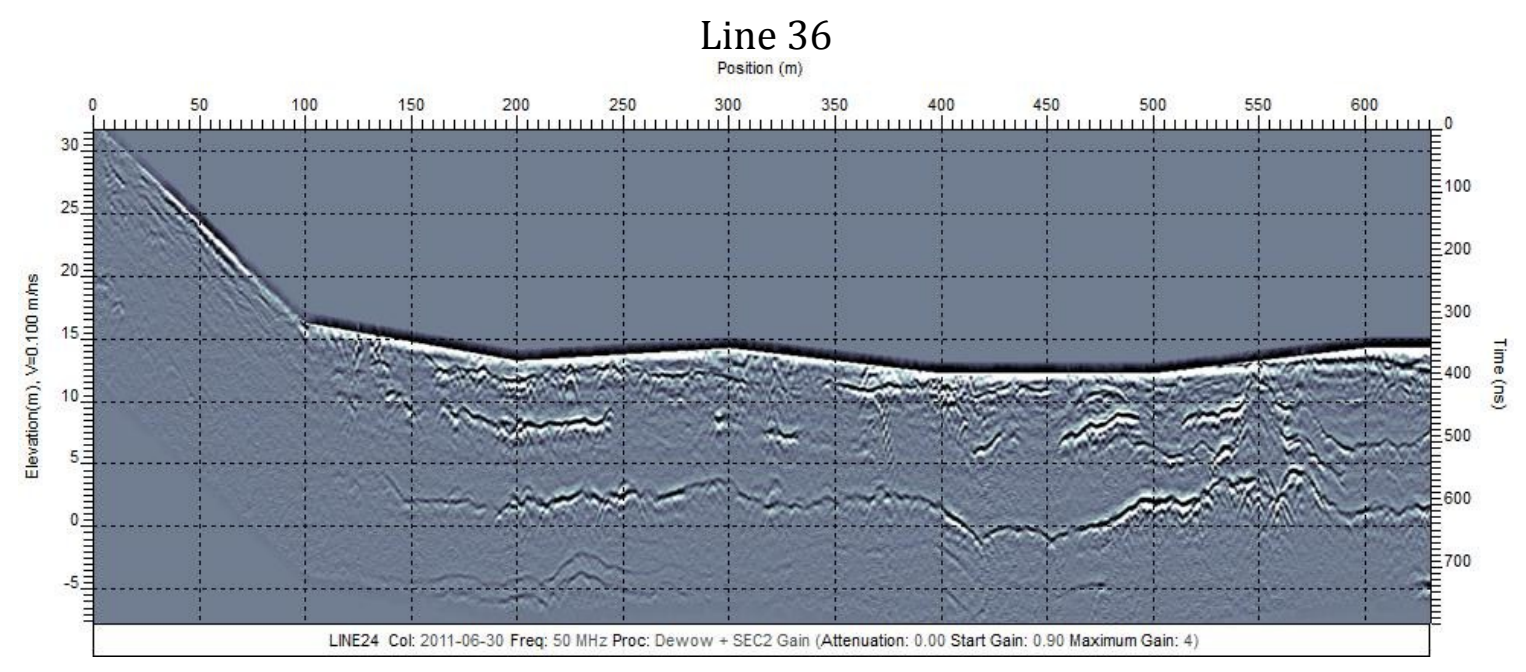

\section{Line 37}

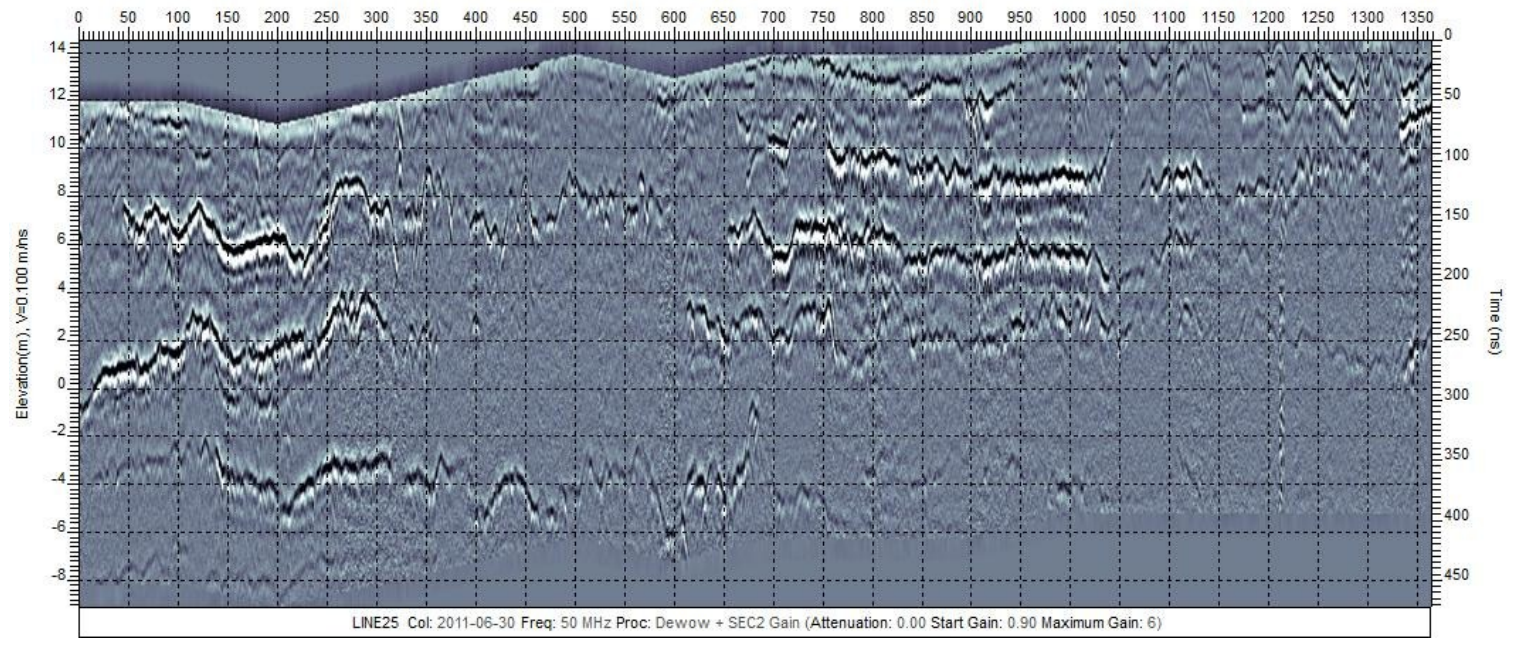




\section{Line 38}

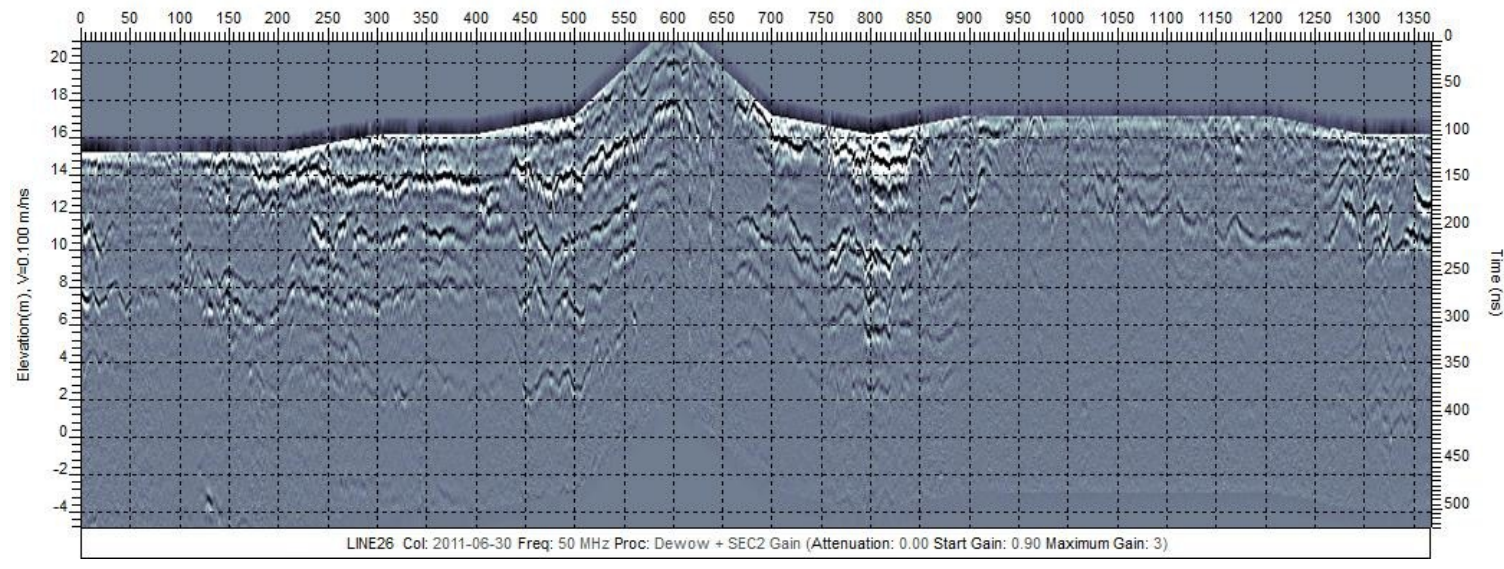

\section{Line 39}

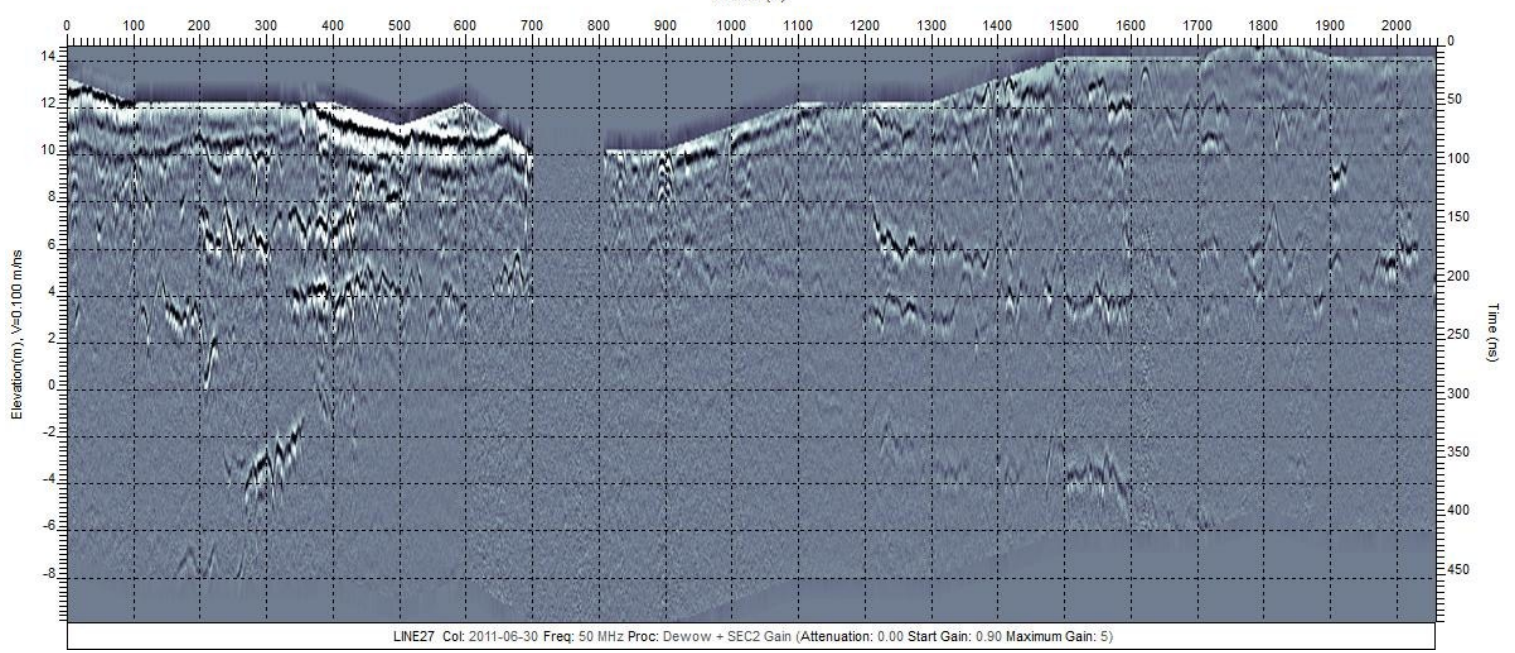




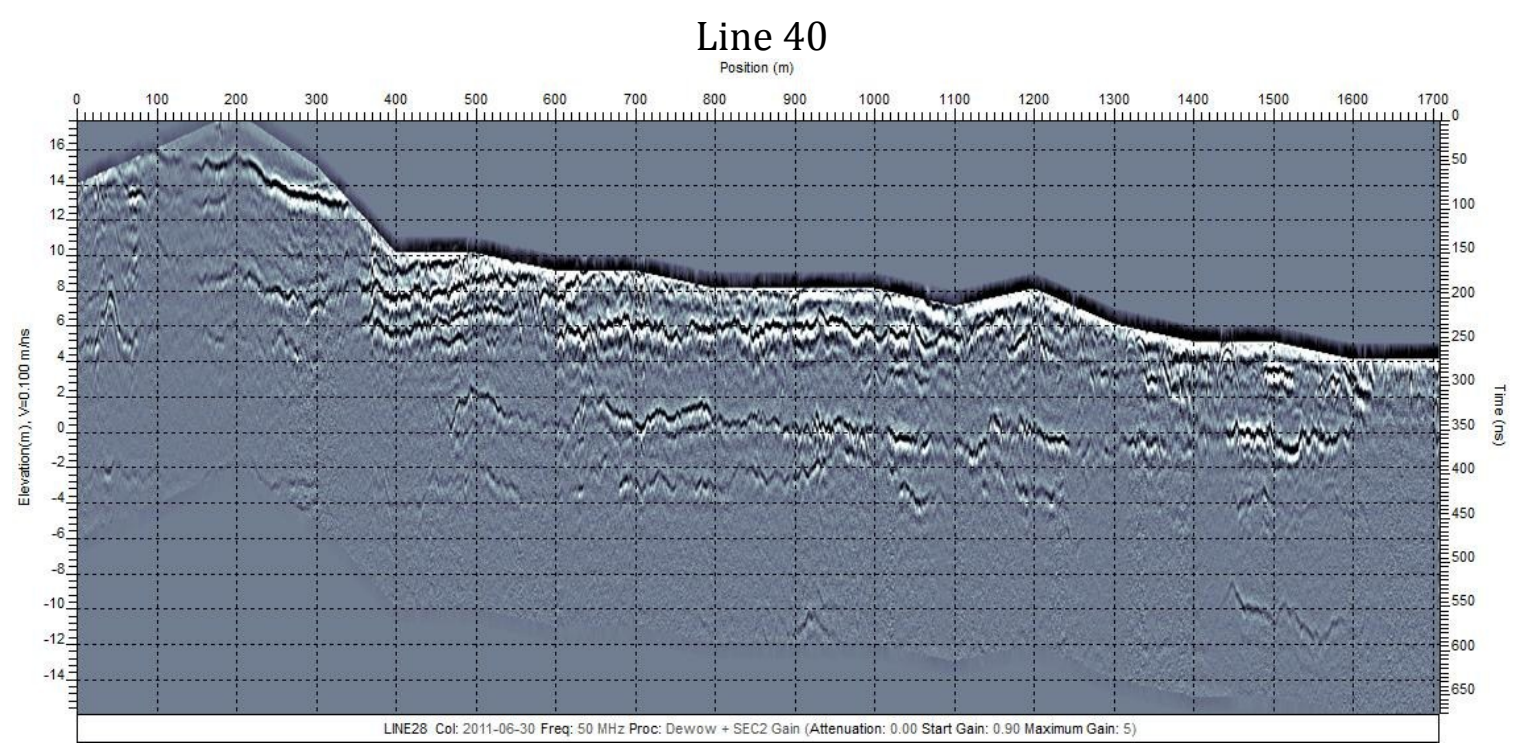

\section{Line 41}

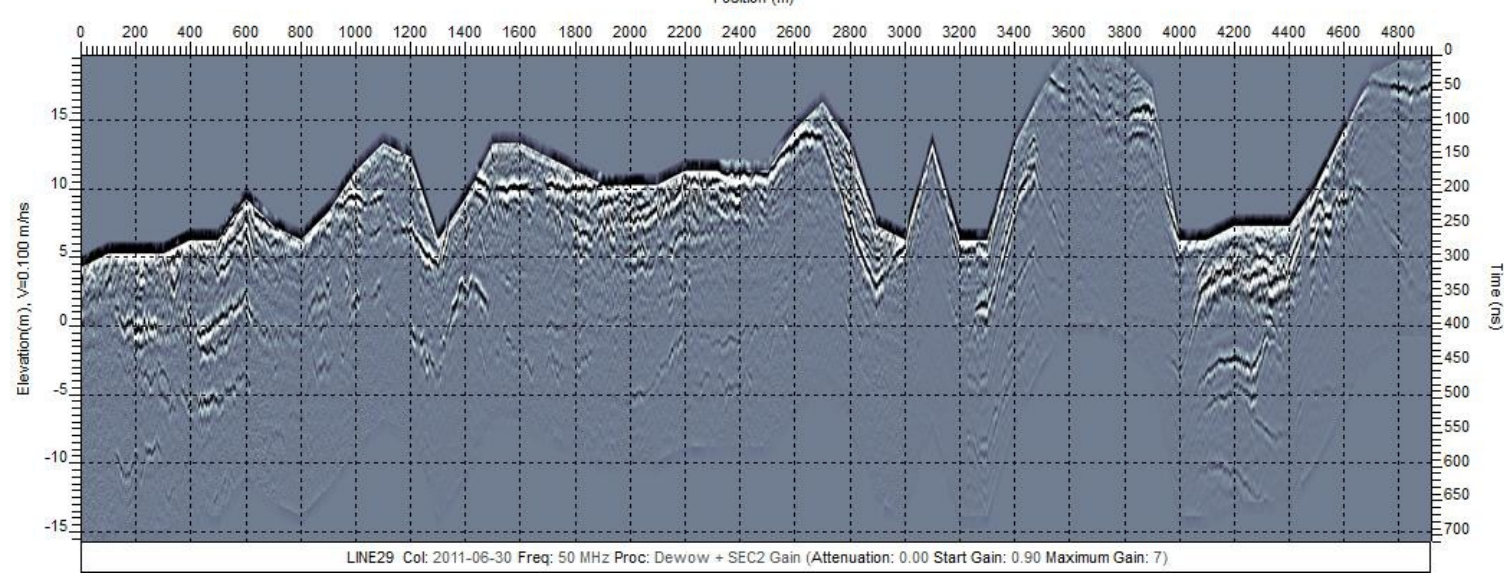

\section{Line 42}

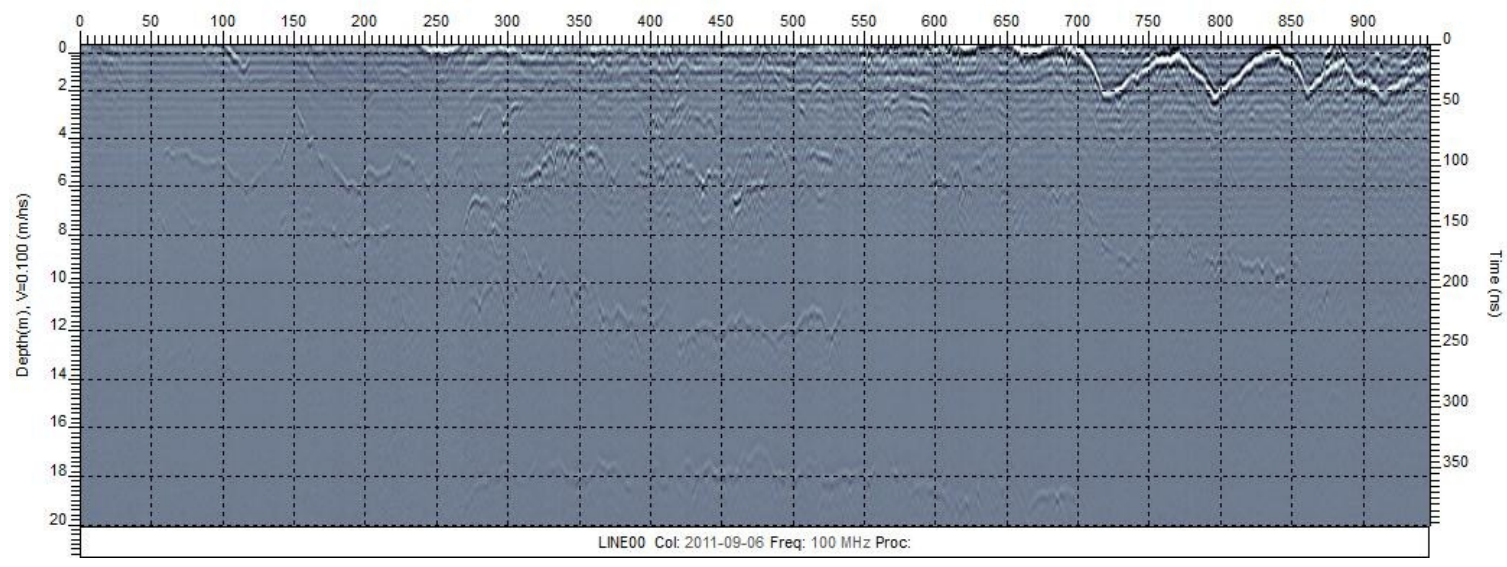




\section{Line 43}

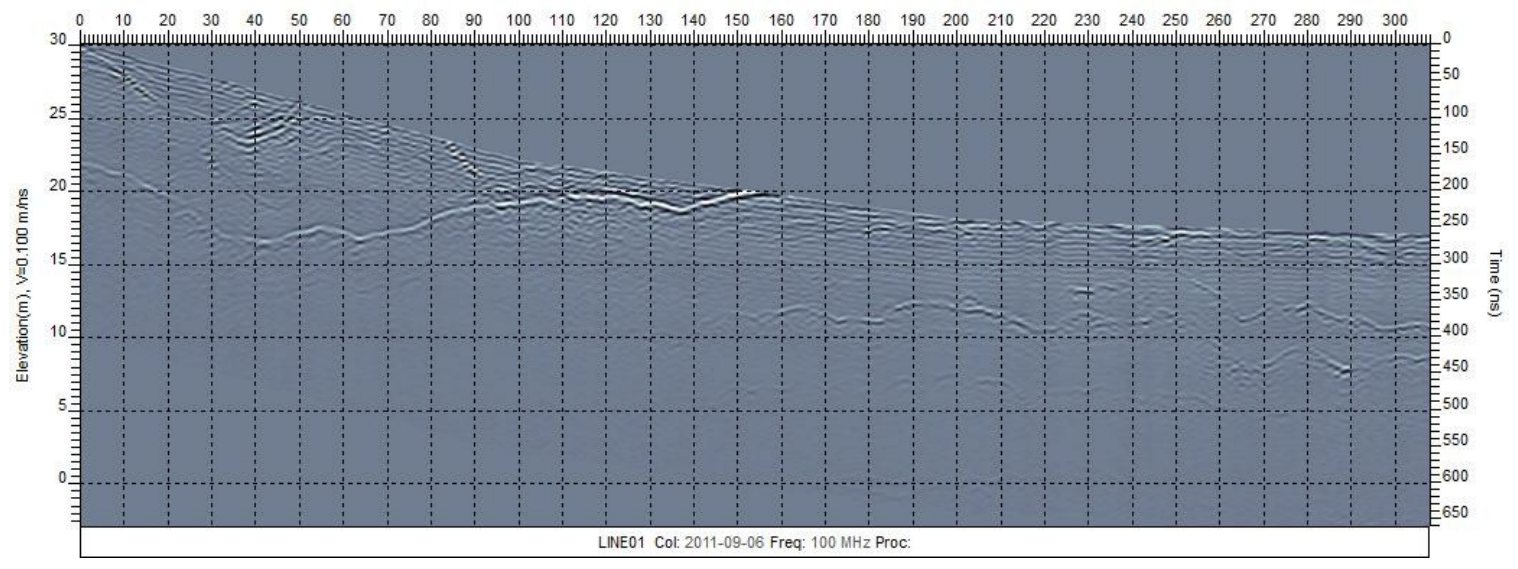

\section{Line 44}

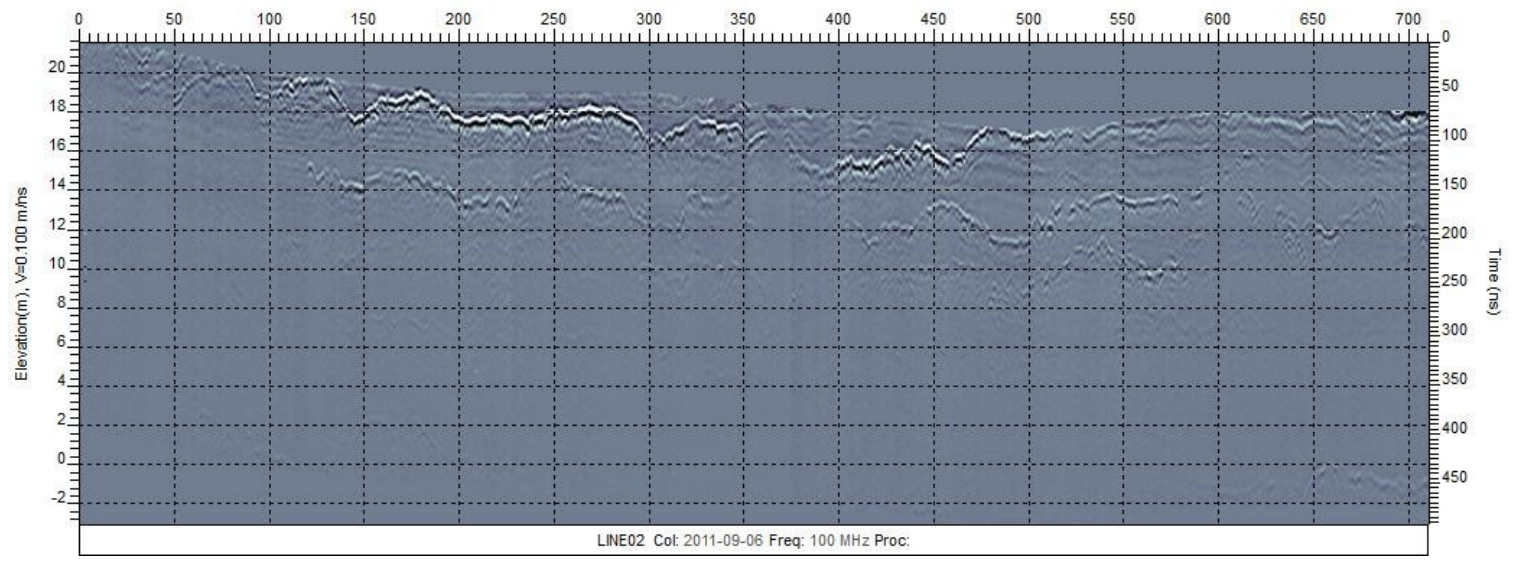




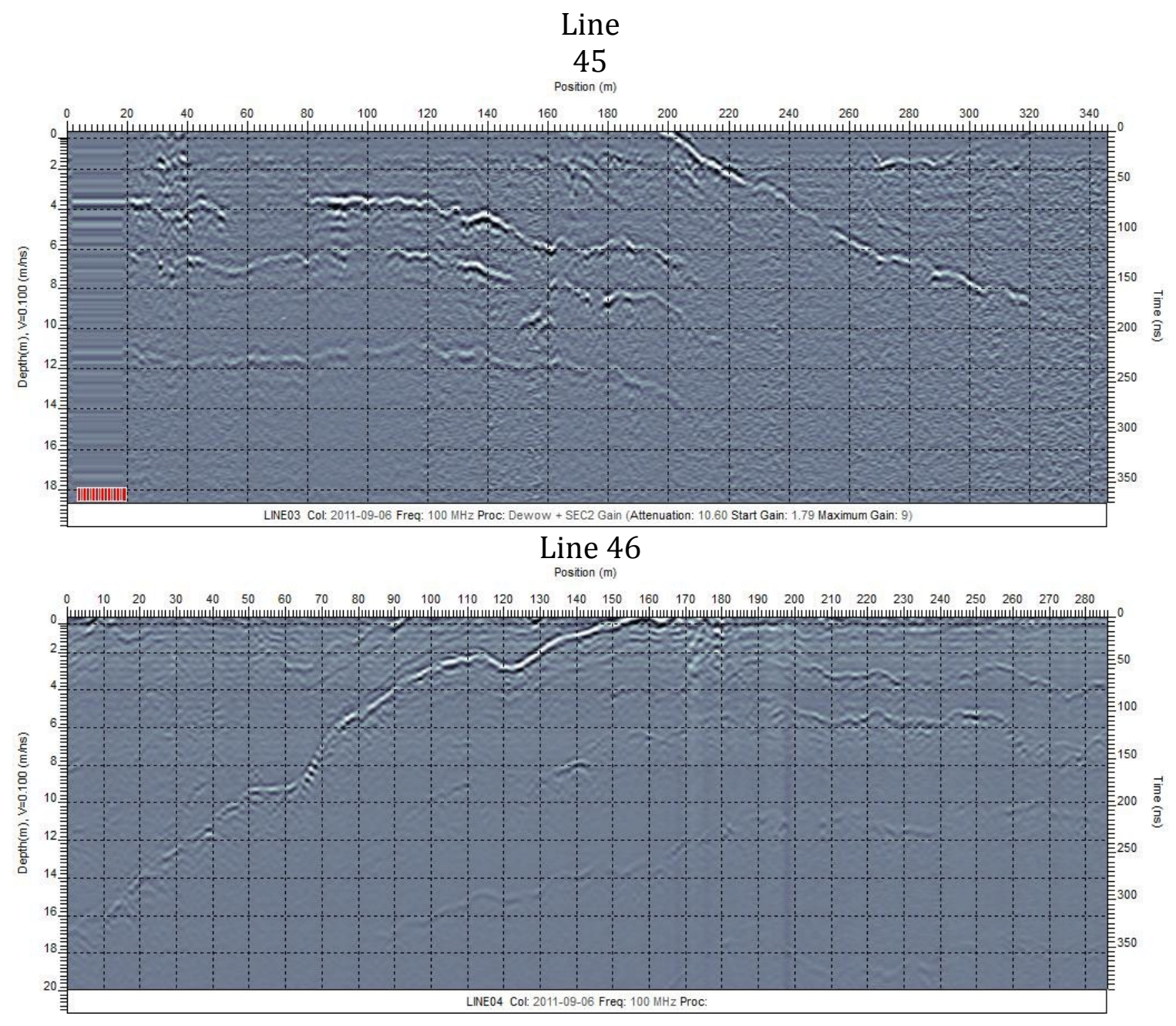



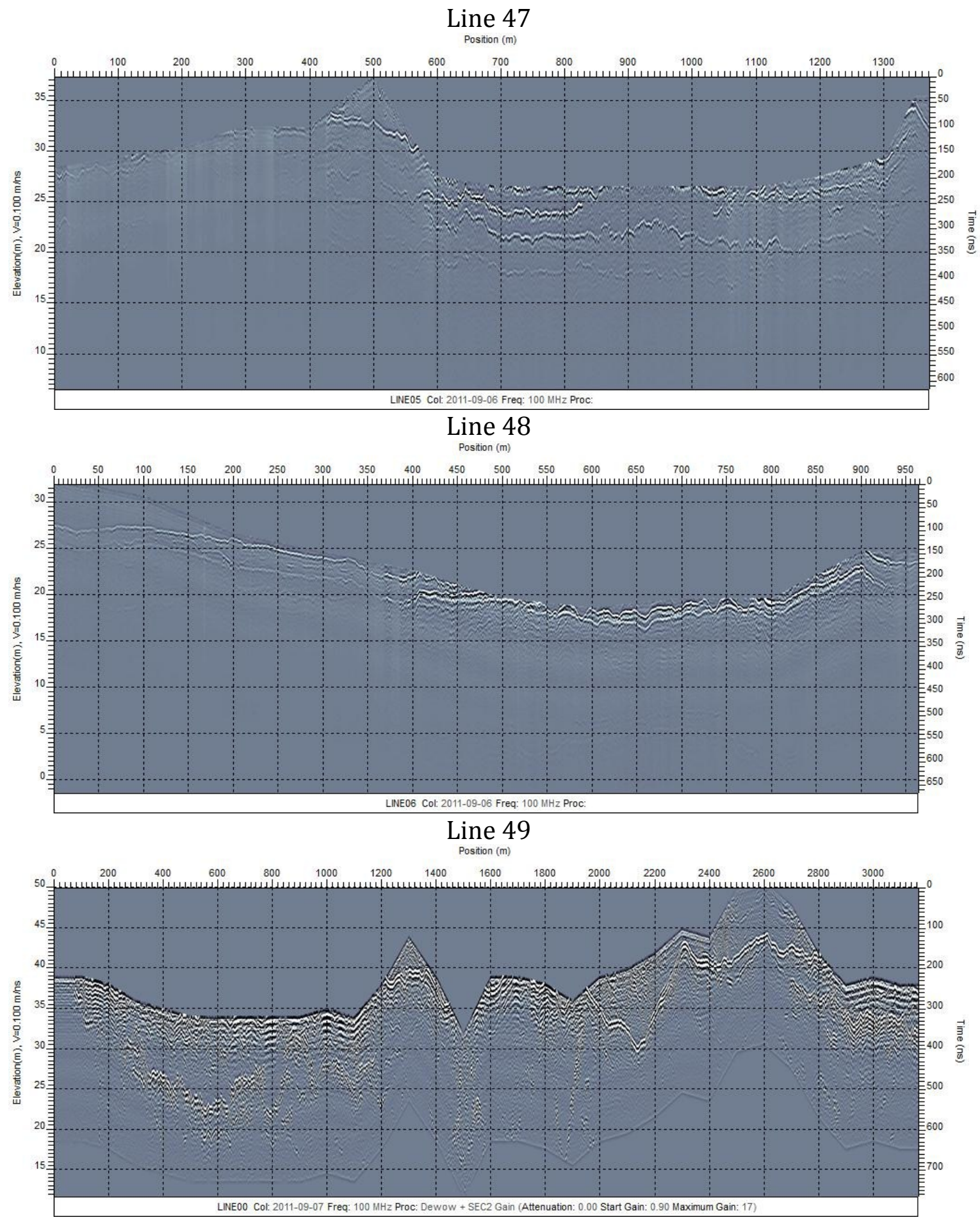


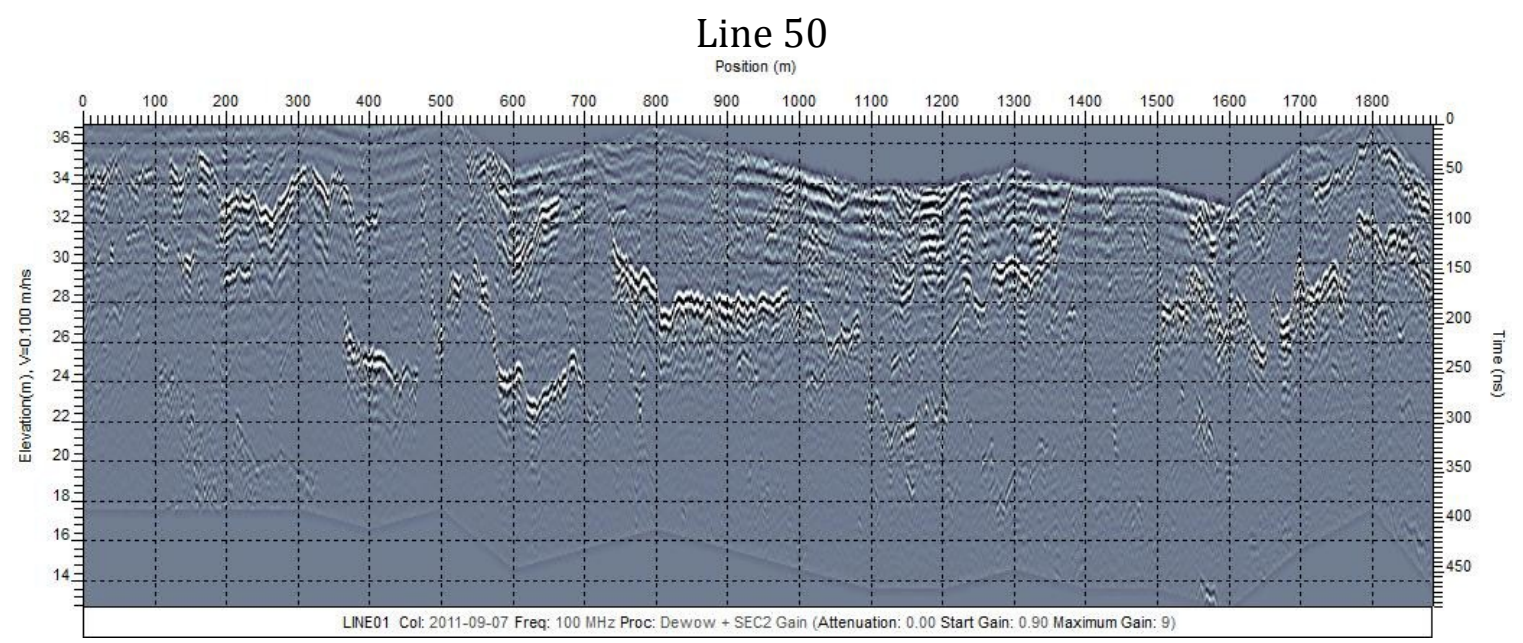

Line

\section{1}

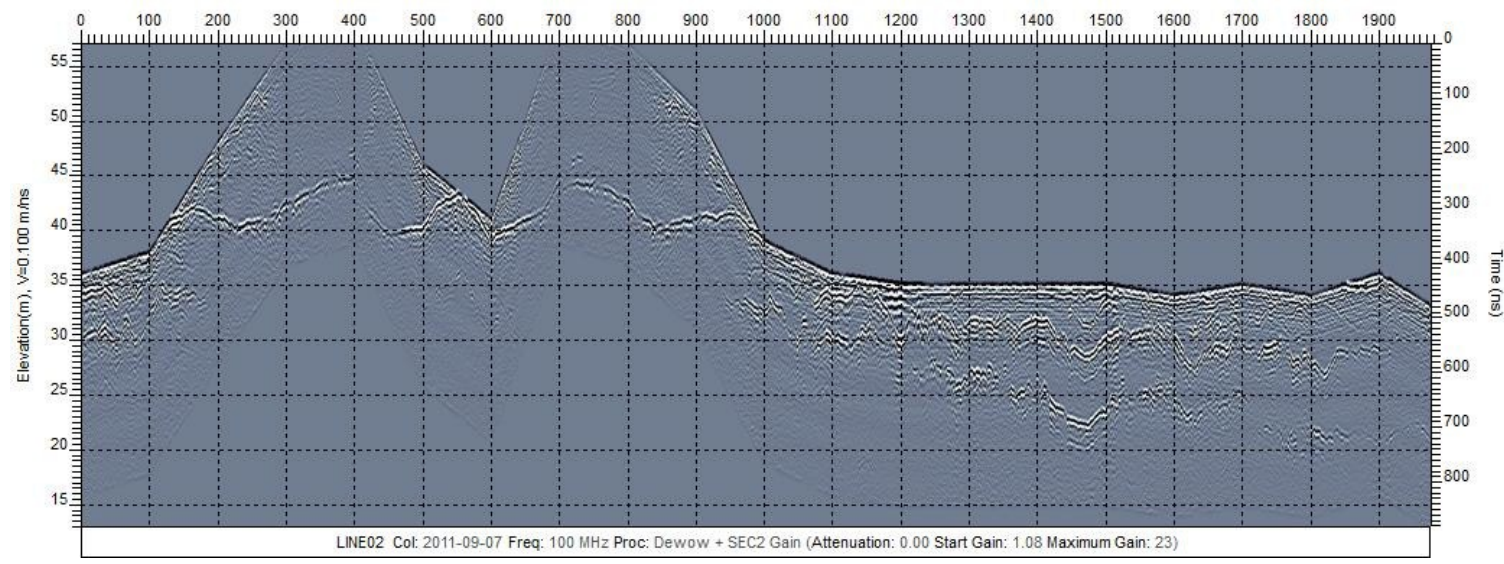

\section{Line 52}

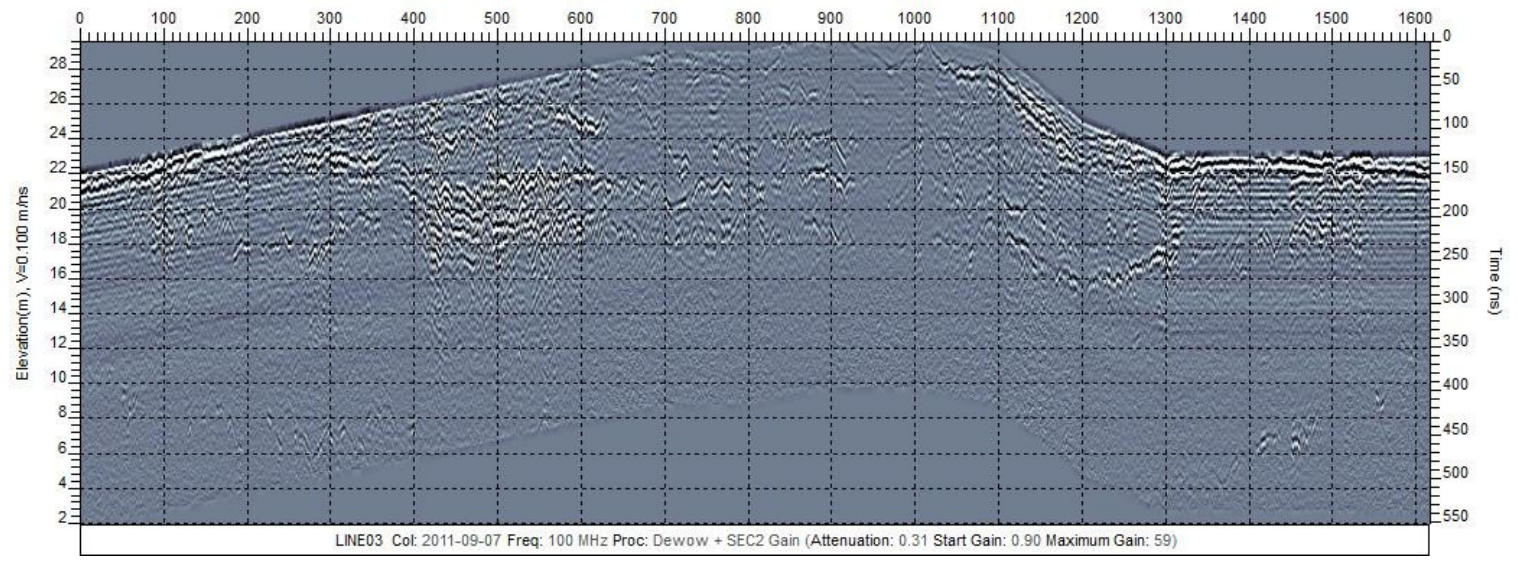



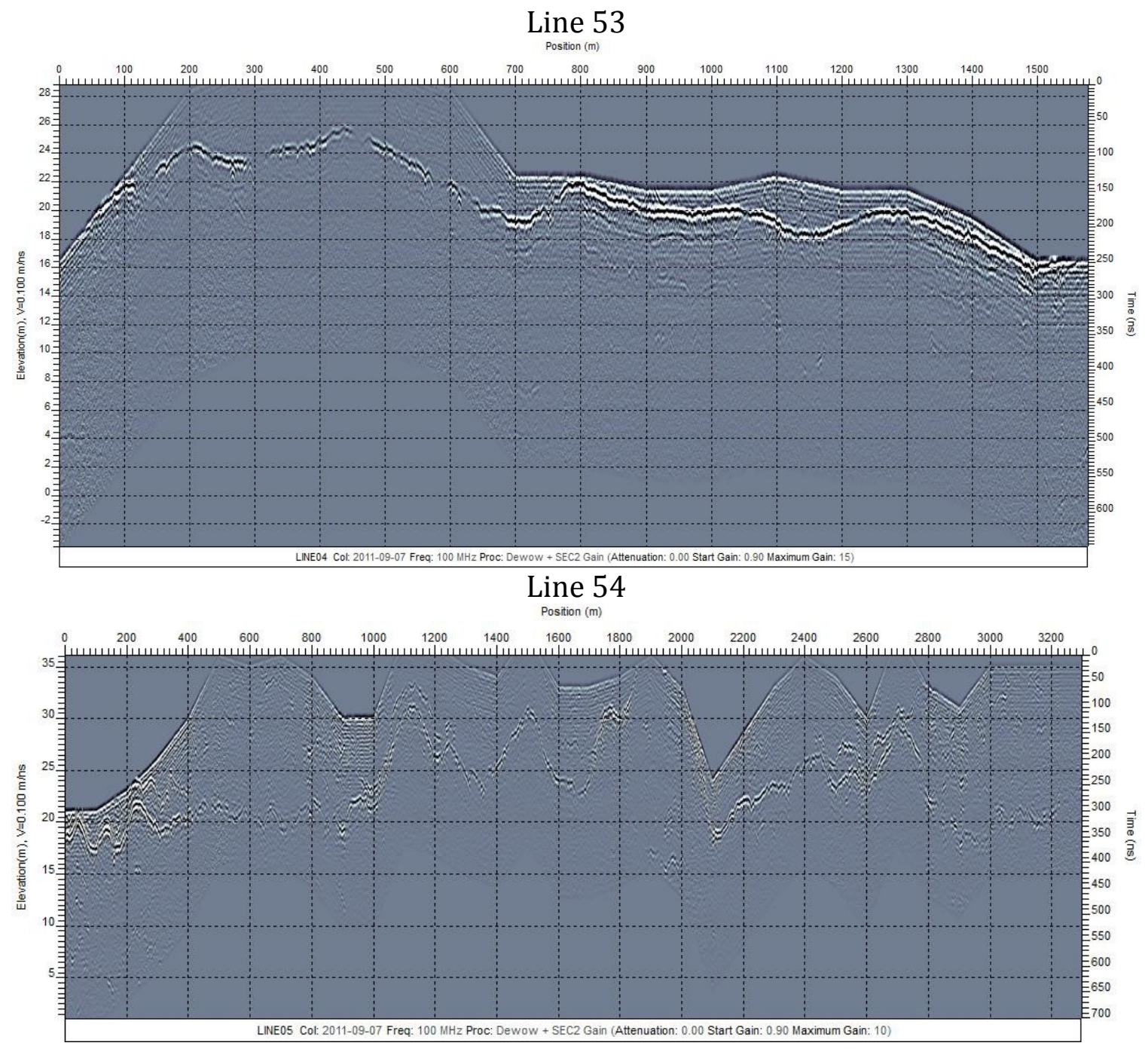